\title{
Total Synthesis of Microcystin-LF and Derivatives Thereof
}

\author{
Ivan Zemskov, ${ }^{\dagger}$ Stefan Altaner, ${ }^{\ddagger}$ Daniel R. Dietrich, ${ }^{\ddagger}$ and Valentin Wittmann ${ }^{* \dagger}{ }^{\dagger}$ \\ ${ }^{\dagger}$ Department of Chemistry and Konstanz Research School Chemical Biology (KoRS-CB), University of Konstanz, 78457 Konstanz, \\ Germany \\ ${ }^{\ddagger}$ Department of Biology and Graduate School Biological Sciences (GBS), University of Konstanz, 78457 Konstanz, Germany
}

\section{Supporting Information}

ABSTRACT: Microcystins (MCs) are highly toxic natural products which are produced by cyanobacteria. They can be released to the water during harmful algal blooms and are a serious threat to animals and humans. Described is the total synthesis of the cyanotoxin microcystin-LF (MC-LF, 1a) and two derivatives thereof. Deuterated derivative $\mathbf{1 b}$ is of interest as an internal standard during MC quantification in biological samples by mass spectrometry and alkyne-labeled 1c can be employed for toxin derivatization by click chemistry with an azide-containing reporter molecule or as an activity-based probe to identify interaction partners. Application of tert-butyl ester protecting groups for erythro- $\beta$-D-methylaspartic acid and $\gamma$-D-glutamic acid were key for an isomerization-free synthesis. The analytical data of synthetic MC-LF were identical to those of an authentic sample of the natural product. All derivatives $1 \mathrm{a}-\mathrm{c}$ were determined to be potent inhibitors of protein phosphatase- 1 with similar activity.

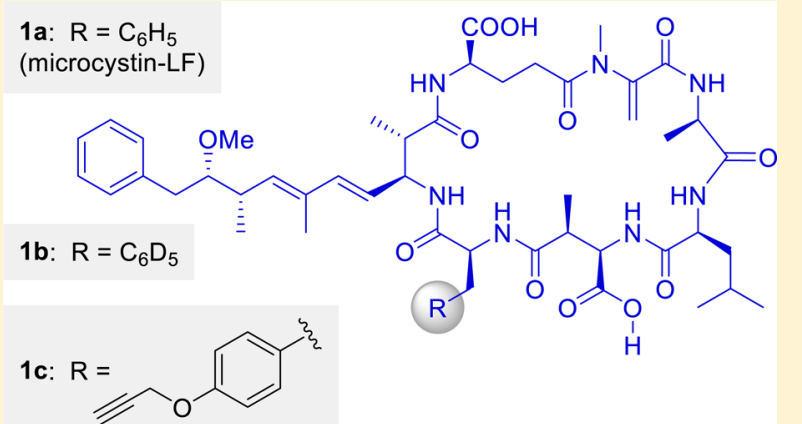

\section{INTRODUCTION}

Microcystins (MCs) are highly toxic natural products which are produced by cyanobacteria and, according to the WHO, are among the most dangerous water pollutants. ${ }^{1}$ Widespread harmful algal blooms in densely populated areas, which are favored by global warming along with eutrophication of surface waters, ${ }^{2}$ resulted in a shutdown of the public water supply for millions of people, for example in Toledo, Ohio, USA, (August 2014) and around lake Taihu in China (July 2007)..$^{2,3}$ The sole analytical method for congener-specific MC detection enabling the identification and quantification of MCs is liquid chromatography-mass spectrometry/mass spectrometry (LCMS/MS $)^{2 b, 4}$ However, the lack of certified reference compounds limits the applicability of this method. ${ }^{2 \mathrm{~b}}$ Although research on MCs has been conducted since $1878,{ }^{5}$ their physiological function in cyanobacteria is still under scientific debate. ${ }^{6}$ Consequently, the total synthesis of MCs would provide access to a yet missing variety of reference compounds as well as microcystin derivatives for structure-activity relationship studies enabling future studies into the biological roles of MCs. Furthermore, the high cytotoxicity of MCs makes this scaffold an attractive lead structure for the development of novel potent anticancer drugs.

As shown in Figure 1, MCs consist of three D-amino acids in positions 1,3 , and 6 , the $\beta$-amino acid Adda5, and $N$ methyldehydroalanine (Mdha7) which is involved in covalent binding of MCs to ser/thr protein phosphatases by Michael addition of a proximate cysteine residue. ${ }^{7}$ Two L-amino acids in positions 2 and 4 are variable and account for the major differences amongst the more than 100 individual congeners,

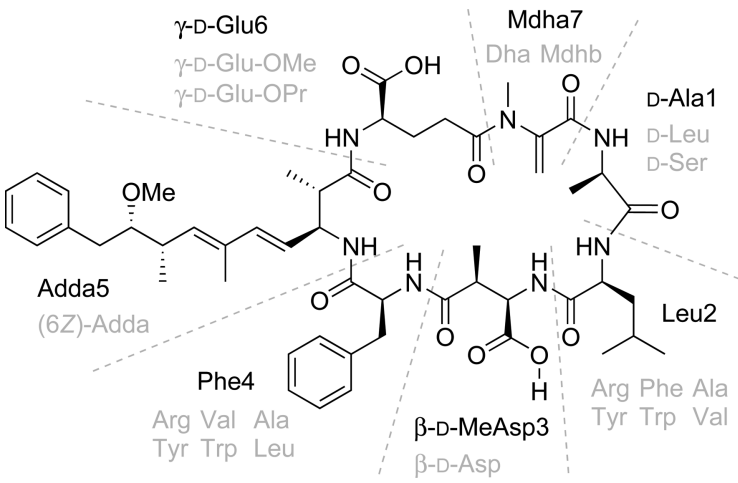

Figure 1. Microcystin-LF (MC-LF) and some amino acid variations (gray) of naturally occurring congeners. The two amino acids indicated in the name ( $\mathrm{LF}$ in the current example) denote the natural L-amino acids in positions 2 and 4 . Adda $=(2 S, 3 S, 4 E, 6 E, 8 S, 9 S)-3$ amino-9-methoxy-2,6,8-trimethyl-10-phenyldeca-4,6-dienoic acid, D$\mathrm{Ala}=\mathrm{D}$-alanine, $\gamma$-D-Glu $=\gamma$-D-glutamic acid, Mdha $=N$ methyldehydroalanine, $\beta$-D-MeAsp $=$ erythro- $\beta$-D-methylaspartic acid.

that have been reported so far. $^{8}$ Despite numerous attempts 9 the total synthesis of a natural microcystin (MC-LA) was accomplished only once. ${ }^{10}$ This landmark achievement featured protection of $\beta$-D-MeAsp3 and $\gamma$-D-Glu 6 by methyl esters that were cleaved under basic conditions in the last synthetic step. Unfortunately, this treatment led to the formation of several

Received: January 23, 2017

Published: March 15, 2017 
uncharacterized isomers of the final product. ${ }^{10}$ In our interpretation the isomerization can be attributed to a cyclization involving $\beta$-D-MeAsp3 (I, Scheme 1) leading to

Scheme 1. Proposed Formation of Aspartimide II and Subsequent Isomerization during the Saponification of Methyl Ester Protected MC-LA I

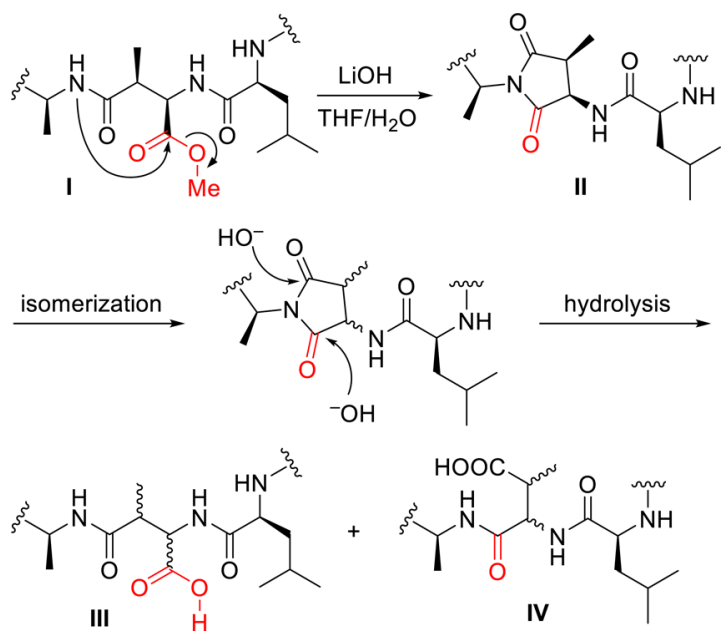

aspartimide II which is prone to isomerization at the chiral centers in the $\alpha$ - and $\beta$-positions. Ring opening by basic hydrolysis can lead to the stereoisomers III of desired MC-LA as well as constitutional isomers IV. Despite extensive investigation of different methyl ester cleavage conditions, the isomerization could not be avoided and resulted in significant loss of material. ${ }^{10}$ To identify natural MC-LA, the isomeric mixture was separated by HPLC and the isomers were compared to an authentic sample of the cyanotoxin. ${ }^{10}$ The identification of the desired isomers was particularly intricate during the synthesis of unnatural derivatives for which no standard was available. ${ }^{11}$
Here, we present an isomerization-free synthetic strategy and its application to the first total synthesis of MC-LF (1a) and its deuterated derivative $\mathbf{1 b}$ (Scheme 2) which is of interest as an internal standard during MC quantification by mass spectrometry. Since this approach delivers only one isomer, the synthesis of unnatural MC derivatives becomes feasible which we demonstrate by the preparation of derivative 1c. The alkynelabeled $1 \mathrm{c}$ can be employed for toxin derivatization by click chemistry with an azide-containing reporter molecule, e.g., biotin or a fluorescent dye, and, furthermore, be used as an activity-based probe to identify interaction partners. ${ }^{12}$ According to crystal structures of MCs in complex with ser/thr protein phosphatases $^{13}$ the side chain at position 4 of the MC backbone is not involved in binding and thus represents an optimal position for synthetic modifications.

\section{RESULTS AND DISCUSSION}

Retrosynthetic Analysis. For the synthesis of $1 \mathrm{a}-\mathrm{c}$ we followed a fragment-based strategy using tert-butyl esters as protecting groups for $\beta$-D-MeAsp3 and $\gamma$-D-Glu6 in order to suppress aspartimide formation. ${ }^{14}$ In contrast to the previous approach, ${ }^{10}$ in which $N$-methylphosphonylsarcosine was incorporated and subsequently converted into Mdha7 by a Horner-Wadsworth-Emmons reaction, we incorporated $\mathrm{N}$ methylphenylselenocysteine $(\mathrm{NMeSecPh})$ as Mdha precursor that was transformed into Mdha in the final step of the synthesis. For the macrocyclization, we decided to use the peptide bond between residues 4 and 5 which is also the cyclization site during biosynthesis of MCs. ${ }^{15}$ In addition, this disconnection has proven reliable in the former synthetic approach. $^{10}$

The linear precursors $\mathbf{2 a}-\mathbf{c}$ were synthesized in a convergent manner from fragments $\mathbf{3}, \mathbf{4}$, and $\mathbf{5 a}-\mathbf{c}$. Several syntheses of Boc-Adda-OH 3 have been reported. ${ }^{9 a, 16}$ We followed the route developed by Pearson et al. that delivers 3 in 13 steps with the best overall yield. ${ }^{16 a}$ Fmoc groups served as N-terminal protection of fragments $\mathbf{4}$ and $\mathbf{5 a}-\mathbf{c}$. The presence of Fmoc,

Scheme 2. Retrosynthetic Analysis of MC Derivatives 1a-c
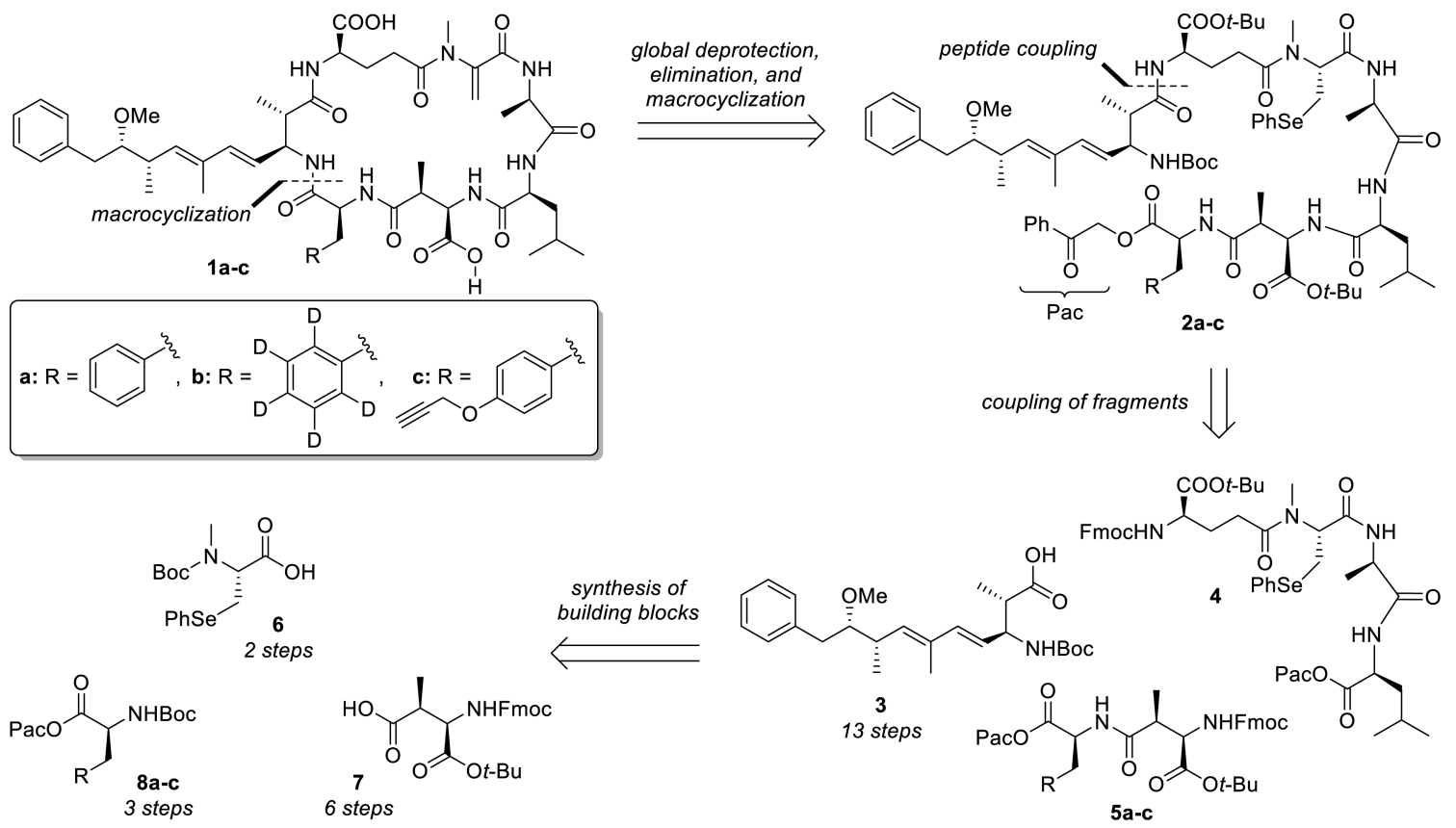
tert-butyl ester and the phenylselenocysteine moiety in fragments $\mathbf{4}$ and $\mathbf{5 a}-\mathbf{c}$ required a C-terminal protection which can be cleaved in the presence of these three groups and withstands the conditions of Fmoc deprotection. In our approach we used the phenacyl (Pac) protecting group which is removed under mild reductive conditions. ${ }^{17}$ Tetrapeptide $\mathbf{4}$ and dipeptides $\mathbf{5 a}-\mathrm{c}$ were obtained from $\mathrm{NMeSecPh}$ derivative $\mathbf{6},{ }^{18}$ $\beta$-D-MeAsp derivative 7 and the building blocks $8 \mathbf{8 a},{ }^{17} \mathbf{8 b}$, and $8 \mathrm{c}$.

Synthesis of Tetrapeptide 4. We started our synthesis with the preparation of tetrapeptide fragment 4 (Scheme 3 ).

Scheme 3. Synthesis of Tetrapeptide Fragment $4^{a}$
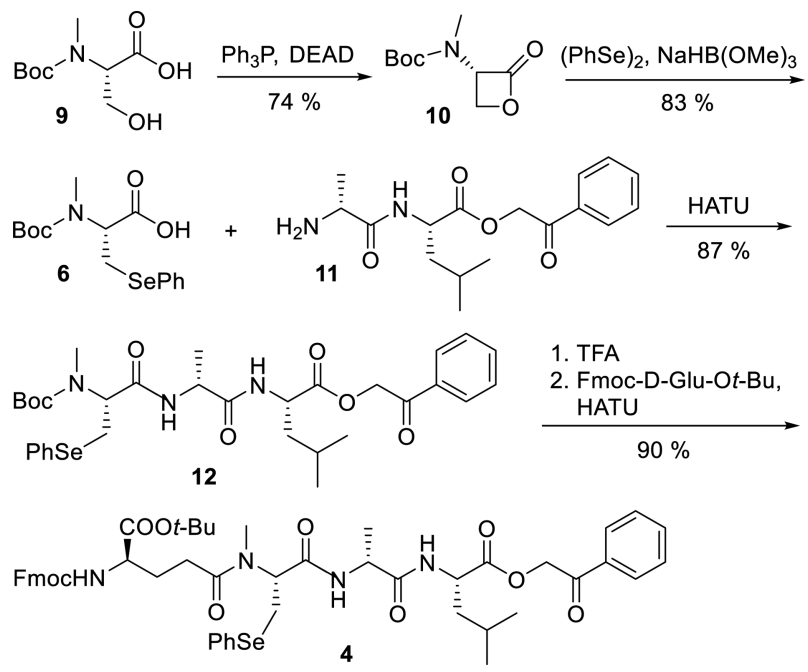

${ }^{a}$ HATU represents 1-[bis(dimethylamino)methylene]-1H-1,2,3triazolo $[4,5-b]$ pyridinium 3 -oxide hexafluorophosphate.

Boc-NMeSecPh-OH 6 was synthesized starting from Boc- $N$ methyl-L-serine 9 using the strategy developed by van der Donk and co-workers for the synthesis of Boc-SecPh- $\mathrm{OH}^{19}$ and coupled with dipeptide 11 to give $12 .{ }^{18}$ Tripeptide $\mathbf{1 2}$ was then deprotected with TFA and coupled with Fmoc-D-Glu-Ot-Bu to give fragment 4.

Synthesis of Dipeptides $5 \mathbf{a}-\mathbf{C}$. In position 3 of the vast majority of the MCs erythro- $\beta$-methyl D-aspartic acid (DMeAsp) is found. Up to date several synthetic routes toward derivatives of this amino acid have been published. ${ }^{10,16 e-g, 20}$ However, all these published approaches feature methyl or ethyl ester protecting groups, which are crucial for the generation of the stereocenter at the $\beta$-carbon atom. Since the literature-known building blocks cannot be easily transformed into 7, we synthesized Fmoc-D-MeAsp-Ot-Bu 7 starting from D-aspartic acid $\mathbf{1 3}$ as shown in Scheme 4. The amino group of 13 was benzylated by reductive amination and the $\beta$ carboxy group was regioselectively esterified under acidic conditions to give benzyl ester 14. The free $\alpha$-carboxy group of 14 was tert-butylated and subsequently the secondary amine was protected with the phenylfluorenyl ( $\mathrm{PhFl}$ ) group to give 15. This sterically hindered group suppresses deprotonation at the $\alpha$-carbon and allows enolate formation by selective deprotonation at the $\beta$-position of $\mathbf{1 5}$ in the subsequent step. Thus, treatment of $\mathbf{1 5}$ with lithium bis(trimethylsilyl)amide (LHMDS) followed by addition of methyl iodide led to exclusive methylation of the $\beta$-position to give erythro-16 and threo-16 in a ratio of 5:1. The stereoselectivity of this step can
Scheme 4. Synthesis of Fmoc-D-MeAsp-Ot-Bu 7

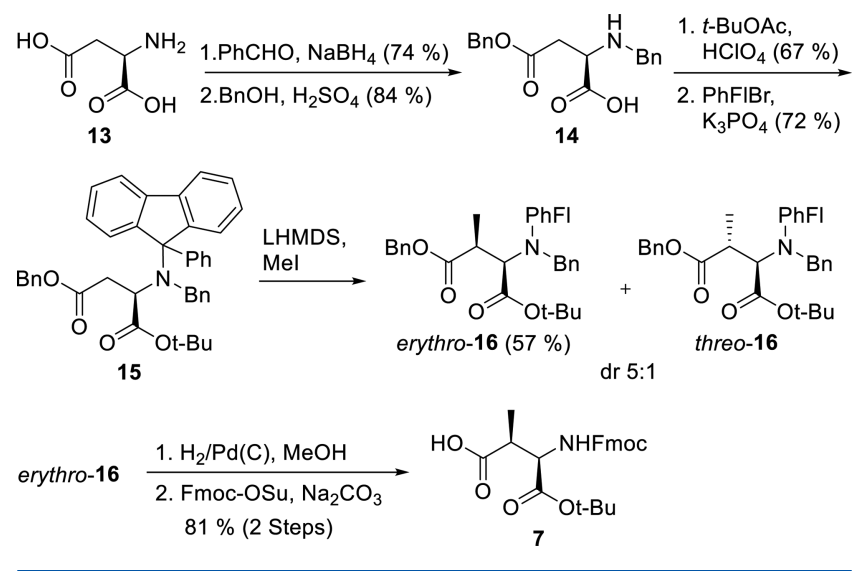

be explained by preferred formation of the $(Z)$-lithium enolate which adopts a hydrogen-in-plane conformation that is attacked opposite to the bulky nitrogen protecting groups. ${ }^{21}$ The isomers erythro-16 and threo-16 were readily separated by column chromatography and the configuration of erythro-16 was verified by complete deprotection and subsequent NMR analysis $^{22}$ (see Supporting Information) as well as optical rotation measurement. ${ }^{20}$ Hydrogenolysis of erythro-16 followed by Fmoc protection of the free amino group gave building block 7 .

The phenacyl protected propargyl tyrosine building block Boc-Tyr (Prg)-OPac 8c (Prg = propargyl) was synthesized in three steps starting from Boc-Tyr-OH 17 (Scheme 5A).

Scheme 5. (A) Synthesis of Alkyne Labeled Building Block $8 c$ and (B) Synthesis of Dipeptide Fragments $5 a-c^{a}$
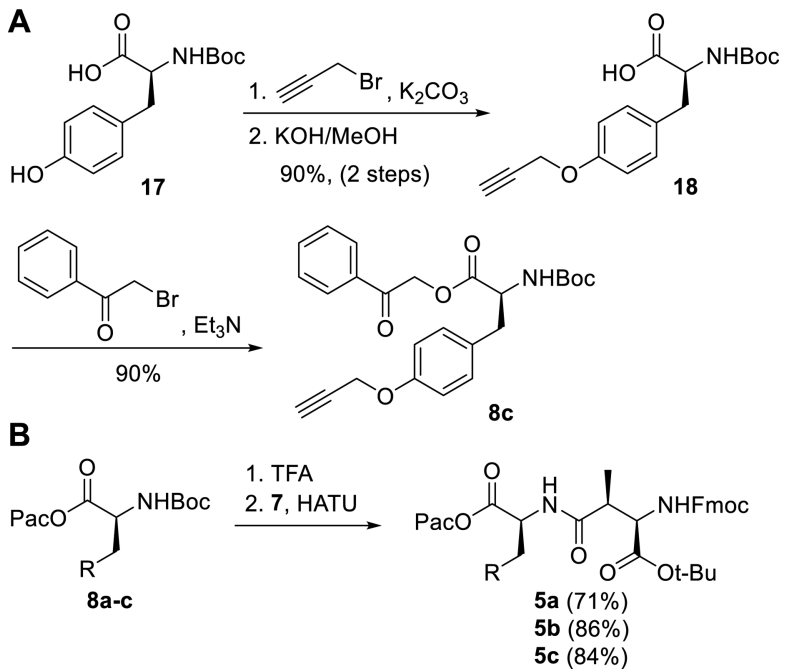

${ }^{a}$ For definitions of $a-c$, see Scheme 2

Double propargylation of 17 followed by saponification of the propargyl ester gave $\mathbf{1 8}$ that was alkylated with phenacyl bromide yielding $\mathbf{8 c}$ in a high yield. $\mathbf{8 c}$ as well as literature known $\mathbf{8} \mathbf{a}^{17}$ and analogously prepared, isotopically labeled $\mathbf{8 b}$ were $\mathrm{N}$-terminally deprotected and coupled with D-MeAsp derivative 7 to give dipeptides $\mathbf{5 a - c}$ (Scheme 5B).

Synthesis of Linear Heptapeptides. With all fragments in hand, heptapeptides $\mathbf{2 a - c}$ were assembled (Scheme 6). The C-terminal phenacyl ester of tetrapeptide 4 was reductively 
Scheme 6. Synthesis of Linear Heptapeptides 22a-c by Fragment Couplings ${ }^{a}$
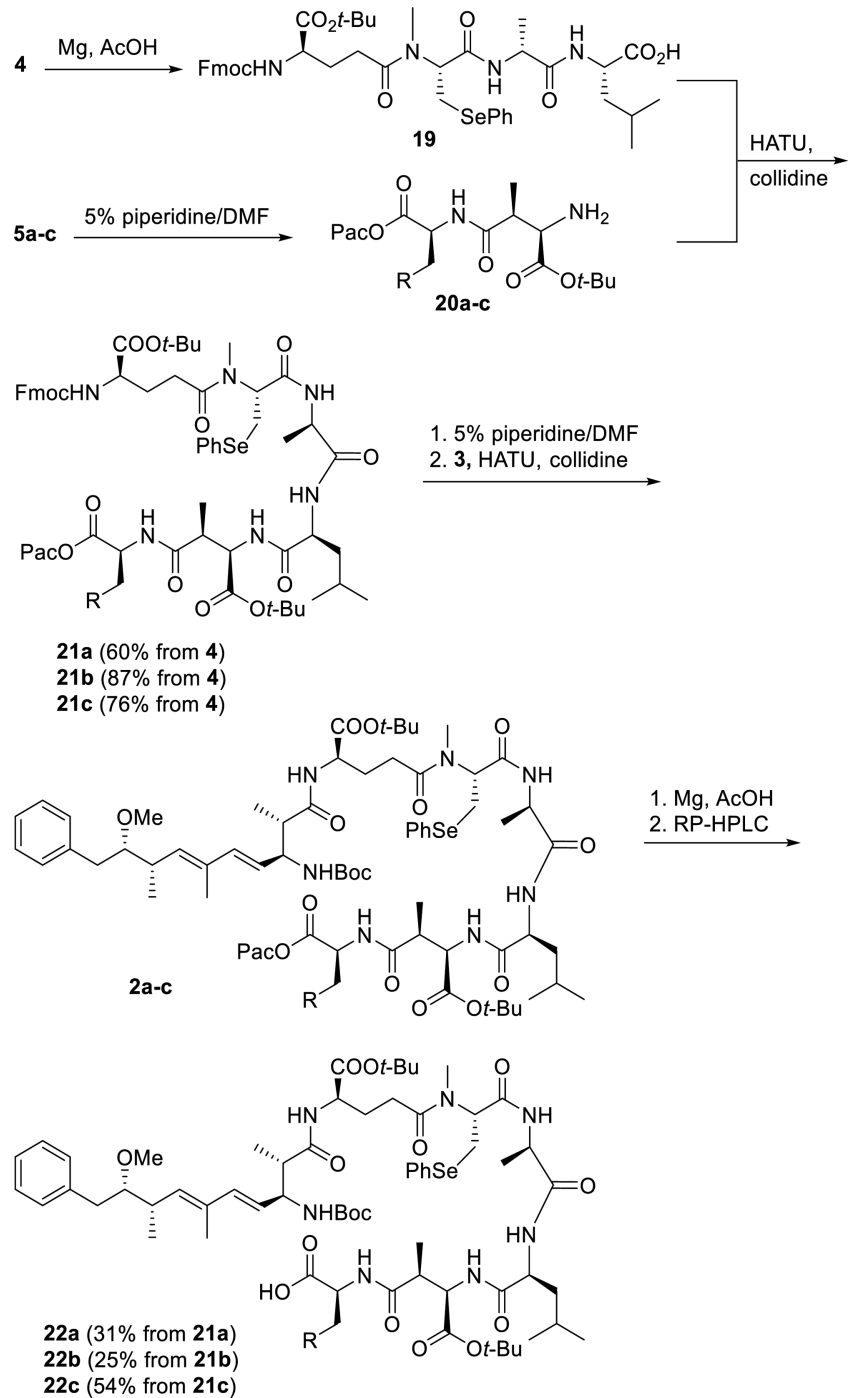

${ }^{a}$ For definitions of $a-c$, see Scheme 2

cleaved to give 19. Fmoc deprotection of dipeptides $5 a-c$ was performed with diluted (5\%) piperidine in DMF to avoid possible cleavage of the $\mathrm{Pac}$ ester giving 20a-c. The subsequent fragment coupling of 19 and a slight excess of $20 a-c$ was performed with HATU/collidine leading to $21 \mathbf{a}-\mathbf{c}$. Under these conditions isomerization at the C-terminal Leu residue of fragment $\mathbf{1 9}$ is minimized as it was also reported by others. $^{10,23}$ The hexapeptides 21a-c were N-terminally deprotected and Boc-Adda-OH 3 was coupled to give heptapeptides $2 \mathrm{a}-\mathbf{c}$. Removal of the Pac group led to macrocyclization precursors $22 \mathbf{a}-\mathbf{c}$. We found that it was essential to purify compounds $22 \mathrm{a}-\mathrm{c}$ by RP-HPLC to prevent byproduct formation during the subsequent macrocyclization step.

Macrocyclization and Final Steps. The C-termini of 22a-c were activated as pentafluorophenyl (Pfp) ester and the $t$-butyl esters along with the Boc group were removed by TFA treatment (Scheme 7). Macrocyclization was induced under basic conditions applying a two-phase system of chloroform and phosphate buffer $(\mathrm{pH}=9.5)$ to give cyclopeptides $23 \mathrm{a}-\mathrm{c}$ which were purified by RP-HPLC. According to HPLC
Scheme 7. Deprotection and Macrocyclization

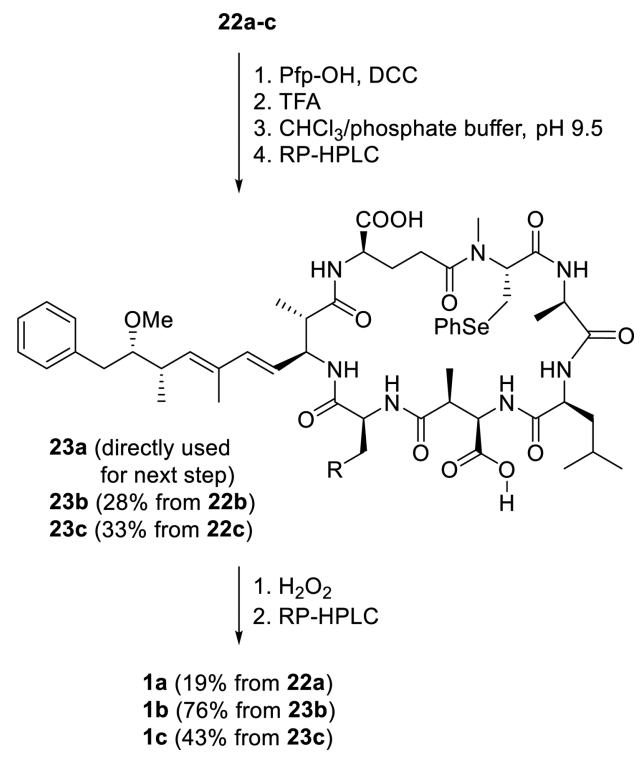

approximately $20 \%$ (in case of $23 \mathbf{a}$ and $23 \mathbf{b}$ ) and $10 \%$ (in case of 23c), respectively, of an isomeric product, possibly due to epimerization at C-terminal amino acid during macrocyclization, were observed. Subsequent selenoxide elimination under mild oxidative conditions gave the desired MC derivatives 1a-c. All final products were fully characterized by one- and two-dimensional NMR spectroscopy and HRMS. The analytical data of synthetic MC-LF (1a) were identical to those of a commercial MC-LF sample confirming the structure of the synthetic material. In addition, coinjection of both a mixture of natural and synthetic $1 \mathrm{a}$ as well as a mixture of $\mathbf{1 a}$ and $\mathbf{1 b}$ led to single peaks in the LC-MS chromatograms (Supporting Information).

Inhibition of Protein Phosphatase-1. In order to confirm that the biological activities of synthetic and natural MC-LF are identical, we determined the potency of both compounds to inhibit the hydrolysis of $p$-nitrophenyl phosphate catalyzed by protein phosphatase-1 (PP1, Figure 2). As expected, the $\mathrm{IC}_{50}$

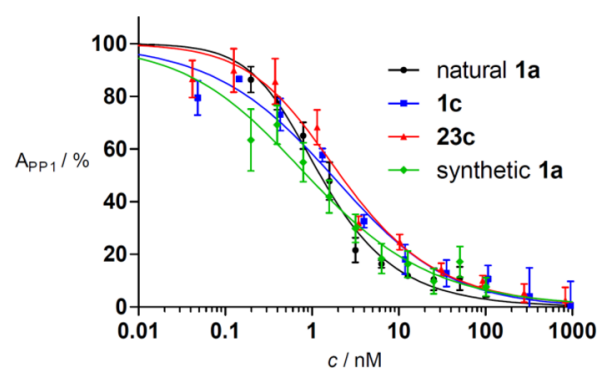

Figure 2. PP1 inhibition assay with natural MC-LF and synthetic compounds 1a, 1c, and 23c (values from three independent experiments). $\mathrm{A}_{\mathrm{PP} 1}=$ activity of $\mathrm{PP} 1$.

values obtained with this robust assay ${ }^{24}$ are very similar within the accuracy of this assay (synthetic 1a: $\mathrm{IC}_{50}=870 \mathrm{pM}$, natural la: $\mathrm{IC}_{50}=1.2 \mathrm{nM}$ ) further verifying the authenticity of the synthetic material. We also evaluated the inhibitory potency of the propargylated derivative $1 \mathrm{c}$ and its precursor 23c lacking the Michael acceptor Mdha. The similar $\mathrm{IC}_{50}$ value of $\mathbf{1 c}\left(\mathrm{IC}_{50}\right.$ $=1.7 \mathrm{nM}$ ) shows that the modification at position 4 has only a minor influence on phosphatase binding and inhibition as 
expected from the crystal structure of PP1 in complex with MC-LR. ${ }^{13 b}$ Phenylselenocystein derivative 23c, lacking the capability to covalently bind to PP1, has a similar inhibitory potency $\left(\mathrm{IC}_{50}=2.1 \mathrm{nM}\right)$. Our results show that neither the modification at position 4 nor the one at position 7 of the scaffold disrupt PP1 inhibition. The fact that the absence of the Michael acceptor in compound 23c does not result in reduced inhibition potency is in line with previous findings that have shown that covalent binding of the toxin to PP1 is a slow process and not required for phosphatase inhibition which is rather achieved by the initial fast noncovalent interaction. However, it is remarkable that the large side chain of $\mathrm{NMeSecPh}$ is tolerated during this binding process, thereby dramatically expanding the application domain of derivatized MCs.

\section{CONCLUSION}

In summary, we developed a novel strategy for the synthesis of MCs. Application of the $\mathrm{Fmoc} / \mathrm{t}$-Bu protecting group strategy enabled the isomerization-free synthesis of MC-LF as well as a deuterated and an alkyne-labeled derivative thereof. The incorporation of a phenylselenocysteine moiety as precursor for the Mdha residue gave access to a novel potent and reversible phosphatase inhibitor that cannot undergo covalent binding to the protein. The synthesized MC derivatives can be broadly applied for improved MC detection and quantification and pave the way for future approaches to understanding the biological roles of MCs in various organisms.

\section{EXPERIMENTAL SECTION}

General Experimental Methods. Technical solvents (petroleum ether and EtOAc) were distilled prior to use. THF and $\mathrm{CH}_{2} \mathrm{Cl}_{2}$ were distilled from $\mathrm{Na} / \mathrm{K}$ or $\mathrm{CaH}_{2}$ under inert atmosphere immediately prior to use. Peptide grade DMF was used for peptide couplings. A sample of natural microcystin-LF was obtained from Enzo Life Sciences (ALX-350-081-C100, $100 \mu \mathrm{g}$ ) and used as received. The compounds $3,{ }^{16 a} \mathbf{6}^{18}{ }^{18} \mathbf{a},{ }^{17}$ and $10^{18}$ were synthesized according to the literature. For the reactions performed under inert gas conditions (nitrogen) Schlenk technique and oven-dried glassware were used. Analytical thin layer chromatography (TLC) was performed using TLC silica gel $60 \mathrm{~F}_{254}$ coated aluminum sheets (Merck). Spots were visualized either by UV light $(\lambda=254 \mathrm{~nm})$ or by dipping and heating using ethanolic ninhydrin solution $(3 \% \mathrm{w} / \mathrm{v})$, aqueous potassium permanganate $(1 \% \mathrm{w} / \mathrm{v})$, anisaldehyde solution $(135 \mathrm{~mL} \mathrm{EtOH}, 5 \mathrm{~mL}$ conc. $\mathrm{H}_{2} \mathrm{SO}_{4}, 15 \mathrm{~mL}$ glacial acetic acid, and $3.7 \mathrm{~mL} p$-anisaldehyde), or Seebach's stain $\left(25 \mathrm{~g}\right.$ phosphomolybdic acid, $10 \mathrm{~g} \mathrm{Ce}\left(\mathrm{SO}_{4}\right)_{2} \cdot 4 \mathrm{H}_{2} \mathrm{O}$, and $60 \mathrm{~mL}$ conc. $\mathrm{H}_{2} \mathrm{SO}_{4}$ in $1 \mathrm{~L} \mathrm{H}_{2} \mathrm{O}$ ). Preparative flash column chromatography (FC) was performed using Geduran 60 silica gel (40-60 $\mu \mathrm{m}$, Merck). NMR spectra were recorded on Bruker Avance III 400 or Bruker Avance III 600 instruments. Chemical shifts $\delta$ are reported in ppm relative to solvent signals $\left(\mathrm{CDCl}_{3} \delta_{\mathrm{H}}=7.26 \mathrm{ppm}, \delta_{\mathrm{C}}\right.$ $=77.2 \mathrm{ppm} ; \mathrm{CD}_{3} \mathrm{OD} \delta_{\mathrm{H}}=3.34 \mathrm{ppm} ; \delta_{\mathrm{C}}=49.0 \mathrm{ppm} ; \mathrm{DMSO}-d_{6} \delta_{\mathrm{H}}=$ $2.50 \mathrm{ppm}, \delta_{\mathrm{C}}=39.5 \mathrm{ppm}$ ). For all new compounds two-dimensional NMR experiments (COSY, HSQC, and HMBC) were used for signal assignments. For numbering of carbons see Supporting Information.

Semipreparative and analytical RP-HPLC was performed using a Shimadzu LC-20A prominence system (LC-20AT pumps, SIL-20A auto sampler, CTO-20AC column oven, SPD-M2OA PDA detector, CBM-20A communication bus module and LC-Solution software). A Kinetex 5u C18 100A, AXIA $(250 \times 21.2 \mathrm{~mm}$, Phenomenex $)$ column was used as a stationary phase at a flow rate of $10 \mathrm{~mL} \mathrm{~min}^{-1}$ unless mentioned otherwise. LC-MS measurements were performed on a Shimadzu LCMS-2020 system (LC-20 AD high pressure pumps, SIL20AT HAT autosampler, CTO-20AC column oven, SPD-20A UV-vis detector, CBM-20A communication bus module, LCMS-2020 ESIdetector and LC-MS-Solution software) using a Nucleodur 100-3
C18ec $(4 \times 125 \mathrm{~mm}$, Macherey-Nagel $)$ reversed phase column as stationary phase at a flow rate of $0.4 \mathrm{~mL} \mathrm{~min}{ }^{-1}$. A gradient of water with $0.1 \%$ formic acid (mobile phase A) and acetonitrile with $0.1 \%$ formic acid (mobile phase B) was used for the HPLC and LC-MS separations. Elemental analyses were performed by the microanalytical laboratory of the University of Konstanz using an Elementar vario EL instrument. HRMS measurements were performed on a Bruker micrOTOF II (ESI-TOF) or a Thermo LTQ Orbitrap Discovery (ESIOrbitrap) instrument.

General Procedures. GP1: Phenacyl Protection. ${ }^{17}$ The amino acid derivative (1.0 equiv) is dissolved in EtOAc. Then $\mathrm{Et}_{3} \mathrm{~N}$ (1.1 equiv) and phenacyl bromide (1.1 equiv) are added and the reaction mixture is stirred at $\mathrm{rt}$ for $4 \mathrm{~h}$. During the reaction, the formation of a white precipitate can be observed. After $4 \mathrm{~h}$ the mixture is diluted with EtOAc and washed with brine $(1 \times)$, sat. $\mathrm{NaHCO}_{3}$ solution $(1 \times)$, and brine $(2 \times)$. The organic phase is dried over $\mathrm{Na}_{2} \mathrm{SO}_{4}$, filtered, and concentrated under reduced pressure.

GP2: Phenacyl Deprotection. The protected peptide is dissolved in $\mathrm{MeOH} / \mathrm{DMF}$ (8:2, $8 \mu \mathrm{L} \mathrm{mg}^{-1}$ peptide). Then Mg-turnings (0.16 mg/ mg peptide $)$ and acetic acid $\left(0.8 \mu \mathrm{L} \mathrm{mg}^{-1}\right.$ peptide $)$ are added and the reaction mixture is cooled to $0{ }^{\circ} \mathrm{C}$. After $20 \mathrm{~min}$ cooling is removed and the reaction mixture is stirred at $\mathrm{rt}$ for $30 \mathrm{~min}$. The reaction mixture is filtered, the volatiles are removed under reduced pressure, and the residue is taken up in $\mathrm{CH}_{2} \mathrm{Cl}_{2} / \mathrm{MeOH}$ (9:1). The mixture is filtered through $3 \mathrm{~cm}^{3}$ silica column which is extensively washed with $\mathrm{CH}_{2} \mathrm{Cl}_{2} / \mathrm{MeOH}$ (9:1). The solvents are removed under reduced pressure and the residue is lyophilized. The obtained deprotected peptide is used without further purification.

GP3: Fmoc Deprotection. The peptide is dissolved in 5\% piperidine in DMF (v/v). After $3 \mathrm{~min}$, the solution is diluted with DMF and the volatiles are removed under reduced pressure. The residue is coevaporated with toluene $(3 \times)$ and used without further purification.

GP4: Boc/t-Bu Deprotection. The starting material is dissolved in neat TFA and stirred at rt for $30 \mathrm{~min}$. Subsequently the TFA is removed and the residue is coevaporated with toluene, EtOAc, and petroleum ether (each $1 \times$ ) and used without further purification.

GP5: Fmoc Protection. The amino acid (1.0 equiv) is suspended in $\mathrm{Na}_{2} \mathrm{CO}_{3}\left(10 \% \mathrm{w} / \mathrm{v}, 1.25 \mathrm{~mL} \mathrm{mmol}^{-1}\right.$ amino acid). Then Fmoc-OSu (1.3 equiv) in dioxane $\left(1.875 \mathrm{~mL} \mathrm{mmol}{ }^{-1}\right.$ amino acid) is added, and the mixture is stirred at $\mathrm{rt}$ overnight. The reaction mixture is diluted with $\mathrm{H}_{2} \mathrm{O}$ and EtOAc, acidified with aqueous $\mathrm{NaHSO}_{4}(1 \mathrm{M})$ to $\mathrm{pH}<$ 3 , and extracted with EtOAc $(3 \times)$. The combined organic phases are washed with brine $(1 \times)$, dried over $\mathrm{Na}_{2} \mathrm{SO}_{4}$, filtered, and the volatiles removed under reduced pressure. The crude product is purified with FC.

GP6: Peptide Coupling. The amine and carboxylic acid are dissolved in DMF. The resulting solution is cooled to $0{ }^{\circ} \mathrm{C}$. Then base (DIPEA or collidine) and after $5 \mathrm{~min}$ the coupling reagent (HATU or HBTU) are added. The resulting yellowish solution is stirred at $0{ }^{\circ} \mathrm{C}$ for $45 \mathrm{~min}$ and at $\mathrm{rt}$ overnight. The reaction mixture is diluted with EtOAc and washed subsequently with $\mathrm{H}_{2} \mathrm{O}, 1: 1$ diluted saturated citric acid solution, 1:1 diluted saturated $\mathrm{NaHCO}_{3}$ solution, and brine (each $1 \times$ ). The organic phase is dried over $\mathrm{Na}_{2} \mathrm{SO}_{4}$, filtered, and purified with FC.

GP7: Macrocylization. The HPLC-purified C-terminally deprotected heptapeptide (1.0 equiv) is placed in a $4 \mathrm{~mL}$ glass vial. Then pentafluorophenol (1.95 equiv), dissolved in freshly distilled EtOAc (24.2 $\mathrm{mL} \mathrm{mmol}^{-1}$ peptide) and solid DCC are added. The reaction mixture is cooled to $0{ }^{\circ} \mathrm{C}$, stirred for $90 \mathrm{~min}$ and then at $\mathrm{rt}$ for $8-10 \mathrm{~h}$. Afterward, the solvent is removed and the activated peptide is treated with TFA according to GP4. The resulting C-terminally activated unprotected heptapeptide is dissolved in $\mathrm{CHCl}_{3}\left(515 \mathrm{~mL} \mathrm{mmol}^{-1}\right.$ peptide). The resulting solution is added dropwise over a period of 10 min to a vigorously mechanically stirred mixture of $\mathrm{CHCl}_{3}(875 \mathrm{~mL}$ $\mathrm{mmol}^{-1}$ peptide) and $\mathrm{pH}=9.5$ phosphate buffer $(1 \mathrm{M}, 875 \mathrm{~mL}$ $\mathrm{mmol}^{-1}$ peptide). After $30 \mathrm{~min}$, the reaction mixture is diluted with a small amount of $\mathrm{CHCl}_{3}$ and $\mathrm{H}_{2} \mathrm{O}$. The phases are separated, the aqueous phase is acidified with $\mathrm{NaHSO}_{4}(1 \mathrm{M})$ to $\mathrm{pH}<3$ and extracted with EtOAc $(3 \times)$. The organic phases are combined, washed 
with brine, and dried over $\mathrm{Na}_{2} \mathrm{SO}_{4}$. The crude macrocyclic heptapeptide is lyophilized and purified using HPLC.

GP8: Selenoxide Elimination. The macrocyclic peptide is dissolved in $\mathrm{MeCN} / \mathrm{H}_{2} \mathrm{O}(3: 2,1 \mathrm{~mL})$ and $30 \%$ aqueous $\mathrm{H}_{2} \mathrm{O}_{2}(4 \mu \mathrm{L})$ is added. After $1 \mathrm{~h}$ at $\mathrm{rt}$, the reaction mixture is quenched with $\mathrm{Me}_{2} \mathrm{~S}(50 \mu \mathrm{L})$ and purified by HPLC.

Synthesized Compounds (Sorted According to Compound Number). Microcystin-LF (1a). The C-terminally unprotected heptapeptide 22a (15 mg, $10.9 \mu \mathrm{mol})$ was macrocyclized using pentafluorophenol $(4.0 \mathrm{mg}, 21.3 \mu \mathrm{mol})$ and DCC $(2.8 \mathrm{mg}, 13.3 \mu \mathrm{mol})$ according to GP7. The crude macrocycle 23a was purified by semipreparative RP-HPLC (gradient: $60-90 \% \mathrm{~B}$ in $30 \mathrm{~min}, t_{\mathrm{R}}=13.3$ $\mathrm{min}$ ). The cyclic peptide 23a was transformed to 1a according to GP8 and the reaction mixture was separated by semipreparative RP-HPLC (gradient: $50-70 \% \mathrm{~B}$ in $20 \mathrm{~min}, t_{\mathrm{R}}=13.2 \mathrm{~min}$ ). MC-LF 1a was obtained as a white amorphous solid (2.0 mg, 19\%). LC-MS analysis of synthetic la coinjected with natural MC-LF resulted in a single peak with the expected mass (Figure S3). ${ }^{1} \mathrm{H}$ NMR $\left(600 \mathrm{MHz}, \mathrm{CD}_{3} \mathrm{OD}\right.$, $300 \mathrm{~K}) \delta 8.89(\mathrm{~d}, J=9.6 \mathrm{~Hz}, 1 \mathrm{H}, \mathrm{NH}$ MeAsp $), 8.17-8.08(\mathrm{~m}, 2 \mathrm{H}, \mathrm{NH}$ Leu, NH Phe), 7.46 (d, $J=8.2 \mathrm{~Hz}, 1 \mathrm{H}, \mathrm{NH} \mathrm{Ala}), 7.31(\mathrm{~d}, J=9.2 \mathrm{~Hz}$, $1 \mathrm{H}, \mathrm{NH}$ Adda), 7.27-7.25 (m, 2H, Ar), 7.23-7.14 (m, 8H, Ar), 6.35 $(\mathrm{d}, J=15.5 \mathrm{~Hz}, 1 \mathrm{H}, \mathrm{H}-5 \mathrm{Adda}), 5.89\left(\mathrm{~s}, 1 \mathrm{H}, \mathrm{C}=\mathrm{CH}_{2}\right), 5.51(\mathrm{~d}, J=9.8$ $\mathrm{Hz}, 1 \mathrm{H}, \mathrm{H}-7 \mathrm{Adda}), 5.45$ (s, $\left.1 \mathrm{H}, \mathrm{C}=\mathrm{CH}_{2}\right), 5.43(\mathrm{dd}, J=15.5,8.6 \mathrm{~Hz}$ $1 \mathrm{H}, \mathrm{H}-4$ Adda), 4.74-4.69 (m, H-3 Adda), 4.58-4.49 (m, 3H, H- $\alpha$ MeAsp, H- $\alpha$ Phe, H- $\alpha$ Ala), 4.45 (t, $J=7.4$ Hz, 1H, H- $\alpha$ Glu), $4.22-$ 4.18 (m, 1H, H- $\alpha$ Leu), 3.50 (dd, $J=14.1,3.2 \mathrm{~Hz}, 1 \mathrm{H}, \mathrm{H}-\beta$ Phe), 3.38 (s, 3H, $-\mathrm{NCH}_{3}$ ), 3.30-3.27 (m, $1 \mathrm{H}, \mathrm{H}-9$ Adda), 3.26 (s, 3H, $\left.-\mathrm{OCH}_{3}\right)$, $2.93(\mathrm{dq}, J=7.2,3.3 \mathrm{~Hz}, 1 \mathrm{H}, \mathrm{H}-\beta \mathrm{MeAsp}), 2.84$ (dd, $J=14.0,4.8 \mathrm{~Hz}$, 1H, H-10 Adda), 2.74-2.68 (m, 2H, H-10 Adda, H-2 Adda), 2.662.55 (m, 4H, H-8 Adda, $2 \times$ H- $\gamma$ Glu, $\mathrm{H}-\beta$ Phe $), 2.19-2.11(\mathrm{~m}, 1 \mathrm{H}, \mathrm{H}-$ $\beta \mathrm{Glu}), 1.91-1.83$ (m, $1 \mathrm{H}, \mathrm{H}-\beta \mathrm{Leu}), 1.80-1.68$ (m, $2 \mathrm{H}, \mathrm{H}-\beta \mathrm{Glu}, \mathrm{H}-$ $\gamma$ Leu), 1.65 (s, 3H, 3xH-6' Adda), 1.53 (ddd, $J=13.9,9.8,4.2 \mathrm{~Hz}, 1 \mathrm{H}$, $\mathrm{H}-\beta$ Leu $), 1.11$ (d, $J=6.9 \mathrm{~Hz}, 3 \mathrm{H}, 3 \mathrm{xH}-2^{\prime}$ Adda), $1.04(\mathrm{~d}, J=6.7 \mathrm{~Hz}$, $3 \mathrm{H}, 3 \mathrm{xH}-8^{\prime}$ Adda), 0.99 (d, $J=7.4 \mathrm{~Hz}, 3 \mathrm{H}, \mathrm{CH}_{3} \mathrm{Ala}$ ), 0.88 (d, $J=6.6$ $\mathrm{Hz}, 3 \mathrm{H}, 3 \mathrm{xH}-\delta$ Leu $), 0.86(\mathrm{~d}, J=6.5 \mathrm{~Hz}, 3 \mathrm{H}, 3 \mathrm{xH}-\delta$ Leu $), 0.76(\mathrm{~d}, J=$ $\left.7.2 \mathrm{~Hz}, 3 \mathrm{H}, \mathrm{CH}_{3} \mathrm{MeAsp}\right) ;{ }^{13} \mathrm{C} \mathrm{NMR}\left(151 \mathrm{MHz}, \mathrm{CD}_{3} \mathrm{OD}, 300 \mathrm{~K}\right) \delta$ $178.4(\mathrm{C}=\mathrm{O}$ MeAsp $), 176.5(\mathrm{C}=\mathrm{O}), 176.4(\mathrm{C}=\mathrm{O}), 176.0(\mathrm{C}=\mathrm{O})$, $175.7(\mathrm{C}=\mathrm{O}), 175.2(\mathrm{C}=\mathrm{O}), 175.2(\mathrm{C}=\mathrm{O}), 171.5(\mathrm{C}=\mathrm{O}$ Phe $)$, 166.0 ( $\mathrm{C}=\mathrm{O}$ Mdha), $146.2\left(-\underline{\mathrm{C}}=\mathrm{CH}_{2}\right), 140.6$ (C Ar), $139.4(\mathrm{C}-5$ Adda), 139.2 (C Ar), 137.6 (C-7 Adda), 133.7 (C-6 Adda), 130.5 (C $\mathrm{Ar}), 130.1$ (2xC Ar), 129.5 (2xC Ar), 129.2 (C Ar), 127.9 (C Ar), 127.1 (C Ar), 125.9 (C-4 Adda), $114.4\left(-\mathrm{C}=\mathrm{CH}_{2}\right), 88.4$ (C-9 Adda), $58.8\left(-\mathrm{OCH}_{3}\right), 56.1$ (C-7 Adda), 55.3 (C- $\alpha$ MeAsp), 55.3 (C- $\alpha$ Phe), 55.2 (C- $\alpha$ Leu ), 53.3 (C- $\alpha$ Glu), 49.6 (C- $\alpha$ Ala), 46.0 (C-2 Adda), 40.8 (C- $\beta$ Leu ), 40.6 (C- $\beta$ MeAsp), 39.0 (C-10 Adda), 38.5 (- $-\mathrm{NCH}_{3}$ ), 38.1 (C- $\beta$ Phe), 37.8 (C-8 Adda), 33.4 (C- $\gamma$ Glu), 29.5 (C- $\beta$ Glu), 25.7 (C- $\gamma$ Leu ), 23.5 (C- $\delta$ Leu ), 21.2 (C- $\delta$ Leu), $17.4\left(\mathrm{CH}_{3} \mathrm{Ala}\right), 16.5$ (C-8' Adda), 16.4 (C-2' Adda), 15.0 ( $\left.\mathrm{CH}_{3} \mathrm{MeAsp}\right), 12.9$ (C-6' Adda). HRMS (ESI-Orbitrap) $m / z:[\mathrm{M}+\mathrm{H}]^{+}$Calcd for $\mathrm{C}_{52} \mathrm{H}_{72} \mathrm{~N}_{7} \mathrm{O}_{12}$ 986.52335; Found 986. 52418.

[Phe- $\left.d_{5}^{4}\right]$-Microcystin-LF (1b). The macrocyclic derivative $23 \mathrm{~b}$ (5 $\mathrm{mg}, 4.35 \mu \mathrm{mol}$ ) was transformed to 1a according to GP8, and the reaction mixture was separated by semipreparative RP-HPLC (gradient: $50-70 \% \mathrm{~B}$ in $20 \mathrm{~min}, t_{\mathrm{R}}=13.6 \mathrm{~min}$ ). The microcystin 1b was obtained as a white amorphous solid $(3.3 \mathrm{mg}, 76 \%)$. LC-MS analysis of synthetic $\mathbf{1 b}$ coinjected with MC-LF resulted in a single peak with the expected masses of both deuterated $\mathbf{1 b}$ and undeuterated MC-LF (Figure S4). ${ }^{1} \mathrm{H}$ NMR $\left(600 \mathrm{MHz}, \mathrm{CD}_{3} \mathrm{OD}\right.$, $284 \mathrm{~K}) \delta 8.16(\mathrm{~d}, J=6.8 \mathrm{~Hz}, 1 \mathrm{H}, \mathrm{NH}$ Leu $), 8.07(\mathrm{~d}, J=9.1 \mathrm{~Hz}, 1 \mathrm{H}$, $\mathrm{NH}$ MeAsp), $7.56(\mathrm{~d}, J=8.4 \mathrm{~Hz}, 1 \mathrm{H}, \mathrm{NH} \mathrm{Ala}), 7.27-7.25(\mathrm{~m}, 2 \mathrm{H}$, Ar), 7.23-7.15 (m, 3H, Ar), 6.35 (d, J=15.5 Hz, 1H, H-5 Adda), 5.89 $\left(\mathrm{s}, 1 \mathrm{H},-\mathrm{C}=\mathrm{CH}_{2}\right), 5.51(\mathrm{~d}, J=9.9 \mathrm{~Hz}, 1 \mathrm{H}, \mathrm{H}-7 \mathrm{Adda}), 5.46(\mathrm{~s}, 1 \mathrm{H}$, $\left.-\mathrm{C}=\mathrm{CH}_{2}\right), 5.45(\mathrm{dd}, J=15.6,8.6 \mathrm{~Hz}, 1 \mathrm{H}, \mathrm{H}-4 \mathrm{Adda}), 4.69$ (dd, $J=$ 11.0, $8.7 \mathrm{~Hz}, 1 \mathrm{H}, \mathrm{H}-3$ Adda $), 4.58-4.49(\mathrm{~m}, 3 \mathrm{H}, \mathrm{H}-\alpha$ MeAsp, $\mathrm{H}-\alpha$ Phe- $d_{5}, \mathrm{H}-\alpha$ Ala $), 4.40(\mathrm{t}, J=7.5 \mathrm{~Hz}, 1 \mathrm{H}, \mathrm{H}-\alpha \mathrm{Glu}), 4.23-4.13(\mathrm{~m}$, $1 \mathrm{H}, \mathrm{H}-\alpha$ Leu), 3.49 (dd, $J=14.1,3.4 \mathrm{~Hz}, 1 \mathrm{H}, \mathrm{H}-\beta$ Phe- $d_{5}$ ), 3.37 (s, $\left.3 \mathrm{H},-\mathrm{NCH}_{3}\right), 3.30-3.28\left(\mathrm{~m}, 1 \mathrm{H}, \mathrm{H}-9\right.$ Adda), $3.26\left(\mathrm{~s}, 3 \mathrm{H},-\mathrm{OCH}_{3}\right)$, $2.95(\mathrm{dq}, J=7.2,3.5 \mathrm{~Hz}, 1 \mathrm{H}, \mathrm{H}-\beta \mathrm{MeAsp}), 2.85(\mathrm{dd}, J=14.0,4.7 \mathrm{~Hz}$, $1 \mathrm{H}, \mathrm{H}-10$ Adda), 2.80 (dd, $J=10.9,6.9 \mathrm{~Hz}, 1 \mathrm{H}, \mathrm{H}-2$ Adda), 2.69 (dd, $J$ $=13.9,7.3 \mathrm{~Hz}, 1 \mathrm{H}, \mathrm{H}-10 \mathrm{Adda}), 2.65-2.52(\mathrm{~m}, 4 \mathrm{H}, \mathrm{H}-8$ Adda, $\mathrm{H}-\beta$
Phe- $d_{5}, 2 x H-\gamma$ Glu), 2.17-2.07 (m, $1 \mathrm{H}, \mathrm{H}-\beta$ Glu), 1.90 (ddd, $J=15.5$, $12.8,4.1 \mathrm{~Hz}, 1 \mathrm{H}, \mathrm{H}-\beta$ Leu $), 1.80-1.69$ (m, $2 \mathrm{H}, \mathrm{H}-\beta$ Glu, H- $\gamma$ Leu), 1.65 (s, 3H, 3xH-6' Adda), 1.52 (ddd, $J=13.8,10.2,3.9 \mathrm{~Hz}, 1 \mathrm{H}, \mathrm{H}-\beta$ Leu), 1.10 (d, $J=6.9 \mathrm{~Hz}, 3 \mathrm{H}, 3 \times \mathrm{H}-2^{\prime}$ Adda), $1.04(\mathrm{~d}, J=6.7 \mathrm{~Hz}, 3 \mathrm{H}$, $3 \mathrm{xH}-8^{\prime}$ Adda), $0.97\left(\mathrm{~d}, J=7.4 \mathrm{~Hz}, 3 \mathrm{H},-\mathrm{CH}_{3} \mathrm{Ala}\right), 0.88(\mathrm{~d}, J=6.6 \mathrm{~Hz}$, $3 \mathrm{H}, 3 \mathrm{xH}-\delta \mathrm{Leu}), 0.85(\mathrm{~d}, J=6.6 \mathrm{~Hz}, 3 \mathrm{H}, 3 \mathrm{xH}-\delta \mathrm{Leu}), 0.75(\mathrm{~d}, J=7.2$ $\left.\mathrm{Hz}, 3 \mathrm{H}, \mathrm{CH}_{3} \mathrm{MeAsp}\right) ;{ }^{13} \mathrm{C}$ NMR (151 MHz, $\left.\mathrm{CD}_{3} \mathrm{OD}, 284 \mathrm{~K}\right): \delta=$ $178.5(\mathrm{C}=\mathrm{O} \mathrm{MeAsp}), 176.6(\mathrm{C}=\mathrm{O}), 176.5(\mathrm{C}=\mathrm{O}), 176.2(\mathrm{C}=\mathrm{O})$, $175.6(\mathrm{C}=\mathrm{O}), 175.3(\mathrm{C}=\mathrm{O}), 175.2(\mathrm{C}=\mathrm{O}), 171.6(\mathrm{C}=\mathrm{O}$ Phe $)$, 166.0 ( $\mathrm{C}=\mathrm{O}$ Mdha), $146.2\left(-\mathrm{C}=\mathrm{CH}_{2}\right), 140.5$ (C Ar), 139.3 (C-5 Adda), 139.0 (C Ar), 137.5 (C-7 Adda), 133.7 (C-6 Adda), 130.6 (C $\mathrm{Ar}$ ), 129.2 (C Ar), 127.1 (C Ar), 126.0 (C-4 Adda), 114.5 (-C= $\underline{\mathrm{CH}}_{2}$ ), 88.3 (C-9 Adda), $58.7\left(-\mathrm{OCH}_{3}\right), 56.2$ (C-7 Adda), 55.6 (C- $\alpha$ MeAsp), 55.2 (C- $\alpha$ Phe- $d_{5}$ ), 55.1 (C- $\alpha$ Leu), 53.6 (C- $\alpha$ Glu), 49.6 (C$\alpha$ Ala), 45.7 (C-2 Adda), 40.8 (C- $\beta$ Leu), 38.9 (C-10 Adda), 38.5 (- $\mathrm{NCH}_{3}$ ), 38.0 (C- $\beta$ Phe- $d_{5}$ ), 37.7 (C-8 Adda), 33.4 (C- $\gamma$ Glu), 29.2 (C- $\beta$ Glu ), 25.7 (C- $\gamma$ Leu ), 23.6 (C- $\delta$ Leu ), 21.2 (C- $\delta$ Leu), 17.3 ( $\left.-\mathrm{CH}_{3} \mathrm{Ala}\right), 16.6$ (C-8' Adda), 16.3 (C-2' Adda), $15.0\left(\mathrm{CH}_{3} \mathrm{MeAsp}\right)$, 12.9 (C-6' Adda); HRMS (ESI-TOF) $\mathrm{m} / z:[\mathrm{M}+\mathrm{H}]^{+}$Calcd for $\mathrm{C}_{52} \mathrm{H}_{67} \mathrm{D}_{5} \mathrm{~N}_{7} \mathrm{O}_{12}$ 991.5547; Found 991.5553.

Microcystin-LY(Prg) (1c). The macrocyclic derivative 23c (6.2 mg, $5.18 \mu \mathrm{mol}$ ) was transformed to $1 \mathrm{c}$ according to GP8 and the reaction mixture was separated by semipreparative RP-HPLC (gradient: 50$70 \% \mathrm{~B}$ in $20 \mathrm{~min}, t_{\mathrm{R}}=14.1 \mathrm{~min}$ ). The microcystin $1 \mathrm{c}$ was obtained as a white amorphous solid $(2.3 \mathrm{mg}, 43 \%) .{ }^{1} \mathrm{H}$ NMR $\left(600 \mathrm{MHz}, \mathrm{CD}_{3} \mathrm{OD}\right.$, $300 \mathrm{~K}) \delta 8.89(\mathrm{~d}, J=9.6 \mathrm{~Hz}, 1 \mathrm{H}, \mathrm{NH} \operatorname{Tyr}(\operatorname{Prg})), 8.21(\mathrm{~d}, J=8.7 \mathrm{~Hz}$, $1 \mathrm{H}, \mathrm{NH}$ MeAsp), 8.11 (d, $J=6.7 \mathrm{~Hz}, 1 \mathrm{H}, \mathrm{NH} \mathrm{Leu}), 7.43$ (d, $J=8.0$ $\mathrm{Hz}, 1 \mathrm{H}, \mathrm{NH}$ Ala $), 7.28-7.26$ (m, 2H, Ar), 7.22-7.16 (m, 3H, Ar), $7.09(\mathrm{~d}, J=8.6 \mathrm{~Hz}, 2 \mathrm{H}, \mathrm{Ar}), 6.84(\mathrm{~d}, J=8.7 \mathrm{~Hz}, 2 \mathrm{H}, \mathrm{Ar}), 6.35(\mathrm{~d}, J=$ $15.5 \mathrm{~Hz}, 1 \mathrm{H}, \mathrm{H}-5 \mathrm{Adda}), 5.90\left(\mathrm{~s}, 1 \mathrm{H},-\mathrm{C}=\mathrm{CH}_{2}\right), 5.51(\mathrm{~d}, J=9.8 \mathrm{~Hz}$, $1 \mathrm{H}, \mathrm{H}-7 \mathrm{Adda}), 5.46\left(\mathrm{~s}, 1 \mathrm{H},-\mathrm{C}=\mathrm{CH}_{2}\right), 5.42(\mathrm{dd}, J=15.5,8.7 \mathrm{~Hz}, 1 \mathrm{H}$, H-4 Adda), 4.71 (dd, $J=11.0,8.6 \mathrm{~Hz}, 1 \mathrm{H}, \mathrm{H}-3$ Adda), 4.65 (d, $J=2.3$ $\mathrm{Hz}, 2 \mathrm{H},-\mathrm{OCH}_{2}-\operatorname{Tyr}(\operatorname{Prg})$ ), 4.57-4.50 (m, 3H, H- $\alpha$ MeAsp, H- $\alpha$ $\operatorname{Tyr}(\operatorname{Prg}), \mathrm{H}-\alpha \mathrm{Ala}), 4.46$ (dd, $J=8.8,6.1 \mathrm{~Hz}, 1 \mathrm{H}, \mathrm{H}-\alpha \mathrm{Glu}), 4.22-$ 4.15 (m, $1 \mathrm{H}, \mathrm{H}-\alpha$ Leu ), 3.44 (dd, $J=14.1,3.1 \mathrm{~Hz}, 1 \mathrm{H}, \mathrm{H}-\beta \operatorname{Tyr}(\operatorname{Prg})$ ), 3.37 (s, $\left.3 \mathrm{H},-\mathrm{NCH}_{3}\right), 3.30-3.26(\mathrm{~m}, 1 \mathrm{H}, \mathrm{H}-9$ Adda), $3.26(\mathrm{~s}, 3 \mathrm{H}$, $\left.-\mathrm{OCH}_{3}\right), 2.96-2.91(\mathrm{~m}, 1 \mathrm{H}, \mathrm{H}-\beta$ MeAsp $), 2.91(\mathrm{t}, J=2.4 \mathrm{~Hz}, 1 \mathrm{H}$, $-\mathrm{C} \equiv \mathrm{CH}$ ), 2.84 (dd, $J=14.0,4.7 \mathrm{~Hz}, 1 \mathrm{H}, \mathrm{H}-10 \mathrm{Adda}), 2.73-2.66$ (m, $2 \mathrm{H}, \mathrm{H}-2$ Adda, $\mathrm{H}-10$ Adda), 2.63 (dq, $J=9.9,6.6 \mathrm{~Hz}, 1 \mathrm{H}, \mathrm{H}-8$ Adda), $2.61-2.56$ (m, 1H, 2xH- $\gamma$ Glu), 2.51 (dd, $J=14.1,11.9 \mathrm{~Hz}, 1 \mathrm{H}, \mathrm{H}-\beta$ $\operatorname{Tyr}(\operatorname{Prg})), 2.19-2.11(\mathrm{~m}, 1 \mathrm{H}, \mathrm{H}-\beta \mathrm{Glu}), 1.89-1.83(\mathrm{~m}, 1 \mathrm{H}, \mathrm{H}-\beta$ Leu), $1.79-1.73(\mathrm{~m}, 1 \mathrm{H}, \mathrm{H}-\gamma$ Leu $), 1.73-1.65(\mathrm{~m}, 1 \mathrm{H}, \mathrm{H}-\beta$ Glu $), 1.65$ (d, $J=1 \mathrm{~Hz}, 3 \mathrm{H}, 3 \times \mathrm{xH}-6^{\prime}$ Adda), 1.52 (ddd, $J=13.7,9.8,4.1 \mathrm{~Hz}, 1 \mathrm{H}$, H- $\beta$ Leu ), 1.11 (d, $J=6.9 \mathrm{~Hz}, 3 \mathrm{xH}-2^{\prime}$ Adda), 1.04 (d, $J=6.7 \mathrm{~Hz}, 3 \mathrm{xH}-$ $8^{\prime}$ Adda), 1.01 (d, $\left.J=7.4 \mathrm{~Hz}, 3 \mathrm{H}, \mathrm{CH}_{3} \mathrm{Ala}\right), 0.89$ (d, $J=6.6 \mathrm{~Hz}, 3 \mathrm{H}$, $3 \mathrm{xH}-\delta \mathrm{Leu}), 0.86(\mathrm{~d}, J=6.6 \mathrm{~Hz}, 3 \mathrm{H}, 3 \mathrm{xH}-\delta \mathrm{Leu}), 0.81(\mathrm{~d}, J=7.2 \mathrm{~Hz}$, $\left.3 \mathrm{H}, \mathrm{CH}_{3} \mathrm{MeAsp}\right) ;{ }^{13} \mathrm{C}$ NMR $\left(151 \mathrm{MHz}, \mathrm{CD}_{3} \mathrm{OD}, 300 \mathrm{~K}\right) \delta 178.4$ $(\mathrm{C}=\mathrm{O}$ MeAsp $), 176.4(\mathrm{C}=\mathrm{O}), 175.9(\mathrm{C}=\mathrm{O}), 175.8(\mathrm{C}=\mathrm{O}), 175.2$ $(\mathrm{C}=\mathrm{O}), 175.0(\mathrm{C}=\mathrm{O}), 171.5(\mathrm{C}=\mathrm{O}), 166.0(\mathrm{C}=\mathrm{O}), 165.9(\mathrm{C}=$ O), 158.0 (-C-O-CH-$), 146.2\left(-\mathrm{C}=\mathrm{CH}_{2}\right), 140.5$ (C Ar Adda), 139.4 (C-5 Adda), 137.7 (C-7 Adda), 133.7 (C-6 Adda), 131.8 (C Ar Tyr(Prg)), 131.1 (2xC Ar Tyr(Prg)), 130.5 (2xC Ar Adda), 129.2 (2xC Ar Adda), 127.1 (CH Ar Adda), 125.8 (C-4 Adda), 116.0 (2xC $\operatorname{Ar} \operatorname{Tyr}(\operatorname{Prg})), 114.4\left(-\mathrm{C}=\mathrm{CH}_{2}\right), 88.4$ (C-9 Adda), 79.8 (-C $\left.\equiv \mathrm{CH}\right)$, $76.8(-\mathrm{C} \equiv \underline{\mathrm{CH}}), 58.7\left(-\mathrm{OCH}_{3}\right), 56.5\left(-\mathrm{OCH}_{2}-\right), 56.0$ (C-3 Adda), 55.4, 55.3, 55.2 (m, 3C, C- $\alpha$ Leu, C- $\alpha$ MeAsp, C- $\alpha$ Tyr(Prg)), 53.2 (C- $\alpha$ Glu ), 49.6 (C- $\alpha$ Ala ), 46.0 (C-2 Adda), 40.8 (C- $\beta$ Leu), 40.5 (C$\beta$ MeAsp), 39.0 (C-10 Adda), 38.5 (- $\left.\mathrm{NCH}_{3}\right), 37.7$ (C-8 Adda), 37.2 (C- $\beta$ Tyr(Prg)), 33.4 (C- $\gamma$ Glu ), 29.6 (C- $\beta$ Glu ), 25.7 (C- $\gamma$ Leu ), 23.5 $\left(\mathrm{CH}_{3} \mathrm{Leu}\right), 21.2\left(\mathrm{CH}_{3} \mathrm{Leu}\right), 17.4\left(\mathrm{CH}_{3} \mathrm{Ala}\right), 16.5$ (C-8' $\left.\mathrm{Adda}\right), 16.4$ (C-2' Adda), 15.2 ( $\mathrm{CH}_{3}$ MeAsp), 12.9 (C-6' Adda); HRMS (ESITOF) $m / z:[\mathrm{M}+\mathrm{H}]^{+}$Calcd for $\mathrm{C}_{55} \mathrm{H}_{74} \mathrm{~N}_{7} \mathrm{O}_{13}$ 1040.5339; Found 1040.5353 .

Fmoc- $\gamma$-D-Glu(Ot-Bu)-N-MeSecPh-D-Ala-Leu-OPac (4). Tripeptide $12(297 \mathrm{mg}, 449.5 \mu \mathrm{mol})$ was deprotected according to GP4. The Nterminally deprotected tripeptide $(91 \mathrm{mg}, 107.5 \mu \mathrm{mol}$ ) and Fmoc-DGlu-Ot-Bu (249 mg, $584.4 \mu \mathrm{mol})$ were dissolved in DMF $(2 \mathrm{~mL})$. Peptide coupling was performed according to GP6 using HATU (222 $\mathrm{mg}, 584.4 \mu \mathrm{mol})$ and DIPEA $(313 \mu \mathrm{L}, 1.8 \mathrm{mmol})$. The crude product was purified by FC to give tetrapeptide 4 (390 $\mathrm{mg}, 90 \%$ ) as a white 
amorphous solid: $R_{f}=0.77$ (EtOAc); ${ }^{1} \mathrm{H}$ NMR $\left(400 \mathrm{MHz}, \mathrm{CDCl}_{3}\right.$, $300 \mathrm{~K}) \delta 7.80-7.70(\mathrm{~m}, 4 \mathrm{H}, 4 \mathrm{x} \mathrm{H}-\mathrm{Ar}), 7.68-7.54(\mathrm{~m}, 3 \mathrm{H}, 3 \mathrm{x} \mathrm{H}-\mathrm{Ar})$, 7.53-7.47 (m, 1H, 2x H-Ar), 7.45-7.35 (m, 4H, 4x H-Ar), 7.337.25 (m, 2H, 2x H-Ar), 7.24-7.19 (m, 4H, 3x H-Ar, NH Ala), 6.84 $(\mathrm{d}, J=8.3 \mathrm{~Hz}, 1 \mathrm{H}, \mathrm{NH}$ Leu $), 5.57$ (d, $J=8.0 \mathrm{~Hz}, 1 \mathrm{H}, \mathrm{NH} \mathrm{Glu}), 5.35$ (dd, $J=10.2,5.3 \mathrm{~Hz}, 1 \mathrm{H}, \mathrm{H}-\alpha \mathrm{NMeSecPh}), 5.19$ (d, $J=16.5 \mathrm{~Hz}, 1 \mathrm{H}$, $\left.-\mathrm{C}(\mathrm{O}) \mathrm{C}_{2}-\mathrm{O}\right), 4.94\left(\mathrm{~d}, J=16.5 \mathrm{~Hz}, 1 \mathrm{H},-\mathrm{C}(\mathrm{O}) \mathrm{C}_{2}-\mathrm{O}\right), 4.65-4.53$ (m, $2 \mathrm{H}, \mathrm{H}-\alpha$ Leu, H- $\alpha$ Ala), 4.44-4.38 (m, $1 \mathrm{H},-\mathrm{OC} \underline{\mathrm{H}}_{2}-\mathrm{CH}-\mathrm{Fmoc}$ ), 4.35-4.25 (m, $2 \mathrm{H},-\mathrm{OCH}_{2}$-CH- Fmoc, H- $\alpha$ Glu $), 4.17(\mathrm{t}, J=6.9 \mathrm{~Hz}$, $1 \mathrm{H},-\mathrm{OCH}_{2}-\mathrm{C} \underline{\mathrm{H}}-\mathrm{Fmoc}$ ), $3.63(\mathrm{dd}, J=13.0,5.2 \mathrm{~Hz}, 1 \mathrm{H}, \mathrm{H}-\beta$ $\mathrm{NMeSecPh}$ ), 3.19 (dd, $J=12.9,10.5 \mathrm{~Hz}, 1 \mathrm{H}, \mathrm{H}-\beta \mathrm{NMeSecPh}$ ), 2.76 (s, 3H, $-\mathrm{NCH}_{3}$ ), 2.47-2.32 (m, $\left.2 \mathrm{H}, 2 \mathrm{x} \mathrm{H}-\gamma \mathrm{Glu}\right), 2.18$ (dd, $J=15.6$, $4.4 \mathrm{~Hz}, 1 \mathrm{H}, \mathrm{H}-\beta \mathrm{Glu}), 1.82-1.73(\mathrm{~m}, J=3.1 \mathrm{~Hz}, 2 \mathrm{H}, \mathrm{H}-\beta$ Leu, $\mathrm{H}-\gamma$ Leu), $1.70-1.60(\mathrm{~m}, 2 \mathrm{H}, \mathrm{H}-\beta$ Leu, $\mathrm{H}-\beta \mathrm{Glu}), 1.48$ (s, 9H, ${ }^{\mathrm{t}} \mathrm{Bu}$ ), 1.36 $\left(\mathrm{d}, J=7.1 \mathrm{~Hz}, 3 \mathrm{H}, \mathrm{CH}_{3} \mathrm{Ala}\right), 0.97(\mathrm{~d}, J=6.3 \mathrm{~Hz}, 3 \mathrm{H}, 3 \mathrm{xH}-\delta$ Leu $)$, $0.95(\mathrm{~d}, J=6.3 \mathrm{~Hz}, 3 \mathrm{H}, 3 \mathrm{xH}-\delta \mathrm{Leu}) ;{ }^{13} \mathrm{C}$ NMR $\left(101 \mathrm{MHz}, \mathrm{CDCl}_{3}\right.$, $300 \mathrm{~K}) \delta 173.4(\mathrm{C}=\mathrm{O}), 172.6(\mathrm{C}=\mathrm{O}), 172.1(\mathrm{C}=\mathrm{O}), 171.7(\mathrm{C}=$ $\mathrm{O}), 171.3(\mathrm{C}=\mathrm{O}), 170.5(\mathrm{C}=\mathrm{O}), 156.5(\mathrm{C}=\mathrm{O}), 144.3(\mathrm{C} \mathrm{Ar})$, 143.8 (C Ar), 141.5 (C Ar), 141.4 (C Ar), 134.1 (C Ar), 134.1 (C Ar), 133.2 (C Ar), 129.8 (C Ar), 129.3 (2C Ar), 129.0 (C Ar), 127.8 (C $\mathrm{Ar}), 127.8$ (C Ar), 127.4 (C Ar), 127.3 (C Ar), 127.3 (C Ar), 125.5 (C Ar) $125.3(\mathrm{C} \mathrm{Ar}), 120.0(2 \mathrm{C} \mathrm{Ar}), 82.7\left(-\underline{\mathrm{C}}\left(\mathrm{CH}_{3}\right)_{3}\right), 67.0\left(-\mathrm{O}_{\mathrm{CH}}-\right.$ $\mathrm{CH}-\mathrm{Fmoc}), 66.3\left(\mathrm{CH}_{2} \mathrm{Pac}\right), 58.0(\mathrm{C}-\alpha \mathrm{NMeSecPh}), 53.4\left(-\mathrm{OCH}_{2}-\right.$ CH-Fmoc), 50.7 (C- $\alpha$ Leu), 48.6 (C- $\alpha$ Ala), 47.2 (C- $\alpha$ Glu), 41.2 (C$\beta$ Leu), $32.2\left(-\mathrm{NCH}_{3}\right), 28.84$ (C- $\beta$ Glu ), 28.75 (C- $\left.\gamma \mathrm{Glu}\right), 28.2$ (3C, $\left.-\mathrm{C}\left(\mathrm{CH}_{3}\right)_{3}\right), 26.4(\mathrm{C}-\beta \mathrm{NMeSecPh}), 25.0$ (C- $\gamma$ Leu $), 23.1$ (C- $\delta$ Leu $)$, $21.8(\mathrm{C}-\delta$ Leu $) 16.1\left(\mathrm{CH}_{3}\right.$ Ala); HRMS (ESI-TOF) $m / z:[\mathrm{M}+\mathrm{H}]^{+}$ Calcd for $\mathrm{C}_{51} \mathrm{H}_{61} \mathrm{~N}_{4} \mathrm{O}_{10} \mathrm{Se}$ 969.35474; Found 969.35351.

Fmoc- $\beta$-D-MeAsp(Ot-Bu)-Phe-OH (5a). Boc-Phe-OPac ${ }^{17}$ 8a (120 $\mathrm{mg}, 313 \mu \mathrm{mol}$ ) was deprotected according to GP4. The obtained $\mathrm{H}$ Phe-OPac and Fmoc-D-MeAsp-Ot-Bu 7 (140 mg, $329 \mu$ mol) were dissolved in DMF (3 mL). Peptide coupling was performed according to GP6 using HATU (125 mg, $329 \mu \mathrm{mol})$ and DIPEA (165 $\mu \mathrm{L}, 329$ $\mu \mathrm{mol}$ ). The crude product was purified by FC (petroleum ether/ EtOAc 2:1) to give dipeptide $\mathbf{5 a}(153 \mathrm{mg}, 71 \%)$ as a white amorphous solid: $R_{f}=0.77$ (petroleum ether/EtOAc 1:1); ${ }^{1} \mathrm{H}$ NMR (400 MHz, $\left.\mathrm{CDCl}_{3}, 300 \mathrm{~K}\right) \delta 7.95-7.87(\mathrm{~m}, 2 \mathrm{H}, \mathrm{Ar}), 7.76(\mathrm{~d}, J=7.6 \mathrm{~Hz}, 2 \mathrm{H}, \mathrm{Ar})$, 7.65-7.60 (m, 2H, Ar), 7.52-7.48 (m, 2H, Ar), 7.40-7.37 (m, $2 \mathrm{H}$, Ar), 7.34-7.20 (m, 8H, Ar), 6.13-6.05 (m, 1H, NH MeAsp, NH Phe), 5.50 (d, $\left.J=16.3 \mathrm{~Hz}, 1 \mathrm{H}, \mathrm{CH}_{2} \mathrm{Pac}\right), 5.34(\mathrm{~d}, J=16.3 \mathrm{~Hz}, 1 \mathrm{H}$, $\mathrm{CH}_{2} \mathrm{Pac}$ ), 5.01 (ddd, $J=13.0,7.4,5.5 \mathrm{~Hz}, 1 \mathrm{H}, \mathrm{H}-\alpha$ Phe), 4.41 (dd, $J=$ $\left.10.2,7.2 \mathrm{~Hz}, 1 \mathrm{H},-\mathrm{OC} \underline{\mathrm{H}}_{2}-\mathrm{CH}-\mathrm{Fmoc}\right), 4.36-4.28\left(\mathrm{~m}, 2 \mathrm{H},-\mathrm{OC} \underline{\mathrm{H}}_{2}-\mathrm{CH}-\right.$ Fmoc, $\mathrm{H}-\alpha \mathrm{MeAsp}), 4.24\left(\mathrm{t}, J=7.2 \mathrm{~Hz}, 1 \mathrm{H},-\mathrm{OCH}_{2}-\mathrm{C} \underline{\mathrm{H}}-\mathrm{Fmoc}\right)$, 3.42 (dd, $J=14.2,5.6 \mathrm{~Hz}, 1 \mathrm{H}, \mathrm{H}-\beta$ Phe), 3.19 (dd, $J=14.2,7.1 \mathrm{~Hz}$, $1 \mathrm{H}, \mathrm{H}-\beta$ Phe), 3.04 (qd, $J=7.3,3.8 \mathrm{~Hz}, 1 \mathrm{H}, \mathrm{H}-\beta$ MeAsp), 1.41 (s, 9H, $t$-Bu), $1.15\left(\mathrm{~d}, J=7.3 \mathrm{~Hz}, 3 \mathrm{H}, \mathrm{CH}_{3} \mathrm{MeAsp}\right) ;{ }^{13} \mathrm{C}$ NMR $(101 \mathrm{MHz}$, $\left.\mathrm{CDCl}_{3}, 300 \mathrm{~K}\right) \delta 191.4(\mathrm{C}=\mathrm{O}), 173.6(\mathrm{C}=\mathrm{O}), 171.2(\mathrm{C}=\mathrm{O}), 170.1$ $(\mathrm{C}=\mathrm{O}), 157.1(\mathrm{C}=\mathrm{O}), 144.2$ (C Ar), 144.0 (C Ar), 141.4 (C Ar), 135.9 (C Ar), 134.3 (C Ar), 134.1 (C Ar), 129.6 (2C Ar), 129.1 (2C, $\mathrm{Ar}), 128.8$ (2C Ar), 127.9 (2C Ar), 127.8 (2C Ar), 127.4 (C Ar), 127.2 (2C Ar), 127.2 (C Ar), 125.5 (C Ar), 125.4 (C Ar), 120.1 (C Ar) 120.0 (C Ar), $82.5\left(-\underline{C}\left(\mathrm{CH}_{3}\right)_{3}\right), 67.3\left(-\mathrm{OCH}_{2}-\mathrm{CH}-\mathrm{Fmoc}\right), 66.7$ $\left(\mathrm{CH}_{2} \mathrm{Pac}\right), 57.1$ ( $\left.-\mathrm{OCH}_{2}-\mathrm{CH}-\mathrm{Fmoc}\right), 53.0$ (C- $\alpha$ Phe), 47.3 (C- $\alpha$ MeAsp), 41.6 (C- $\beta$ MeAsp), 37.8 (C- $\beta$ Phe), 28.0 (3C, - $\left.\mathrm{C}\left(\mathrm{CH}_{3}\right)_{3}\right)$, $15.2\left(\mathrm{CH}_{3}\right.$ MeAsp); HRMS (ESI-TOF) $\mathrm{m} / z:[\mathrm{M}+\mathrm{H}]^{+}$Calcd for $\mathrm{C}_{41} \mathrm{H}_{43} \mathrm{~N}_{2} \mathrm{O}_{8}$ 691.30139; Found 691.30123.

Fmoc- $\beta$-D-MeAsp (Ot-Bu)-Phe- $d_{5}-\mathrm{OH}$ (5b). Boc-Phe- $d_{5}$-OPac $8 \mathbf{b}$ (43 mg, $109.7 \mu \mathrm{mol}$ ) was deprotected according to GP4. The obtained H-Phe- $d_{5}$-OPac and Fmoc-D-MeAsp-Ot-Bu $7(49 \mathrm{mg}, 115.0 \mu \mathrm{mol})$ were dissolved in DMF $(1 \mathrm{~mL})$. Peptide coupling was performed according to GP6 using HATU (44 mg, $115.0 \mu \mathrm{mol}$ ) and DIPEA (57.2 $\mu \mathrm{L}, 329.0 \mu \mathrm{mol}$ ). The crude product was purified by FC (petroleum ether/EtOAc 2:1) to give dipeptide $5 \mathbf{b}(66 \mathrm{mg}, 86 \%)$ as a white amorphous solid: $R_{f}=0.77$ (petroleum ether/EtOAc $\left.1: 1\right) ;{ }^{1} \mathrm{H}$ NMR $\left(400 \mathrm{MHz}, \mathrm{CDCl}_{3}, 300 \mathrm{~K}\right) \delta 7.93-7.87(\mathrm{~m}, 2 \mathrm{H}, \mathrm{Ar}), 7.76(\mathrm{~d}, J=7.6$ $\mathrm{Hz}, 2 \mathrm{H}, \mathrm{Ar}$ ), 7.66-7.59 (m, 3H, Ar), 7.52-7.48 (m, 2H, Ar), 7.407.48 (m, 2H, Ar), 7.32-7.27 (m, 2H, Ar), 6.12-6.03 (m, 2H, NH MeAsp, NH Phe- $\left.d_{5}\right), 5.50\left(\mathrm{~d}, J=16.3 \mathrm{~Hz}, 1 \mathrm{H}, \mathrm{CH}_{2} \mathrm{Pac}\right), 5.34(\mathrm{~d}, J=$ $16.3 \mathrm{~Hz}, 1 \mathrm{H}, \mathrm{CH}_{2} \mathrm{Pac}$ ), 5.01 (ddd, $J=13.0,7.2,5.5 \mathrm{~Hz}, 1 \mathrm{H}, \mathrm{H}-\alpha$ Phe), 4.41 (dd, $\left.J=10.2,7.2 \mathrm{~Hz}, 1 \mathrm{H},-\mathrm{OC} \underline{H}_{2}-\mathrm{CH}-\mathrm{Fmoc}\right), 4.36-4.28(\mathrm{~m}, 2 \mathrm{H}$,
-OCH ${ }_{2}-\mathrm{CH}-$ Fmoc, $\mathrm{H}-\alpha$ MeAsp), $4.24\left(\mathrm{t}, J=7.3 \mathrm{~Hz}, 1 \mathrm{H},-\mathrm{OCH}_{2}-\right.$ C H- Fmoc), 3.42 (dd, $J=14.2,5.6 \mathrm{~Hz}, 1 \mathrm{H}, \mathrm{H}-\beta$ Phe), 3.19 (dd, $J=$ $14.2,7.1 \mathrm{~Hz}, 1 \mathrm{H}, \mathrm{H}-\beta$ Phe), 3.04 (qd, $J=7.1,3.9 \mathrm{~Hz}, 1 \mathrm{H}, \mathrm{H}-\beta$ MeAsp), 1.41 (s, 9H, $t$-Bu), 1.15 (d, $\left.J=7.2 \mathrm{~Hz}, 3 \mathrm{H}, \mathrm{CH}_{3} \mathrm{MeAsp}\right) ;{ }^{13} \mathrm{C}$ NMR $\left(101 \mathrm{MHz}, \mathrm{CDCl}_{3}, 300 \mathrm{~K}\right) \delta 191.4(\mathrm{C}=\mathrm{O}), 173.6(\mathrm{C}=\mathrm{O})$, $171.2(\mathrm{C}=\mathrm{O}), 170.1(\mathrm{C}=\mathrm{O}), 157.1(\mathrm{C}=\mathrm{O}), 141.4(\mathrm{C} \mathrm{Ar}), 134.3(\mathrm{C}$ Ar), 134.1 (C Ar), 129.1 (2C Ar), 127.9 (2C Ar), 127.8 (2C Ar), 127.2 (2C Ar), 125.5 (C Ar), 125.4 (C Ar), 120.1 (2C Ar), $82.5\left(-\underline{C}\left(\mathrm{CH}_{3}\right)_{3}\right)$, $67.4\left(-\mathrm{OCH}_{2}-\mathrm{CH}-\mathrm{Fmoc}\right), 66.7\left(\mathrm{CH}_{2} \mathrm{Pac}\right), 56.1\left(-\mathrm{OCH}_{2}-\underline{\mathrm{CH}}-\right.$ Fmoc), 53.0 (C- $\alpha$ Phe- $d_{5}$ ), 47.4 (C- $\alpha$ MeAsp), 41.6 (C- $\beta$ MeAsp), 37.7 (C- $\beta$ Phe- $\left.d_{5}\right), 28.0\left(3 \mathrm{C},-\mathrm{C}\left(\mathrm{CH}_{3}\right)_{3}\right), 15.2\left(\mathrm{CH}_{3}\right.$ MeAsp); HRMS (ESI-TOF) $m / z:[\mathrm{M}+\mathrm{H}]^{+}$Calcd for $\mathrm{C}_{41} \mathrm{H}_{38} \mathrm{D}_{5} \mathrm{~N}_{2} \mathrm{O}_{8}$ 696.3328; Found 696.3313.

Fmoc- $\beta$-D-MeAsp(Ot-Bu)-Tyr(Prg)-OH (5c). Boc-Tyr(Prg)-OPac 8c $(137 \mathrm{mg}, 313 \mu \mathrm{mol})$ was deprotected according to GP4. The obtained H-Tyr(Prg)-OPac and Fmoc-D-MeAsp-O $t^{-} \mathrm{Bu} 7(140 \mathrm{mg}$, $329 \mu \mathrm{mol})$ were dissolved in DMF (3 mL). Peptide coupling was performed according to GP6 using HATU (125 mg, $329 \mu \mathrm{mol})$ and DIPEA $(165 \mu \mathrm{L}, 329 \mu \mathrm{mol})$. The crude product was purified by FC to give dipeptide $5 \mathrm{c}(181 \mathrm{mg}, 84 \%)$ as a white amorphous solid: $R_{f}=0.3$ (petroleum ether/EtOAc 2:1); ${ }^{1} \mathrm{H}$ NMR $\left(400 \mathrm{MHz}, \mathrm{CDCl}_{3}, 300 \mathrm{~K}\right) \delta$ 7.94-7.86 (m, 2H, Ar), 7.75 (d, $J=7.5 \mathrm{~Hz}, 2 \mathrm{H}, \mathrm{Ar}), 7.67-7.58(\mathrm{~m}$, $3 \mathrm{H}, \mathrm{Ar}$ ), 7.52-7.48 (m, 2H, Ar), 7.40-7.36 (m, 2H, Ar), 7.31-7.27 (m, 2H, Ar), 7.17 (d, J = 8.6 Hz, 2H, Ar), 6.94-6.90 (m, 2H, Ar), 6.11-6.03 (m, 2H, NH MeAsp, NH Phe), 5.50 (d, $J=16.3 \mathrm{~Hz}, 1 \mathrm{H}$, $\mathrm{CH}_{2} \mathrm{Pac}$ ), 5.33 (d, $J=16.3 \mathrm{~Hz}, 1 \mathrm{H}, \mathrm{CH}_{2} \mathrm{Pac}$ ), 4.97 (ddd, $J=13.3,6.8$, $6.0 \mathrm{~Hz}, 1 \mathrm{H}, \mathrm{H}-\alpha \operatorname{Tyr}(\operatorname{Prg})), 4.65\left(\mathrm{~d}, J=2.3 \mathrm{~Hz}, 2 \mathrm{H},-\mathrm{OCH}_{2}-\right.$ $\operatorname{Tyr}(\operatorname{Prg})), 4.42$ (dd, $J=10.1,7.2 \mathrm{~Hz}, 1 \mathrm{H},-\mathrm{OCH}_{2}-\mathrm{CH}-\mathrm{Fmoc}$ ), $4.37-$ $4.30\left(\mathrm{~m}, 2 \mathrm{H}, \mathrm{H}-\alpha\right.$ MeAsp, -OC $\left.\underline{\mathrm{H}}_{2}-\mathrm{CH}-\mathrm{Fmoc}\right), 4.29-4.21(\mathrm{~m}, 1 \mathrm{H}$, $-\mathrm{OCH}_{2}-\mathrm{C} \underline{\mathrm{H}}-\mathrm{Fmoc}$ ), 3.36 (dd, $J=14.3,5.8 \mathrm{~Hz}, 1 \mathrm{H}, \mathrm{H}-\beta$ Tyr $(\operatorname{Prg})$ ), $3.16(\mathrm{dd}, J=14.3,6.8 \mathrm{~Hz}, 1 \mathrm{H}, \mathrm{H}-\beta \operatorname{Tyr}(\operatorname{Prg})), 3.05(\mathrm{qd}, J=7.3,3.5$ $\mathrm{Hz}, 1 \mathrm{H}, \mathrm{H}-\beta \mathrm{MeAsp}), 2.49(\mathrm{t}, J=2.2 \mathrm{~Hz}, 1 \mathrm{H},-\mathrm{C} \equiv \mathrm{CH}), 1.41(\mathrm{~s}, 9 \mathrm{H}$, $t$-Bu), 1.17 (d, $\left.J=7.2 \mathrm{~Hz}, 3 \mathrm{H}, \mathrm{CH}_{3} \mathrm{MeAsp}\right) ;{ }^{13} \mathrm{C} \mathrm{NMR}(101 \mathrm{MHz}$, $\left.\mathrm{CDCl}_{3}, 300 \mathrm{~K}\right) \delta 191.4(\mathrm{C}=\mathrm{O}), 173.6(\mathrm{C}=\mathrm{O}), 171.2(\mathrm{C}=\mathrm{O}), 170.1$ $(\mathrm{C}=\mathrm{O}), 157.1(\mathrm{C}=\mathrm{O}) 156.9$ (C Ar), 141.4 (C Ar), 134.3 (C Ar), 134.1 (C Ar), 130.7 (2C, Ar), 129.1 (2C, Ar), 128.8 (C Ar), 127.9 (2C, Ar), 127.8 (2C, Ar), 127.2 (C Ar), 127.2 (C Ar), 125.5 (C Ar), 125.4 (C Ar), 120.1 (C Ar), $115.2(2 \mathrm{C}, \mathrm{Ar}), 82.5\left(-\mathrm{C}\left(\mathrm{CH}_{3}\right)_{3}\right), 78.7$ $(-\mathrm{C} \equiv \mathrm{CH}), 75.7(-\mathrm{C} \equiv \underline{\mathrm{CH}}), 67.4\left(-\mathrm{O}^{-} \mathrm{H}_{2}-\mathrm{CH}-\mathrm{Fmoc}\right), 66.7\left(\mathrm{CH}_{2}\right.$ Pac), 57.1 (C- $\alpha$ MeAsp), $56.0\left(-\mathrm{OCH}_{2}-\mathrm{Tyr}(\operatorname{Prg})\right)$, 53.1 (C- $\alpha$ $\operatorname{Tyr}(\operatorname{Prg})), 47.3\left(\mathrm{~m}, 1 \mathrm{H},-\mathrm{OCH}_{2}-\underline{\mathrm{C}} \mathrm{H}-\mathrm{Fmoc}\right), 41.6$ (C- $\beta$ MeAsp), 36.9 (C- $\beta \operatorname{Tyr}(\operatorname{Prg}))$, $28.0\left(3 \mathrm{C},-\mathrm{C}\left(\mathrm{CH}_{3}\right)_{3}\right), 15.3\left(\mathrm{CH}_{3} \mathrm{MeAsp}\right)$; HRMS (ESI-TOF) $m / z$ : $[\mathrm{M}+\mathrm{H}]^{+}$Calcd for $\mathrm{C}_{44} \mathrm{H}_{45} \mathrm{~N}_{2} \mathrm{O}_{9} 745.31196$; Found 745.31092.

Fmoc-D-MeAsp-Ot-Bu (7). The amino acid erythro-16 (1.00 g, 1.6 $\mathrm{mmol})$ was suspended in methanol $(13 \mathrm{~mL})$ and $10 \% \mathrm{Pd} / \mathrm{C}$ catalyst (410 mg, wet, $53.7 \%$ water) was added. The reaction mixture was hydrogenated overnight at slightly positive hydrogen pressure and filtered through a Celite pad. The residue was further treated according to GP5 using Fmoc-OSu (703 mg, $2.084 \mathrm{mmol}$ ), dioxane (3 $\mathrm{mL}$ ) and $10 \% \mathrm{w} / \mathrm{v}$ aqueous $\mathrm{Na}_{2} \mathrm{CO}_{3}(2 \mathrm{~mL})$. The crude product was purified with FC (petroleum ether/EtOAc/AcOH 74:25:1) to give 7 (572 mg, 84\%) as a white amorphous solid: $R_{f}=0.5$ (petroleum ether/ EtOAc/AcOH 49:50:1); mp 55-57 ${ }^{\circ} \mathrm{C} ;[\alpha]_{\mathrm{D}}^{27}+11.8$ (c 1.0, MeCN); ${ }^{1} \mathrm{H}$ NMR $\left(400 \mathrm{MHz}, \mathrm{CDCl}_{3}, 300 \mathrm{~K}\right) \delta 7.76(\mathrm{~d}, J=7.5 \mathrm{~Hz}, 2 \mathrm{H}, \mathrm{Ar})$, $7.62(\mathrm{~d}, J=7.4 \mathrm{~Hz}, 2 \mathrm{H}, \mathrm{Ar}), 7.42-7.38(\mathrm{~m}, 2 \mathrm{H}, \mathrm{Ar}), 7.34-7.29(\mathrm{~m}$, $2 \mathrm{H}, \mathrm{Ar}), 5.75(\mathrm{~d}, J=8.9 \mathrm{~Hz}, 1 \mathrm{H}, \mathrm{NH}), 4.59(\mathrm{dd}, J=8.9,3.6 \mathrm{~Hz}, 1 \mathrm{H}$, $\mathrm{H}-\alpha$ ), $4.49-4.34$ (m, 2H, $\mathrm{CH}_{2}$ Fmoc), 4.25 (t, $J=7.1 \mathrm{~Hz}, 1 \mathrm{H}, \mathrm{CH}$ Fmoc), 3.30 (qd, J = 7.3, $3.6 \mathrm{~Hz}, 1 \mathrm{H}, \mathrm{H}-\beta) 1.46\left(\mathrm{~s}, 9 \mathrm{H},{ }^{\mathrm{t}} \mathrm{Bu}\right), 1.27(\mathrm{~d}, J$ $\left.=7.3 \mathrm{~Hz}, 3 \mathrm{H}, \mathrm{CH}_{3}\right) ;{ }^{13} \mathrm{C} \mathrm{NMR}\left(101 \mathrm{MHz}, \mathrm{CDCl}_{3}, 300 \mathrm{~K}\right) \delta 178.7$ $(\mathrm{C}=\mathrm{O}), 169.7(\mathrm{C}=\mathrm{O}), 156.7$ ( $=\mathrm{O}$ Fmoc), 144.1 (C Ar), 143.9 (C $\mathrm{Ar}), 141.5$ (2C Ar), 127.9 (2C Ar), 127.2 (2C Ar), 125.3 (2C Ar), 120.1 (C Ar), 120.1 (C Ar), $83.2\left(-\underline{C}\left(\mathrm{CH}_{3}\right)_{3}\right), 67.4\left(\mathrm{CH}_{2} \mathrm{Fmoc}\right), 56.2$ $(\mathrm{C}-\alpha), 47.3$ (CH Fmoc), $41.5(\mathrm{C}-\beta), 28.0\left(3 \mathrm{C},-\mathrm{C}\left(\underline{\mathrm{CH}}_{3}\right)_{3}\right), 13.0$ $\left(\mathrm{CH}_{3}\right)$; HRMS (ESI-TOF) $\mathrm{m} / z$ : $[2 \mathrm{M}+\mathrm{H}]^{+}$Calcd for $\mathrm{C}_{48} \mathrm{H}_{55} \mathrm{~N}_{2} \mathrm{O}_{12}$ 851.3750; Found 851.3708; Anal. Calcd for $\mathrm{C}_{24} \mathrm{H}_{27} \mathrm{NO}_{6}$ : C, 67.75; $\mathrm{H}$, 6.40; N, 3.29. Found: C 67.64; H, 6.50; N, 3.38 .

Boc-Phe- $d_{5}$-OPac $(8 b)$. Boc-Phe- $d_{5}-\mathrm{OH}(390 \mathrm{mg}, 1.44 \mathrm{mmol})$ was dissolved in EtOAc $(6 \mathrm{~mL})$ and reacted according to GP1. The product $8 \mathrm{~b}$ was obtained as a white amorphous solid (260 mg, 46\%): 
$R_{f}=0.55$ (petroleum ether/EtOAc 7:3); ${ }^{1} \mathrm{H}$ NMR (400 MHz, $\mathrm{CDCl}_{3}$, $300 \mathrm{~K}) \delta 7.91(\mathrm{~d}, J=7.7 \mathrm{~Hz}, 2 \mathrm{H}, \mathrm{Ar}), 7.62(\mathrm{t}, J=7.4 \mathrm{~Hz}, 1 \mathrm{H}, \mathrm{Ar}), 7.50$ $(\mathrm{t}, J=7.7 \mathrm{~Hz}, 2 \mathrm{H}, \mathrm{Ar}), 5.49\left(\mathrm{~d}, J=16.3 \mathrm{~Hz}, 1 \mathrm{H}, \mathrm{CH}_{2} \mathrm{Pac}\right), 5.31$ (d, $J=$ $\left.16.4 \mathrm{~Hz}, 1 \mathrm{H}, \mathrm{CH}_{2} \mathrm{Pac}\right), 4.97(\mathrm{~d}, J=7.7 \mathrm{~Hz}, 1 \mathrm{H}, \mathrm{NH}), 4.77-4.72(\mathrm{~m}$, $1 \mathrm{H}, \mathrm{H}-\alpha$ ), 3.35 (dd, $J=14.1,5.3 \mathrm{~Hz}, 1 \mathrm{H}, \mathrm{H}-\beta$ ), 3.15 (dd, $J=14.0,7.0$ $\mathrm{Hz}, 1 \mathrm{H}, \mathrm{H}-\beta), 1.40\left(\mathrm{~s}, 9 \mathrm{H},{ }^{\mathrm{t}} \mathrm{Bu}\right) ;{ }^{13} \mathrm{C}$ NMR $\left(101 \mathrm{MHz}, \mathrm{CDCl}_{3}, 300\right.$ $\mathrm{K}): \delta=191.7(\mathrm{C}=\mathrm{O}), 171.8(\mathrm{C}=\mathrm{O}), 155.3(\mathrm{C} \mathrm{Ar}), 134.2(\mathrm{C} \mathrm{Ar})$, 129.1 (2C, $\mathrm{Ar}), 127.9$ (2C, $\mathrm{Ar}), 80.1\left(-\mathrm{C}\left(\mathrm{CH}_{3}\right)_{3}\right), 66.6\left(\mathrm{CH}_{2} \mathrm{Pac}\right)$, 54.5 (C- $\alpha), 38.2(\mathrm{C}-\beta), 28.4$ (3C, - $\left.\mathrm{C}\left(\underline{\mathrm{CH}}_{3}\right)_{3}\right)$; HRMS (ESI-TOF) $\mathrm{m} /$ $z:[2 \mathrm{M}+\mathrm{H}]^{+}$Calcd for $\mathrm{C}_{44} \mathrm{H}_{41} \mathrm{D}_{10} \mathrm{~N}_{2} \mathrm{O}_{10}$ 777.4166; Found 777.4151.

Boc-Tyr(Prg)-OPac (8c). The carboxylic acid 18 (350 mg, 1.10 $\mathrm{mmol}$ ) was dissolved in EtOAc $(5.5 \mathrm{~mL})$ and reacted according to GP1. The product $8 \mathrm{c}$ was obtained as a white amorphous solid (421 $\mathrm{mg}, 90 \%): R_{f}=0.55$ (petroleum ether/EtOAc 7:3); mp 94-95 ${ }^{\circ} \mathrm{C}$; $[\alpha]_{\mathrm{D}}{ }^{25}-21.2(c 0.5, \mathrm{MeCN}) ;{ }^{1} \mathrm{H}$ NMR $\left(400 \mathrm{MHz}, \mathrm{CDCl}_{3}, 300 \mathrm{~K}\right) \delta$ 7.95-7.88 (m, 2H, Ar), 7.65-7.60 (m, 1H, Ar), $7.50(\mathrm{t}, J=7.7 \mathrm{~Hz}$, $2 \mathrm{H}, \mathrm{Ar}$ ), 7.19 (d, $J=8.5 \mathrm{~Hz}, 2 \mathrm{H}, \mathrm{Ar}), 6.94-6.90$ (m, $2 \mathrm{H} \mathrm{Ar}$ ), 5.50 (d, $J$ $\left.=16.4 \mathrm{~Hz}, 1 \mathrm{H}, \mathrm{CH}_{2} \mathrm{Pac}\right), 5.30\left(\mathrm{~d}, J=16.3 \mathrm{~Hz}, 1 \mathrm{H}, \mathrm{CH}_{2} \mathrm{Pac}\right), 4.95(\mathrm{~d}$, $J=7.9 \mathrm{~Hz}, 1 \mathrm{H}, \mathrm{NH}), 4.74-4.69(\mathrm{~m}, 1 \mathrm{H}, \mathrm{H}-\alpha), 4.67(\mathrm{~d}, J=2.4 \mathrm{~Hz}$, $\left.2 \mathrm{H},-\mathrm{OCH}_{2}-\mathrm{Tyr}(\mathrm{Prg})\right), 3.29(\mathrm{dd}, J=14.2,5.4 \mathrm{~Hz}, 1 \mathrm{H}, \mathrm{H}-\beta), 3.11$ $(\mathrm{dd}, J=14.0,6.7 \mathrm{~Hz}, 1 \mathrm{H}, \mathrm{H}-\beta), 2.51(\mathrm{t}, J=2.4 \mathrm{~Hz}, 1 \mathrm{H},-\mathrm{C} \equiv \mathrm{CH})$, $1.41\left(\mathrm{~s}, 9 \mathrm{H},{ }^{\mathrm{t}} \mathrm{Bu}\right) ;{ }^{13} \mathrm{C} \mathrm{NMR}\left(101 \mathrm{MHz}, \mathrm{CDCl}_{3}, 300 \mathrm{~K}\right) \delta 191.7(\mathrm{C}=$ O), $171.8(\mathrm{C}=\mathrm{O}), 156.8\left(-\mathrm{C}-\mathrm{O}-\mathrm{CH}_{2}-\right), 155.3(\mathrm{C}=\mathrm{O}), 134.2(\mathrm{C}$ $\mathrm{Ar}), 130.7$ (2C, Ar), 129.2 (C Ar), 129.1 (2C, Ar), 127.9 (2C, Ar), $115.1(\mathrm{C} \mathrm{Ar}), 80.1\left(-\mathrm{C}\left(\mathrm{CH}_{3}\right)_{3}\right), 78.8(-\mathrm{C} \equiv \mathrm{CH}), 75.6(-\mathrm{C} \equiv \underline{\mathrm{CH}}), 66.5$ $\left(\mathrm{CH}_{2} \mathrm{Pac}\right), 56.0\left(-\mathrm{OCH}_{2}-\mathrm{Tyr}(\mathrm{Prg})\right), 54.5(\mathrm{C}-\alpha), 37.5(\mathrm{C}-\beta), 28.4$ $\left(3 \mathrm{C},-\mathrm{C}\left(\mathrm{C}_{3}\right)_{3}\right)$; HRMS (ESI-TOF) $m / z:[\mathrm{M}+\mathrm{H}]^{+}$Calcd for $\mathrm{C}_{25} \mathrm{H}_{28} \mathrm{NO}_{6}$ : 438.19111; Found 438.19216; Anal. Calcd for $\mathrm{C}_{25} \mathrm{H}_{27} \mathrm{NO}_{6}$ : C, 68.64; H, 6.22; N, 3.20. Found: C, 68.56; H, 6.11; $\mathrm{N}, 3.32$.

Boc-N-MeSecPh-D-Ala-Leu-OPac (12). ${ }^{18}$ Boc-Leu-OPac ${ }^{17}$ (500 mg, $1.43 \mathrm{mmol}$ ) was deprotected according to GP4. Then H-Leu-OPac, Boc-D-Ala-OH (325 mg, $1.72 \mathrm{mmol}$ ) and HOBt $(232 \mathrm{mg}, 1.72 \mathrm{mmol})$ were dissolved in $\mathrm{CH}_{2} \mathrm{Cl}_{2}(5 \mathrm{~mL})$ and coupled according to GP6 using HBTU (651 mg, $1.72 \mathrm{mmol})$ and DIPEA (980 $\mu \mathrm{L}, 5.72 \mathrm{mmol})$. The crude product was purified by FC to give Boc-D-Ala-Leu-OPac ${ }^{18}$ (500 $\mathrm{mg}, 83 \%$ ) as a white solid: $R_{f}=0.66$ (PE/EtOAc 1:1); The analytical data for Boc-D-Ala-Leu-OPac were in agreement with the published ones. ${ }^{18}$ The dipeptide Boc-D-Ala-Leu-OPac $(502 \mathrm{mg}, 1.195 \mathrm{mmol})$ was deprotected according to GP4 to give H-D-Ala-Leu-OPac 11 that was immediately used in the next step. Crude deprotected dipeptide 11 (1.195 mmol) and Boc-NMeSecPh-OH 6 (471 mg, $1.314 \mathrm{mmol})$ were dissolved in DMF ( $5 \mathrm{~mL}$ ) and coupled according to GP6 using HATU (500 mg, $1.314 \mathrm{mmol}$ ) and DIPEA (832 $\mu \mathrm{L}, 4.778 \mathrm{mmol})$. The crude product was purified by FC (petroleum ether/EtOAc 1:1) to give title compound $12(683 \mathrm{mg}, 90 \%)$ as a white amorphous solid. The analytical data for 12 were in agreement with the published ones. ${ }^{18}{ }^{1} \mathrm{H}$ NMR $\left(400 \mathrm{MHz}, \mathrm{CDCl}_{3}\right) \delta 7.92-7.81(\mathrm{dd}, J=8.5,1.3 \mathrm{~Hz}$, $2 \mathrm{H}, \mathrm{Ar}), 7.62(\mathrm{dt}, J=7.5,1.3 \mathrm{~Hz}, 1 \mathrm{H}, \mathrm{Ar}), 7.54-7.45(\mathrm{~m}, 4 \mathrm{H}, \mathrm{Ar})$, 7.27-7.23 (m, 3H, Ar), 6.79 (b, 1H, NH Leu), 6.53 (b, 1H, NH Ala), $5.47\left(\mathrm{~d}, J=16.3 \mathrm{~Hz}, 1 \mathrm{H}, \mathrm{CH}_{2} \mathrm{Pac}\right), 5.22\left(\mathrm{~d}, J=16.3 \mathrm{~Hz}, 1 \mathrm{H}, \mathrm{CH}_{2}\right.$ Pac), 4.69 (b, 1H, H- $\alpha$ Leu), 4.50 (b, 2H, H- $\alpha$ Ala, H- $\alpha$ NMeSecPh), 3.60 (dd, $J=13.0,5.9 \mathrm{~Hz}, 1 \mathrm{H}, \mathrm{H}-\beta \mathrm{NMeSecPh}$ ), 3.16 (b, $1 \mathrm{H}, \mathrm{H}-\beta$ $\mathrm{NMeSecPh}$ ), 2.80 (s, 3H, -NMe), 1.90-1.66 (m, 3H, $2 x \mathrm{xH}-\beta$ Leu, H- $\gamma$ Leu), $1.45\left(\mathrm{~s}, 9 \mathrm{H},{ }^{\mathrm{t}} \mathrm{Bu}\right), 1.38(\mathrm{~d}, J=6.9 \mathrm{~Hz}, 1 \mathrm{H}, \mathrm{Ala}), 0.99(\mathrm{~d}, J=6.3$, $\left.\mathrm{Hz}, 3 \mathrm{H}, \mathrm{CH}_{3} \mathrm{Leu}\right), 0.97$ (d, $J=6.3 \mathrm{~Hz}, 3 \mathrm{H}, \mathrm{CH}_{3} \mathrm{Leu}$ ).

$B n-D-A s p(O B n)-O H$ (14). Starting from Bn-D-Asp-OH (8.61 g, 38.6 $\mathrm{mmol})$, compound $14(10.16 \mathrm{~g}, 84 \%)$ was prepared according to a procedure published for the synthesis of Bn-L-Asp $(\mathrm{OBn})-\mathrm{OH}^{25}$ The analytical data of $\mathbf{1 4}$ were in agreement with the data published for its enantiomer. ${ }^{25}{ }^{1} \mathrm{H}$ NMR (400 MHz, DMSO- $d_{6}, 300 \mathrm{~K}$ ) $\delta 7.43-7.18$ (m, 10H, Ar), $5.10\left(\mathrm{~s}, 2 \mathrm{H}, 1 \mathrm{H},-\mathrm{COOCH}_{2}-\right), 3.92(\mathrm{~d}, J=13.4 \mathrm{~Hz}$, $\left.1 \mathrm{H}, \mathrm{N}-\mathrm{CH}_{2}-\right), 3.80\left(\mathrm{~d}, J=13.4 \mathrm{~Hz}, 1 \mathrm{H}, \mathrm{N}-\mathrm{CH}_{2}-\right), 3.55(\mathrm{t}, J=6.6$ $\mathrm{Hz}, 1 \mathrm{H}, \mathrm{H}-\alpha$ ), 2.80 (dd, $J=16.0,6.2 \mathrm{~Hz}, 1 \mathrm{H}, \mathrm{H}-\beta), 2.70$ (dd, $J=16.0$, $7.1 \mathrm{~Hz}, 1 \mathrm{H}, \mathrm{H}-\beta) ;{ }^{13} \mathrm{C}$ NMR (101 MHz, DMSO- $\left.d_{6}, 300 \mathrm{~K}\right) \delta 170.9$ $(\mathrm{C}=\mathrm{O}), 170.1(\mathrm{C}=\mathrm{O}), 150.0$ (C Ar), 136.8 (C Ar), 136.2 (C Ar), 129.9 (C Ar), 129.0 (C Ar), 128.9 (2C, Ar), 128.6 (C Ar), 128.4 (2C, $\mathrm{Ar}), 128.0$ (C Ar), 124.4 (C Ar), $66.5\left(-\mathrm{COOCH}_{2}-\right), 56.1$ (C- $\left.\alpha\right), 50.4$ $\left(\mathrm{N}-\mathrm{CH}_{2}-\right), 35.4(\mathrm{C}-\beta)$.
Bn-D-Asp(OBn)-Ot-Bu. Bn-D-Asp(OBn)-OH 14 (4.0 g, 12.8 $\mathrm{mmol})$ was suspended in $t$-BuOAc $(72 \mathrm{~mL})$ and $70 \%$ aqueous perchloric acid $(1.840 \mathrm{~mL}, 15.2 \mathrm{mmol})$ was added dropwise. After stirring for $18 \mathrm{~h}$ at $\mathrm{rt}$, water $(40 \mathrm{~mL})$ was added and the phases were separated. The aqueous phase was extracted with EtOAc $(1 \times 30 \mathrm{~mL})$. The organic phases were combined and washed with saturated $\mathrm{NaHCO}_{3}$ solution $(3 \times)$. During the workup, formation of a white precipitate could be observed. The organic phase was filtered, washed with brine and dried with $\mathrm{Na}_{2} \mathrm{SO}_{4}$. The volatiles were removed and $\mathrm{Bn}-\mathrm{D}-\mathrm{Asp}(\mathrm{OBn})-\mathrm{Ot}$-Bu was obtained as a pale yellow oil (3.168 g, $67 \%)$. The analytical data for $\mathrm{Bn}-\mathrm{D}-\mathrm{Asp}(\mathrm{OBn})-\mathrm{O} t-\mathrm{Bu}$ were in agreement with the data published for its enantiomer. ${ }^{25}[\alpha]_{\mathrm{D}}{ }^{26}+$ 17.5 (c 1.0, MeCN); ${ }^{1} \mathrm{H}$ NMR (400 MHz, $\left.\mathrm{CDCl}_{3}, 300 \mathrm{~K}\right) \delta 7.38-7.21$ $(\mathrm{m}, 10 \mathrm{H}, \mathrm{Ar}), 5.15\left(\mathrm{~d}, J=12.3 \mathrm{~Hz}, 1 \mathrm{H},-\mathrm{COOCH}_{2}-\right) 5.11(\mathrm{~d}, J=$ $\left.12.3 \mathrm{~Hz}, 1 \mathrm{H},-\mathrm{COOCH}_{2}-\right), 3.87\left(\mathrm{~d}, J=12.9 \mathrm{~Hz}, 1 \mathrm{H}, \mathrm{N}-\mathrm{CH}_{2}-\right)$, $3.71\left(\mathrm{~d}, J=12.9 \mathrm{~Hz}, 1 \mathrm{H}, \mathrm{N}-\mathrm{CH}_{2}-\right), 3.59(\mathrm{dd}, J=7.1,5.9 \mathrm{~Hz}, 1 \mathrm{H}, \mathrm{H}-$ $\alpha), 2.75(\mathrm{dd}, J=15.6,5.9 \mathrm{~Hz}, 1 \mathrm{H}, \mathrm{H}-\beta), 2.67(\mathrm{dd}, J=15.6,7.2 \mathrm{~Hz}, 1 \mathrm{H}$, $\mathrm{H}-\beta), 1.45(\mathrm{~s}, 9 \mathrm{H}, t-\mathrm{Bu}) ;{ }^{13} \mathrm{C} \mathrm{NMR}\left(101 \mathrm{MHz}, \mathrm{CDCl}_{3}, 300 \mathrm{~K}\right) \delta 172.8$ $(\mathrm{C}=\mathrm{O}), 171.0(\mathrm{C}=\mathrm{O}), 139.9(\mathrm{C} \mathrm{Ar}), 135.9(\mathrm{C} \mathrm{Ar}), 128.7$ (C Ar), 128.5 (2C Ar), 128.4 (2C Ar), 128.4 (C Ar), 128.4 (C Ar), 127.2 (C $\mathrm{Ar}), 81.8\left(-\underline{\mathrm{C}}\left(\mathrm{CH}_{3}\right)_{3}\right), 66.6\left(-\mathrm{COOCH}_{2}-\right), 58.0(\mathrm{C}-\alpha), 52.2(\mathrm{~N}-$ $\left.\mathrm{CH}_{2}-\right)$, $38.6(\mathrm{C}-\beta), 28.2\left(3 \mathrm{C},-\mathrm{C}\left(\mathrm{CH}_{3}\right)_{3}\right)$.

(2R)-4-Benzyl-1-tert-butyl-N-benzyl-N-(9-phenylfluoren-9-yl)-aspartate (15). To the solution of Bn-D-Asp(OBn)-Ot-Bu (1.587 g, $4.274 \mathrm{mmol})$ in dry acetonitrile $(47 \mathrm{~mL})$ anhydrous $\mathrm{K}_{3} \mathrm{PO}_{4}(1.088 \mathrm{~g}$, $5.192 \mathrm{mmol}$ ) and phenylfluorenyl bromide ( $1.324 \mathrm{~g}, 4.122$ equiv) were added. The resulting heterogenic mixture was mechanically stirred for $24 \mathrm{~h}$ at rt, filtered, and the solvent was removed. The crude product was purified by FC to give $15(1.870 \mathrm{~g}, 72 \%)$ as a white solid. The analytical data for $\mathbf{1 5}$ were in agreement with the data published for its enantiomer. ${ }^{25} R_{f}=0.25$ (petroleum ether/EtOAc 15:1); $[\alpha]_{\mathrm{D}}{ }^{29}-25.0$ $(c 1.0, \mathrm{MeCN}) ;{ }^{1} \mathrm{H}$ NMR (400 MHz, $\left.\mathrm{CDCl}_{3}, 300 \mathrm{~K}\right) \delta 7.82(\mathrm{~d}, J=7.1$ $\mathrm{Hz}, 2 \mathrm{H}, \mathrm{Ar}$ ), 7.74 (d, J = 7.5 Hz, 1H, Ar), 7.66 (d, $J=7.4 \mathrm{~Hz}, 1 \mathrm{H}, \mathrm{Ar}$ ), $7.60(\mathrm{~d}, J=7.5 \mathrm{~Hz}, 1 \mathrm{H}, \mathrm{Ar}), 7.56(\mathrm{~d}, J=7.5 \mathrm{~Hz}, 1 \mathrm{H}, \mathrm{Ar}), 7.47$ (d, $J=$ $7.0 \mathrm{~Hz}, 2 \mathrm{H}, \mathrm{Ar}), 7.37(\mathrm{td}, J=7.5,1.0 \mathrm{~Hz}, 1 \mathrm{H}, \mathrm{Ar}), 7.34-7.16(\mathrm{~m}, 11 \mathrm{H}$, Ar), $7.11-7.05$ (m, 2H, Ar), 4.87 (d, $\left.J=12.5 \mathrm{~Hz}, 1 \mathrm{H},-\mathrm{COOCH}_{2}-\right)$, $4.80\left(\mathrm{~d}, J=12.5 \mathrm{~Hz}, 1 \mathrm{H},-\mathrm{COOCH}_{2}-\right), 4.22(\mathrm{~d}, J=13.8 \mathrm{~Hz}, 1 \mathrm{H}, \mathrm{N}-$ $\mathrm{CH}_{2}-$ ), 3.93 (dd, $\left.J=10.9,2.6 \mathrm{~Hz}, 1 \mathrm{H}, \mathrm{H}-\alpha\right), 3.85$ (d, $J=13.9 \mathrm{~Hz}, 1 \mathrm{H}$, $\mathrm{N}-\mathrm{CH}_{2}-$ ), $2.61(\mathrm{dd}, J=15.8,10.9 \mathrm{~Hz}, 1 \mathrm{H}, \mathrm{H}-\beta), 1.98(\mathrm{dd}, J=15.9$, $2.7 \mathrm{~Hz}, 1 \mathrm{H}, \mathrm{H}-\beta), 1.08(\mathrm{~s}, 9 \mathrm{H}, \mathrm{t}-\mathrm{Bu}) ;{ }^{13} \mathrm{C} \mathrm{NMR}\left(101 \mathrm{MHz}, \mathrm{CDCl}_{3}\right.$, $300 \mathrm{~K}) \delta 171.3(\mathrm{C}=\mathrm{O}), 171.2(\mathrm{C}=\mathrm{O}), 147.7(\mathrm{C} \mathrm{Ar}), 146.4(\mathrm{C} \mathrm{Ar})$, 143.8 (C Ar), 141.0 (C Ar), 140.3 (C Ar), 139.0 (C Ar), 136.0 (C Ar), 129.7 (2C Ar), 128.7 (2C Ar), 128.5 (2C Ar), 128.5 (2C Ar), 128.2 (2C Ar), 128.1 (C Ar), 128.0 (2C Ar), 127.7 (C Ar), 127.7 (C Ar), 127.4 (2C Ar), 127.3 (C Ar), 127.1 (C Ar), 126.7 (C Ar), 120.6 (C $\mathrm{Ar}), 120.0$ (2C Ar), $80.8\left(-\underline{\mathrm{C}}\left(\mathrm{CH}_{3}\right)_{3}\right), 79.7$ (ㅌ-Ph), $66.0\left(-\mathrm{COOCH}_{2}-\right.$ ), $57.6(\mathrm{C}-\alpha), 51.8\left(\mathrm{~N}-\mathrm{CH}_{2}-\right), 34.4(\mathrm{C}-\beta), 27.8\left(3 \mathrm{C},-\mathrm{C}\left(\underline{\mathrm{CH}}_{3}\right)_{3}\right)$; Anal. Calcd for $\mathrm{C}_{41} \mathrm{H}_{39} \mathrm{NO}_{4}$ : C, 80.76; H, 6.45; N, 2.30. Found: C, 80.58; H, 6.53; N, 2.46.

(2R,3S)-4-Benzyl-1-tert-butyl-N-benzyl-N-(9-phenylfluoren-9-y1)3-methylaspartate (eryhtro-16). A solution of LHMDS in THF (1.0 M, $8.25 \mathrm{~mL}, 8.25 \mathrm{mmol}$ ) was placed in a Schlenk flask under nitrogen atmosphere and cooled to $<-20{ }^{\circ} \mathrm{C}$. First a solution of aspartic acid derivative $15(2.0 \mathrm{~g}, 3.28 \mathrm{mmol}$ in dry THF $(15 \mathrm{~mL})$ and then a solution of methyl iodide $(707 \mu \mathrm{L}, 11.35 \mathrm{mmol})$ in dry THF $(11 \mathrm{~mL})$ was added slowly. The mixture was stirred for $3 \mathrm{~h}$ at $<-20^{\circ} \mathrm{C}$ and 30 $\mathrm{min}$ at room temperature and quenched with sat. aqueous $\mathrm{NH}_{4} \mathrm{Cl}(10$ $\mathrm{mL})$ and water $(10 \mathrm{~mL})$. The phases were separated and the aqueous phase was extracted with EtOAc $(100 \mathrm{~mL})$. The combined organic phases were washed with brine $(1 \times)$, dried over $\mathrm{Na}_{2} \mathrm{SO}_{4}$, filtered, and the solvents were removed. The crude product was purified by $\mathrm{FC}$ to give eryhtro-16 $(1.17 \mathrm{~g}, 57 \%)$ as a white solid: $R_{\mathrm{f}}=0.4$ (petroleum ether/EtOAc 15:1) mp $115.5^{\circ} \mathrm{C} ;[\alpha]_{\mathrm{D}}{ }^{26}+250.0(c 1.0, \mathrm{MeCN}) ;{ }^{1} \mathrm{H}$ NMR $\left(400 \mathrm{MHz}, \mathrm{CDCl}_{3}, 300 \mathrm{~K}\right) \delta 7.83(\mathrm{~d}, J=7.4 \mathrm{~Hz}, 1 \mathrm{H}, \mathrm{Ar}), 7.73$ (d, $J=7.4 \mathrm{~Hz}, 1 \mathrm{H}, \mathrm{Ar}), 7.62(\mathrm{~d}, J=6.9 \mathrm{~Hz}, 3 \mathrm{H}, \mathrm{Ar}), 7.56$ (d, $J=7.7$ $\mathrm{Hz}, 1 \mathrm{H}, \mathrm{Ar}), 7.47$ (d, $J=7.0 \mathrm{~Hz}, 2 \mathrm{H}, \mathrm{Ar}), 7.44-7.08(\mathrm{~m}, 15 \mathrm{H}, \mathrm{Ar})$, $5.14\left(\mathrm{~d}, J=12.4 \mathrm{~Hz}, 1 \mathrm{H},-\mathrm{COOCH}_{2}-\right), 5.02(\mathrm{~d}, J=12.4 \mathrm{~Hz}, 1 \mathrm{H}$, $-\mathrm{COOCH}_{2}-$ ), $4.67\left(\mathrm{~d}, J=14.3 \mathrm{~Hz}, 1 \mathrm{H}, \mathrm{CH}_{2} \mathrm{~N}-\mathrm{Bn}\right), 4.26(\mathrm{~d}, J=14.3$ $\left.\mathrm{Hz}, 1 \mathrm{H}, \mathrm{CH}_{2} \mathrm{~N}-\mathrm{Bn}\right), 3.97(\mathrm{~d}, J=9.9 \mathrm{~Hz}, 1 \mathrm{H}, \mathrm{H}-\alpha), 2.75$ (dq, $J=9.9$, $7.0 \mathrm{~Hz}, 1 \mathrm{H}, \mathrm{H}-\beta), 1.06$ (s, 9H, $t-\mathrm{Bu}), 0.79\left(\mathrm{~d}, J=7.1 \mathrm{~Hz}, 3 \mathrm{H}, \mathrm{CH}_{3}\right)$; 
${ }^{13} \mathrm{C}$ NMR (101 MHz, $\left.\mathrm{CDCl}_{3}, 300 \mathrm{~K}\right) \delta 174.2$ (-COOBn), 170.3 (-COOt-Bu), 147.1 (C Ar), 146.0 (C Ar), 145.3 (C Ar), 142.2 (C Ar), 142.0 (2C, Ar), 139.6 (C Ar), 136.2 (C Ar), 129.2 (2C, Ar), 128.7 (C Ar), 128.6 (2C, Ar), 128.4 (2C, Ar), 128.3 (C Ar), 128.3 (C Ar), 128.2 (2C, Ar), 128.2 (2C, Ar), 128.0 (2C, Ar), 127.7 (C Ar), 127.6 (C Ar), 127.5 (2C, Ar), 127.4 (C Ar), 127.0 (C Ar), 126.7 (C Ar), 80.9 $\left(-\underline{\mathrm{C}}\left(\mathrm{CH}_{3}\right)_{3}\right), 80.5(\underline{\mathrm{C}}-\mathrm{Ph}), 66.1\left(\mathrm{CH}_{2} \mathrm{Bn}\right), 64.0(\mathrm{C}-\alpha), 51.7\left(\mathrm{CH}_{2} \mathrm{Bn}\right)$, $42.5(\mathrm{C}-\beta), 27.8\left(3 \mathrm{C},-\mathrm{C}\left(\mathrm{CH}_{3}\right)_{3}\right), 15.4\left(\mathrm{CH}_{3}\right)$; Anal. Calcd for $\mathrm{C}_{42} \mathrm{H}_{41} \mathrm{NO}_{4}$ : C, 80.87; H, 6.63; N, 2.25. Found: C, 80.84; H, 6.67; N, 2.42 .

H- $\boldsymbol{\beta}$-D-MeAsp-OH, ((3S)- $\boldsymbol{\beta}$-D-methylaspartic Acid). The amino acid erythro-16 (200 mg, $1.6 \mathrm{mmol})$ was suspended in methanol $(2.84$ $\mathrm{mL}$ ) and $10 \% \mathrm{Pd} / \mathrm{C}$ catalyst $(82 \mathrm{mg}$, wet, $53.7 \%$ water) was added. The reaction mixture was hydrogenated overnight at a slightly positive hydrogen pressure and filtered through a syringe filter. The filtrate was diluted $1: 1$ with aqueous $\mathrm{HCl}(0.1 \mathrm{M})$ and filtered twice through a syringe filter. The volatiles were removed and the residue was coevapotated with EtOAc $(1 \times)$ and toluene $(2 \times)$. The resulting solid was treated with TFA $(0.7 \mathrm{~mL})$ according to GP4. The crude product was purified by HPLC ( $1 \% \mathrm{~B}$ isocratic over $\left.10 \mathrm{~min}, t_{\mathrm{R}}=4.0 \mathrm{~min}\right)$ to give the formic acid salt of $\mathrm{H}-\beta$-D-MeAsp- $\mathrm{OH}^{20}$ as a white amorphous solid (40 mg, 85\%). The optical rotation $\left([\alpha]^{\mathrm{D}}{ }_{23.5}-35.91(c 1.07,5 \mathrm{M}\right.$ $\mathrm{HCl})$ ) was in agreement with published values for $\mathrm{H}-\beta$-D-MeAsp-OH $\left([\alpha]^{\mathrm{D}}{ }_{22}-31.0(c \text { 2.00, } 5 \mathrm{M} \mathrm{HCl})\right)^{20}$ and enantiomeric $(3 R)-\beta$-Lmethylaspartic acid $\left([\alpha]^{\mathrm{D}}{ }_{21}+34.3(c 2.05,5 \mathrm{M} \mathrm{HCl})\right) .{ }^{26}$ A coupling constant ${ }^{3} \mathrm{~J}_{\mathrm{C} \alpha \mathrm{H}-\mathrm{C} \beta \mathrm{H}}$ of $9.0 \mathrm{~Hz}$ determined by ${ }^{1} \mathrm{H}$ NMR $(400 \mathrm{MHz}$, $\mathrm{D} 2 \mathrm{O}, 300 \mathrm{~K}, \mathrm{pD}>14$ ) additionally verifies the erythro configuration of $\mathrm{H}-\beta$-D-MeAsp-OH. ${ }^{22}{ }^{1} \mathrm{H}$ NMR $\left(400 \mathrm{MHz}, \mathrm{D}_{2} \mathrm{O}, 300 \mathrm{~K}, \mathrm{pD}>14\right) \delta$ $2.58(\mathrm{~d}, J=9.0 \mathrm{~Hz}, 1 \mathrm{H}, \mathrm{H}-\alpha), 1.75(\mathrm{dq}, J=8.9,7.2 \mathrm{~Hz}, 1 \mathrm{H}, \mathrm{H}-\beta), 0.44$ $\left(\mathrm{d}, J=7.1 \mathrm{~Hz}, 3 \mathrm{H},-\mathrm{CH}_{3}\right)$.

$\mathrm{N}$-(tert-Butoxycarbonyl)-O-prop-2-yn-1-yl-L-tyrosine (Boc-Tyr(Prg)-OH) (18). ${ }^{27}$ 2-tert-Butoxycarbonylamino-3-[4-(prop-2-ynyloxy)phenyl]-propionic acid propargyl ester ${ }^{28}(3.633 \mathrm{~g}, 10.17 \mathrm{mmol})$ was dissolved in $1 \mathrm{M} \mathrm{KOH}$ solution in methanol $(20.34 \mathrm{~mL}, 20.34 \mathrm{mmol})$ and sonicated for $2 \mathrm{~h}$ at $35{ }^{\circ} \mathrm{C}$. The methanol was removed under reduced pressure. The residue was dissolved in $\mathrm{H}_{2} \mathrm{O}(30 \mathrm{~mL})$ and the aqueous phase was washed with $\mathrm{Et}_{2} \mathrm{O}(2 \times 30 \mathrm{~mL})$. The aqueous phase was acidified with $\mathrm{KHSO}_{4}(1 \mathrm{M})$ to $\mathrm{pH}=2$ and extracted with EtOAc $(2 \times 30 \mathrm{~mL})$. The EtOAc extracts were combined, washed with brine, dried over $\mathrm{MgSO}_{4}$, and the volatiles were removed under reduced pressure. Product $\mathbf{1 8}$ was obtained as a white amorphous solid $(3.1 \mathrm{~g}, 95 \%)$ and used without further purification. The analytical data for 18 were in agreement with the published ones. ${ }^{27}{ }^{1} \mathrm{H}$ NMR (400 $\left.\mathrm{MHz}, \mathrm{CDCl}_{3}\right) \delta 7.12(\mathrm{~d}, J=8.5 \mathrm{~Hz}, 2 \mathrm{H}, \mathrm{Ar}), 6.92(\mathrm{~d}, J=8.6 \mathrm{~Hz}, 2 \mathrm{H}$, Ar), $4.92(\mathrm{~d}, J=7.0 \mathrm{~Hz}, 1 \mathrm{H}, \mathrm{NH}), 4.92\left(\mathrm{~d}, J=2.4 \mathrm{~Hz}, 2 \mathrm{H},-\mathrm{OCH}_{2}\right)$, $4.56(\mathrm{~b}, 1 \mathrm{H}, \mathrm{H}-\alpha), 3.14$ (dd, $J=13.9,5.2 \mathrm{~Hz}, 1 \mathrm{H}, \mathrm{H}-\beta), 3.04$ (dd, $J=$ 13.8, $5.5 \mathrm{~Hz}, 1 \mathrm{H}, \mathrm{H}-\beta), 2.51(\mathrm{t}, J=2.3 \mathrm{~Hz}, 1 \mathrm{H},-\mathrm{C} \equiv \mathrm{CH}), 1.42(\mathrm{~s}, 9 \mathrm{H}$, $t-\mathrm{Bu})$.

Fmoc- $\gamma$-D-Glu(Ot-Bu)-N-MeSecPh-D-Ala-Leu- $\beta$-D-MeAsp(Ot-Bu)Phe-OH (21a). Tetrapeptide $4(61 \mathrm{mg}, 63 \mu \mathrm{mol})$ and dipeptide $5 \mathrm{a}(50$ $\mathrm{mg}, 72 \mu \mathrm{mol})$ were deprotected according to GP2 and GP3, respectively. The products 19 and 20a were dissolved in DMF (1 $\mathrm{mL})$ and coupled according to GP6 using HATU ( $28 \mathrm{mg}, 74 \mu \mathrm{mol})$ and collidine $(25 \mu \mathrm{L}, 188 \mu \mathrm{mol})$. The crude product was purified by FC $\left(\mathrm{CH}_{2} \mathrm{Cl}_{2} / \mathrm{i}\right.$-PrOH $99: 1$ to $\left.95: 5\right)$ to give 21a $(49 \mathrm{mg}, 60 \%)$ as a white amorphous solid: $R_{f}=0.65\left(\mathrm{CH}_{2} \mathrm{Cl}_{2} / \mathrm{i}-\mathrm{PrOH} 95: 5\right) ;{ }^{1} \mathrm{H}$ NMR $\left(600 \mathrm{MHz}, \mathrm{DMSO}-d_{6}, 360 \mathrm{~K}\right) \delta 8.22(\mathrm{~d}, J=8.0 \mathrm{~Hz}, 1 \mathrm{H}, \mathrm{NH}), 7.94(\mathrm{~d}$, $J=7.3 \mathrm{~Hz}, 2 \mathrm{H}, \mathrm{Ar}), 7.86(\mathrm{~d}, J=7.5 \mathrm{~Hz}, 2 \mathrm{H}, \mathrm{Ar}), 7.69-7.66(\mathrm{~m}, 4 \mathrm{H}, 3 \mathrm{x}$ $\mathrm{H}-\mathrm{Ar}, \mathrm{NH}), 7.61(\mathrm{~s}, 1 \mathrm{H}, \mathrm{NH}), 7.60-7.52(\mathrm{~m}, 3 \mathrm{H}, 2 \mathrm{x} \mathrm{H}-\mathrm{Ar}, \mathrm{NH})$, $7.49(\mathrm{~d}, J=6.9 \mathrm{~Hz}, 2 \mathrm{H}, \mathrm{Ar}), 7.40(\mathrm{t}, J=7.4 \mathrm{~Hz}, 2 \mathrm{H}, \mathrm{Ar}), 7.31(\mathrm{t}, J=$ $7.4 \mathrm{~Hz}, 2 \mathrm{H}, \mathrm{Ar}$ ), 7.29-7.22 (m, 7H, Ar), 7.21-7.17 (m, 1H, Ar), 5.45 $\left(\mathrm{d}, J=16.4 \mathrm{~Hz}, 1 \mathrm{H}, \mathrm{CH}_{2} \mathrm{Pac}\right), 5.42\left(\mathrm{~d}, J=16.4 \mathrm{~Hz}, 1 \mathrm{H}, \mathrm{CH}_{2} \mathrm{Pac}\right)$, 5.08-5.00 (b, $1 \mathrm{H}, \mathrm{H}-\alpha \mathrm{NMeSecPh}), 4.72$ (td, $J=8.8,5.0 \mathrm{~Hz}, 1 \mathrm{H}, \mathrm{H}-\alpha$ Phe), 4.36-4.26 (m, 4H, H- $\alpha$ MeAsp, H- $\alpha$ Ala, $-\mathrm{OCH}_{2}-\mathrm{CH}-\mathrm{Fmoc}$ ), 4.25-4.19 (m, 2H, H- $\alpha$ Leu, $\left.-\mathrm{OCH}_{2}-\mathrm{CH}-\mathrm{Fmoc}\right), 4.03-3.98(\mathrm{~m}, 1 \mathrm{H}$, $\mathrm{H}-\alpha \mathrm{Glu}$ ), $3.52-3.45(\mathrm{~m}, 1 \mathrm{H}, \mathrm{H}-\beta$ Phe), 3.25 (dd, $J=14.1,5.0 \mathrm{~Hz}$, $1 \mathrm{H}, \mathrm{H}-\beta$ Phe), 3.17-3.11 (m, $1 \mathrm{H}, \mathrm{H}-\beta$ NMeSecPh), 2.99 (dd, $J=14.2$, $9.4 \mathrm{~Hz}, 1 \mathrm{H}, \mathrm{H}-\beta$ Phe), $2.96-2.93$ (m, 1H, H- $\beta$ MeAsp), 2.87 (bs, 3H, $\left.-\mathrm{NCH}_{3}\right), 2.42-2.34(\mathrm{~m}, 2 \mathrm{H}, 2 \mathrm{x} \mathrm{H}-\gamma \mathrm{Glu}), 2.06-1.99(\mathrm{~m}, 1 \mathrm{H}, \mathrm{H}-\beta$ Glu), $1.93-1.83$ (m, 1H, H- $\beta$ Glu), $1.63-1.55$ (m, H- $\gamma$ Leu), $1.53-$
1.48 (m, 2H, 2x H- $\beta$ Leu), 1.41 (s, 9H, $t-B u$ ), 1.34 (s, 9H, $t$-Bu), 1.22 (d, $\left.J=6.8 \mathrm{~Hz}, 3 \mathrm{H}, \mathrm{CH}_{3} \mathrm{Ala}\right), 0.88$ (d, $\left.J=7.1 \mathrm{~Hz}, 3 \mathrm{H}, \mathrm{CH}_{3} \mathrm{MeAsp}\right)$, 0.85 (d, $J=6.6 \mathrm{~Hz}, 3 \mathrm{H}, 3 \mathrm{xH}-\delta \mathrm{Leu}), 0.80(\mathrm{~d}, J=6.5 \mathrm{~Hz}, 3 \mathrm{H}, 3 \mathrm{xH}-\delta$ Leu); HRMS (ESI-TOF) $m / z:[\mathrm{M}+\mathrm{H}]^{+}$Calcd for $\mathrm{C}_{69} \mathrm{H}_{85} \mathrm{~N}_{6} \mathrm{O}_{14} \mathrm{Se}$ 1301.52835; Found 1301.52994.

Fmoc- $\gamma$-D-Glu(Ot-Bu)-N-MeSecPh-D-Ala-Leu- $\beta$-D-MeAsp(Ot-Bu)Phe- $d_{5}-\mathrm{OH}$ (21b). Tetrapeptide $4(150 \mathrm{mg}, 164.5 \mu \mathrm{mol})$ and dipeptide $\mathbf{5 b}(110 \mathrm{mg}, 158.1 \mu \mathrm{mol})$ were deprotected according to GP2 and GP3, respectively. The crude peptides 19 and 20b were dissolved in DMF $(1 \mathrm{~mL})$ and coupled according to GP6 using HATU (90 mg, $237.2 \mu \mathrm{mol})$ and collidine $(160 \mu \mathrm{L}, 1207 \mu \mathrm{mol})$. The crude product was purified by $\mathrm{FC}\left(\mathrm{CH}_{2} \mathrm{Cl}_{2} / i-\mathrm{PrOH} 99: 1\right.$ to $\left.95: 5\right)$ to give $21 \mathbf{b}(180 \mathrm{mg}, 87 \%)$ as a white amorphous solid: $R_{f}=0.65\left(\mathrm{CH}_{2} \mathrm{Cl}_{2} / i\right.$ PrOH 95:5); The ${ }^{1} \mathrm{H}$ NMR spectrum $(400 \mathrm{MHz})$ recorded at $300 \mathrm{~K}$ showed two sets of signals (ratio approximately 5:1) and peak broadening due to the occurrence of two rotamers of the $\mathrm{N}$ methylated amide bond; due to incomplete H/D-exchange some remaining $\mathrm{NH}$-protons are visible. ${ }^{1} \mathrm{H}$ NMR $\left(400 \mathrm{MHz}, \mathrm{CD}_{3} \mathrm{OD}, 300\right.$ K) $\delta 8.68(\mathrm{~d}, J=8.8 \mathrm{~Hz}, 1 \mathrm{H}, \mathrm{NH}), 7.97-7.87(\mathrm{~m}, 4 \mathrm{H}, 2 \mathrm{x} \mathrm{H}-\mathrm{Ar}, 2 \mathrm{x}$ $\mathrm{NH}), 7.78(\mathrm{~d}, J=7.6 \mathrm{~Hz}, 2 \mathrm{H}, \mathrm{Ar}), 7.71(\mathrm{~d}, J=7.7 \mathrm{~Hz}, 1 \mathrm{H}, \mathrm{NH}), 7.62$ $(\mathrm{t}, J=6.9 \mathrm{~Hz}, 3 \mathrm{H}, \mathrm{Ar}), 7.51-7.42(\mathrm{~m}, 4 \mathrm{H}, \mathrm{Ar}), 7.37(\mathrm{t}, J=7.4 \mathrm{~Hz}, 1 \mathrm{H}$ Ar), 7.31-7.19 (m, 5H, Ar), $7.04(\mathrm{~d}, J=8.6 \mathrm{~Hz}, 1 \mathrm{H}, \mathrm{NH}) 5.49-5.46$ $\left(\mathrm{m}, 2 \mathrm{H}, \mathrm{CH}_{2} \mathrm{Pac}\right.$ ), 4.88 (dd, $J=9.7,4.1 \mathrm{~Hz}, 1 \mathrm{H}, \mathrm{H}-\alpha$ Phe- $d_{5}$ ), 4.44$4.38(\mathrm{~m}, 1 \mathrm{H}, \mathrm{H}-\alpha \mathrm{Ala}), 4.37-4.21\left(\mathrm{~m}, 5 \mathrm{H}, \mathrm{H}-\alpha\right.$ Leu, $-\mathrm{OCH}_{2}-\mathrm{C} \underline{\mathrm{H}}-$ Fmoc, $\mathrm{H}-\alpha$ Ala, $-\mathrm{OCH}_{2}-\mathrm{CH}-\mathrm{Fmoc}$ ), $4.20-4.08$ (m, $2 \mathrm{H}, \mathrm{H}-\alpha$ $\mathrm{NMeSecPh}, \mathrm{H}-\alpha \mathrm{Glu}), 3.66(\mathrm{dd}, J=13.3,5.0 \mathrm{~Hz}, 1 \mathrm{H}, \mathrm{H}-\beta$ $\mathrm{NMeSecPh}$ ), 3.47 (dd, $J=13.3,9.7 \mathrm{~Hz}, 1 \mathrm{H}, \mathrm{H}-\beta \mathrm{NMeSecPh}$ ), 3.40 $\left(\mathrm{dd}, J=14.1,4.3 \mathrm{~Hz}, 1 \mathrm{H}, \mathrm{H}-\beta\right.$ Phe- $\left.d_{5}\right), 3.20\left(\mathrm{~s}, 3 \mathrm{H},-\mathrm{NCH}_{3}\right.$, minor rotamer), $3.11\left(\mathrm{~s}, 3 \mathrm{H},-\mathrm{NCH}_{3}\right.$, major rotamer), 3.05-2.94 (m, $2 \mathrm{H}, \mathrm{H}-$ $\beta$ Phe- $d_{5}, \mathrm{H}-\beta$ MeAsp), 2.54-2.44 (m, 1H, H- $\gamma$ Glu), 2.25-2.11 (m, $2 \mathrm{H}, \mathrm{H}-\beta$ Glu, H- $\gamma$ Glu), $2.00-1.89$ (m, $1 \mathrm{H}, \mathrm{H}-\beta$ Leu), $1.87-1.71$ (m, $2 \mathrm{H}, \mathrm{H}-\gamma$ Leu, H- $\beta$ Glu $), 1.61-1.48(\mathrm{~m}, 1 \mathrm{H}, \mathrm{H}-\beta$ Leu $), 1.45$ (s, 9H, $t$ $\mathrm{Bu}), 1.38(\mathrm{~s}, 9 \mathrm{H}, t-\mathrm{Bu}), 1.19\left(\mathrm{~d}, J=7.3 \mathrm{~Hz}, 3 \mathrm{H}, \mathrm{CH}_{3} \mathrm{Ala}\right), 0.97(\mathrm{~d}, J=$ $6.6 \mathrm{~Hz}, 3 \mathrm{H}, 3 \mathrm{xH}-\delta \mathrm{Leu}$ ), $0.86\left(\mathrm{~m}, 6 \mathrm{H}, 3 \mathrm{xH}-\delta\right.$ Leu, $\mathrm{CH}_{3}$ MeAsp); HRMS (ESI-Orbitrap) $m / z$ : $[\mathrm{M}+\mathrm{H}]^{+}$Calcd for $\mathrm{C}_{69} \mathrm{H}_{80} \mathrm{D}_{5} \mathrm{~N}_{6} \mathrm{O}_{14} \mathrm{Se}$ 1306.55973; Found 1306. 56074.

Fmoc- $\gamma$-D-Glu(Ot-Bu)-N-MeSecPh-D-Ala-Leu- $\beta$-D-MeAsp(Ot-Bu)Tyr(Prg) $-\mathrm{OH}$ (21c). Tetrapeptide $4(130 \mathrm{mg}, 134 \mu \mathrm{mol})$ and dipeptide 5c $(109 \mathrm{mg}, 146 \mu \mathrm{mol})$ were deprotected according to GP2 and GP3, respectively. The products 19 and 20c were dissolved in DMF ( $1 \mathrm{~mL}$ ) and coupled according to GP6 using HATU $(56 \mathrm{mg}$, $146 \mu \mathrm{mol})$ and collidine $(53 \mu \mathrm{L}, 403 \mu \mathrm{mol})$. The crude product was purified by $\mathrm{FC}\left(\mathrm{CH}_{2} \mathrm{Cl}_{2} / i-\mathrm{PrOH} 99: 1\right.$ to $\left.95: 5\right)$ to give 21c $(116 \mathrm{mg}$, $76 \%)$ as a white amorphous solid: $R_{f}=0.63\left(\mathrm{CH}_{2} \mathrm{Cl}_{2} / i-\mathrm{PrOH} 95: 5\right)$; ${ }^{1} \mathrm{H}$ NMR $\left(600 \mathrm{MHz}, \mathrm{DMSO}-d_{6}, 360 \mathrm{~K}\right) \delta 8.19(\mathrm{~d}, J=7.3 \mathrm{~Hz}, 1 \mathrm{H}$, $\mathrm{NH}), 7.94(\mathrm{~d}, J=7.2 \mathrm{~Hz}, 2 \mathrm{H}, \mathrm{Ar}), 7.86(\mathrm{~d}, J=7.5 \mathrm{~Hz}, 2 \mathrm{H}, \mathrm{Ar}), 7.71-$ $7.65(\mathrm{~m}, 3 \mathrm{H}, 3 \mathrm{x} \mathrm{H}-\mathrm{Ar}, \mathrm{NH}), 7.60(\mathrm{~d}, J=8.6 \mathrm{~Hz}, 2 \mathrm{H}, 2 \mathrm{x} \mathrm{NH}), 7.55(\mathrm{t}$, $J=7.7 \mathrm{~Hz}, 2 \mathrm{H}, \mathrm{Ar}), 7.49(\mathrm{~d}, J=8.1 \mathrm{~Hz}, 2 \mathrm{H}, \mathrm{Ar}), 7.40(\mathrm{t}, J=7.4 \mathrm{~Hz}$, $2 \mathrm{H}, \mathrm{Ar}), 7.31(\mathrm{t}, J=7.4 \mathrm{~Hz}, 2 \mathrm{H}, \mathrm{Ar}), 7.29-7.22(\mathrm{~m}, 4 \mathrm{H}, 3 \mathrm{x} \mathrm{H}-\mathrm{Ar}$, $\mathrm{NH}), 7.18(\mathrm{~d}, J=8.6 \mathrm{~Hz}, 2 \mathrm{H}, \mathrm{Ar}), 6.89(\mathrm{~d}, J=8.6 \mathrm{~Hz}, 2 \mathrm{H}, \mathrm{Ar}), 5.46-$ $5.41\left(\mathrm{~m}, 2 \mathrm{H}, \mathrm{CH}_{2} \mathrm{Pac}\right), 5.08-5.00(\mathrm{~m}, 1 \mathrm{H}, \mathrm{H}-\alpha \mathrm{NMeSecPh}), 4.72(\mathrm{~d}$, $\left.J=2.3 \mathrm{~Hz}, 2 \mathrm{H},-\mathrm{OCH}_{2}-\mathrm{Tyr}(\operatorname{Prg})\right), 4.66(\mathrm{td}, J=8.6,5.3 \mathrm{~Hz}, 1 \mathrm{H}, \mathrm{H}-\alpha$ $\operatorname{Tyr}(\operatorname{Prg}))$, $4.36-4.26\left(\mathrm{~m}, 4 \mathrm{H}, \mathrm{H}-\alpha\right.$ MeAsp, $\mathrm{H}-\alpha$ Ala, $-\mathrm{OCH}_{2}-\mathrm{CH}-$ Fmoc), 4.25-4.19 (m, 2H, H- $\alpha$ Leu, $-\mathrm{OCH}_{2}-\mathrm{CH}-$ Fmoc), 4.01 (dd, $J$ $=13.4,8.4 \mathrm{~Hz}, 1 \mathrm{H}, \mathrm{H}-\alpha \mathrm{Glu}), 3.52-3.46(\mathrm{~m}, 1 \mathrm{H}, \mathrm{H}-\beta \mathrm{NMeSecPh})$ $3.32(\mathrm{t}, J=2.3 \mathrm{~Hz}, 1 \mathrm{H},-\mathrm{C} \equiv \mathrm{CH}), 3.18(\mathrm{dd}, J=14.3,5.1 \mathrm{~Hz}, 1 \mathrm{H}, \mathrm{H}-\beta$ Tyr (Prg)), 3.16-3.12 (m, 1H, H- $\beta$ NMeSecPh), 2.99-2.91 (m, $2 \mathrm{H}$, $\mathrm{H}-\beta \operatorname{Tyr}(\mathrm{Prg}), \mathrm{H}-\beta \mathrm{MeAsp}$ ), 2.87 (bs, $3 \mathrm{H},-\mathrm{NCH}_{3}$ ), $2.44-2.35$ (m, $2 \mathrm{H}, 2 \mathrm{x} \mathrm{H}-\gamma \mathrm{Glu}), 2.06-1.99(\mathrm{~m}, 1 \mathrm{H}, \mathrm{H}-\beta \mathrm{Glu}), 1.93-1.85(\mathrm{~m}, 1 \mathrm{H}, \mathrm{H}-$ $\beta$ Glu ), $1.63-1.56$ (m, 1H, H- $\gamma$ Leu ), $1.53-1.48$ (m, $2 \mathrm{H}, 2 \times$ H- $\beta$ Leu $)$, $1.41(\mathrm{~s}, 9 \mathrm{H}, t-\mathrm{Bu}), 1.34(\mathrm{~s}, 9 \mathrm{H}, t-\mathrm{Bu}), 1.23\left(\mathrm{~d}, J=6.9 \mathrm{~Hz}, 3 \mathrm{H}, \mathrm{CH}_{3}\right.$ Ala), $0.91\left(\mathrm{~d}, J=7.2 \mathrm{~Hz}, 3 \mathrm{H}, \mathrm{CH}_{3} \mathrm{MeAsp}\right), 0.85(\mathrm{~d}, J=6.6 \mathrm{~Hz}, 3 \mathrm{H}$, $3 \mathrm{xH}-\delta$ Leu), 0.81 (d, $J=6.5 \mathrm{~Hz}, 3 \mathrm{H}, 3 \mathrm{xH}-\delta$ Leu); HRMS (ESI-TOF) $m / z:[\mathrm{M}+\mathrm{H}]^{+}$Calcd for $\mathrm{C}_{72} \mathrm{H}_{87} \mathrm{~N}_{6} \mathrm{O}_{15} \mathrm{Se} 1355.53891$; Found 1355.54122 .

Boc-Adda- $\gamma$-D-Glu(Ot-Bu)-N-MeSecPh-D-Ala-Leu- $\beta$-D-MeAsp(Ot$B u)-P h e-O H(22 a)$. The hexapeptide 21 a $(100 \mathrm{mg}, 77.0 \mu \mathrm{mol})$ was $\mathrm{N}$ terminally deprotected according to GP3. The deprotected peptide was coupled with Boc-Adda-OH $3^{16 a}(31 \mathrm{mg}, 70.0 \mu \mathrm{mol})$ according to GP6 using HATU (29 mg, $70.0 \mu \mathrm{mol})$ and collidine $(28 \mu \mathrm{L}, 210$ 
$\mu \mathrm{mol})$ in DMF $(1 \mathrm{~mL})$. The crude product was purified by FC (95:5 $\left.\mathrm{CH}_{2} \mathrm{Cl}_{2} / i-\mathrm{PrOH}, R_{f}=0.55\right)$ to give phenacyl protected heptapeptide $\mathbf{2 a}$ as a white amorphous solid. The phenacyl group of $\mathbf{2 a}(50 \mathrm{mg}, 33.5$ $\mu \mathrm{mol}$ ) was removed according to GP2 and the crude product was purified by semipreparative RP-HPLC (gradient: $75-100 \%$ B in 20 min, $\left.t_{\mathrm{R}}=19.9 \mathrm{~min}\right)$ to give $22 \mathrm{a}$ as a white solid $(30 \mathrm{mg}, 31 \%$ from 21a). ${ }^{1} \mathrm{H}$ NMR $\left(600 \mathrm{MHz}, \mathrm{DMSO}-d_{6}, 360 \mathrm{~K}\right) \delta 7.91(\mathrm{~d}, J=4.7 \mathrm{~Hz}$, $1 \mathrm{H}, \mathrm{NH}), 7.82(\mathrm{~d}, J=7.0 \mathrm{~Hz}, 1 \mathrm{H}, \mathrm{NH}), 7.77(\mathrm{~d}, J=6.9 \mathrm{~Hz}, 1 \mathrm{H}, \mathrm{NH})$, 7.68 (b, 1H, NH), 7.50-7.49 (m, 2H, Ar), 7.30-7.21 (m, 7H, Ar), $7.21-7.14(\mathrm{~m}, 6 \mathrm{H}, \mathrm{Ar}), 6.27(\mathrm{~s}, 1 \mathrm{H}, \mathrm{NH}), 6.09$ (d, $J=15.7 \mathrm{~Hz}, 1 \mathrm{H}, \mathrm{H}-$ 5 Adda), 5.48 (dd, $J=15.7,6.6 \mathrm{~Hz}, 1 \mathrm{H}, \mathrm{H}-4$ Adda), 5.38 (d, $J=9.6$ $\mathrm{Hz}, 1 \mathrm{H}, \mathrm{H}-7$ Adda), 5.12-5.05 (m, 1H, H- $\alpha$ NMeSecPh), 4.50-4.44 (m, $1 \mathrm{H}, \mathrm{H}-\alpha$ Phe), 4.32-4.28 (m, 1H, H- $\alpha$ Ala), 4.26-4.20 (m, H- $\alpha$ Leu, H- $\alpha$ MeAsp), 4.15-4.12 (b, 1H, H- $\alpha$ Glu), 4.09 (dd, $J=15.1,6.9$ $\mathrm{Hz}, 1 \mathrm{H}, \mathrm{H}-3 \mathrm{Adda}$ ), 3.51 (d, $J=12.1 \mathrm{~Hz}, 1 \mathrm{H}, \mathrm{H}-\beta \mathrm{NMeSecPh}$ ), $3.27-$ 3.23 (m, $1 \mathrm{H}, \mathrm{H}-9$ Adda), 3.18 (s, $\left.3 \mathrm{H},-\mathrm{OCH}_{3}\right), 3.10$ (b, $2 \mathrm{H}, \mathrm{H}-\beta$ Phe, $\mathrm{H}-\beta \mathrm{NMeSecPh}$ ), $2.94-2.91$ (m, $1 \mathrm{H}, \mathrm{H}-\beta$ MeAsp), 2.88 (dd, $J=13.9$, $8.8 \mathrm{~Hz}, 1 \mathrm{H}, \mathrm{H}-\beta$ Phe), 2.83 (s, $\left.3 \mathrm{H},-\mathrm{NCH}_{3}\right), 2.74$ (dd, $J=14.0,4.8 \mathrm{~Hz}$, $1 \mathrm{H}, \mathrm{H}-10 \mathrm{Adda}$ ), 2.66 (dd, $J=14.0,7.3 \mathrm{~Hz}, 1 \mathrm{H}, \mathrm{H}-10 \mathrm{Adda}), 2.61-$ 2.54 (m, 2H, H-2 Adda, H-8 Adda), 2.38-2.29 (m, $2 \mathrm{H}, 2 \mathrm{xH}-\gamma \mathrm{Glu}$ ), $2.03-1.97(\mathrm{~m}, 1 \mathrm{H}, \mathrm{H}-\beta \mathrm{Glu}), 1.87-1.80(\mathrm{~m}, 1 \mathrm{H}, \mathrm{H}-\beta \mathrm{Glu}), 1.62-1.58$ (m, 1H, H- $\gamma$ Leu), 1.56 (s, 3H, 3xH-6' Adda), 1.52-1.48 (m, $2 \mathrm{H}, \mathrm{H}-\beta$ Leu), $1.40(\mathrm{~s}, 9 \mathrm{H}, t-\mathrm{Bu}), 1.38(\mathrm{~s}, 9 \mathrm{H}, t-\mathrm{Bu}), 1.36(\mathrm{~s}, 9 \mathrm{H}, t-\mathrm{Bu}), 1.23(\mathrm{~d}$, $\left.J=7.1 \mathrm{~Hz}, 3 \mathrm{H}, \mathrm{CH}_{3} \mathrm{Ala}\right), 1.05\left(\mathrm{~d}, J=7.0 \mathrm{~Hz}, 3 \mathrm{H}, 3 \mathrm{xH}-2^{\prime}\right.$ Adda $), 0.97$ $\left(\mathrm{d}, J=6.8 \mathrm{~Hz}, 3 \mathrm{H}, 3 \mathrm{xH}-8^{\prime}\right.$ Adda), 0.90 (d, $J=7.1 \mathrm{~Hz}, 3 \mathrm{H}, \mathrm{CH}_{3}$ MeAsp), $0.86(\mathrm{~d}, J=6.6 \mathrm{~Hz}, 3 \mathrm{H}, 3 \mathrm{xH}-\delta$ Leu $), 0.82(\mathrm{~d}, J=6.5 \mathrm{~Hz}, 3 \mathrm{H}$, $3 \mathrm{xH}-\delta$ Leu); HRMS (ESI-TOF) $m / z:[\mathrm{M}+\mathrm{H}]^{+}$Calcd for $\mathrm{C}_{71} \mathrm{H}_{104} \mathrm{~N}_{7} \mathrm{O}_{15} \mathrm{Se}$ 1374.67624; Found 1374.67841.

Boc-Adda- $\gamma$-D-Glu(Ot-Bu)-N-MeSecPh-D-Ala-Leu- $\beta$-D-MeAsp(Ot$B u)-P h e-d_{5}-O H(22 b)$. The hexapeptide $21 \mathrm{~b}(90 \mathrm{mg}, 69.0 \mu \mathrm{mol})$ was $\mathrm{N}$-terminally deprotected according to GP3. The deprotected peptide was coupled with Boc-Adda-OH $3^{16 \mathrm{a}}(25 \mathrm{mg}, 58.0 \mu \mathrm{mol})$ according to GP6 using HATU ( $33 \mathrm{mg}, 87.0 \mu \mathrm{mol})$ and collidine $(20 \mu \mathrm{L}, 145$ $\mu \mathrm{mol})$ in DMF $(2 \mathrm{~mL})$. The crude product and purified by FC (95:5 $\mathrm{CH}_{2} \mathrm{Cl}_{2} / i$-PrOH, $\left.\mathrm{R}_{f}=0.55\right)$ to give phenacyl protected heptapeptide $\mathbf{2 b}$ as a white solid. The phenacyl group of $\mathbf{2 b}(63 \mathrm{mg}, 42.1 \mu \mathrm{mol})$ was removed according to GP2 and the crude product was purified by semipreparative RP-HPLC (gradient: $75-100 \% \mathrm{~B}$ in $20 \mathrm{~min}, t_{\mathrm{R}}=18.5$ $\mathrm{min}$ ) to give $\mathbf{2 2} \mathbf{b}$ as a white amorphous solid (23 $\mathrm{mg}, 25 \%$ from $\mathbf{2 1 b}$ ). The ${ }^{1} \mathrm{H}$ NMR spectrum $(600 \mathrm{MHz})$ recorded at $300 \mathrm{~K}$ showed two sets of signals (ratio approximately $2: 1$ ) and peak broadening due to the occurrence of two rotamers of the $\mathrm{N}$-methylated amide bond. ${ }^{1} \mathrm{H}$ NMR $\left(600 \mathrm{MHz}, \mathrm{CD}_{3} \mathrm{OD}, 300 \mathrm{~K}\right) \delta 7.56-7.52(\mathrm{~m}, 2 \mathrm{H}, \mathrm{Ar}), 7.33-$ 7.27 (m, 3H, Ar), 7.26-7.23 (m, 2H, Ar), 7.20-7.14 (m, 3H, Ar), 6.22 (d, $J=15.5 \mathrm{~Hz}, 1 \mathrm{H}, \mathrm{H}-5 \mathrm{Adda}), 5.59-5.51$ (m, 1H, H-4 Adda), 5.39 (d, $J=9.7 \mathrm{~Hz}, 1 \mathrm{H}, \mathrm{H}-7$ Adda $), 4.62-4.55$ (m, $1 \mathrm{H}, \mathrm{H}-\alpha$ Phe- $d_{5}$ ), 4.364.29 (m, 5H, H- $\alpha$ Glu, H- $\alpha$ Leu, H- $\alpha$ Ala, H- $\alpha$ Mdha), 4.25-4.19 (m, $1 \mathrm{H}, \mathrm{H}-3$ Adda major rotamer), 4.06-4.03 (m, $1 \mathrm{H}, \mathrm{H}-3$ Adda major rotamer), $3.67(\mathrm{~d}, J=12.7 \mathrm{~Hz}, 1 \mathrm{H}, 1 \mathrm{H}, \mathrm{H}-\beta \mathrm{NMeSecPh}), 3.41-3.35$ $(\mathrm{m}, 1 \mathrm{H}, \mathrm{H}-\beta \mathrm{NMeSecPh}), 3.22\left(\mathrm{~s}, 1 \mathrm{H}, 3 \mathrm{H},-\mathrm{OCH}_{3}\right), 3.27-3.17(\mathrm{~m}$, $2 \mathrm{H}, \mathrm{H}-\beta$ Phe- $d_{5}$, H-9 Adda), 3.11-2.99 (m, $1 \mathrm{H}, \mathrm{H}-\beta$ MeAsp), 3.05 (s, $\left.3 \mathrm{H},-\mathrm{NCH}_{3}\right), 2.93\left(\mathrm{dd}, J=13.8,9.2 \mathrm{~Hz}, 1 \mathrm{H}, \mathrm{H}-\beta\right.$ Phe- $\left.d_{5}\right), 2.80$ (dd, $J=$ 13.9, $3.7 \mathrm{~Hz}, 1 \mathrm{H}, \mathrm{H}-10 \mathrm{Adda}), 2.66$ (dd, $J=13.9,7.4 \mathrm{~Hz}, 2 \mathrm{H}, \mathrm{H}-10$ Adda, H-2 Adda), 2.59 (dq, $J=16.7,6.7 \mathrm{~Hz}, 1 \mathrm{H}, \mathrm{H}-8$ Adda), 2.45$2.39(\mathrm{~m}, 1 \mathrm{H}, \mathrm{H}-\gamma \mathrm{Glu}), 2.36-2.25(\mathrm{~m}, 2 \mathrm{H}, \mathrm{H}-\gamma$ Glu, $\mathrm{H}-\beta$ Glu major rotamer), 2.06-1.98 (m, $1 \mathrm{H}, \mathrm{H}-\beta$ Glu minor rotamer) $1.95-1.87(\mathrm{~m}$, $1 \mathrm{H}, \mathrm{H}-\beta$ Leu $), 1.78-1.68(\mathrm{~m}, 2 \mathrm{H}, \mathrm{H}-\gamma$ Leu, H- $\beta$ Glu $), 1.62(\mathrm{~s}, 3 \mathrm{H}$, $3 \mathrm{xH}-6^{\prime}$ Adda), $1.58-1.51$ (m, $1 \mathrm{H}, \mathrm{H}-\beta$ Leu), 1.46 (s, $\left.9 \mathrm{H}, t-\mathrm{Bu}\right), 1.42$ $(\mathrm{s}, 9 \mathrm{H}, t-\mathrm{Bu}), 1.41(\mathrm{~s}, 9 \mathrm{H}, t-\mathrm{Bu}), 1.25\left(\mathrm{~d}, J=7.4 \mathrm{~Hz}, 3 \mathrm{H}, \mathrm{CH}_{3} \mathrm{Ala}\right)$, 1.16 (s, 3H, 3xH-2' Adda), 1.02 (d, $J=6.7 \mathrm{~Hz}, 3 \mathrm{H}, 3 \mathrm{xH}-8^{\prime}$ Adda), 0.96 (d, $J=6.6 \mathrm{~Hz}, 3 \mathrm{H}, \mathrm{CH}_{3}$ MeAsp), $0.91(\mathrm{~d}, J=7.1 \mathrm{~Hz}, 3 \mathrm{H}, 3 \mathrm{xH}-\delta \mathrm{Leu})$, $0.88(\mathrm{~d}, J=6.5 \mathrm{~Hz}, 3 \mathrm{H}, 3 \mathrm{xH}-\delta$ Leu); HRMS (ESI-Orbitrap) $m / z:[\mathrm{M}$ $+\mathrm{H}]^{+}$Calcd for $\mathrm{C}_{71} \mathrm{H}_{99} \mathrm{D}_{5} \mathrm{~N}_{7} \mathrm{O}_{15} \mathrm{Se}$ 1379.70640; Found 1379. 70814 .

Boc-Adda- $\gamma$-D-Glu(Ot-Bu)-N-MeSecPh-D-Ala-Leu- $\beta$-D-MeAsp(Ot$\mathrm{Bu})-\mathrm{Tyr}(\operatorname{Prg})-\mathrm{OH}$ (22c). The hexapeptide 21c $(110 \mathrm{mg}, 81.2 \mu \mathrm{mol})$ was N-terminally deprotected according to GP3. The deprotected peptide was coupled with Boc-Adda-OH $3^{16 \mathrm{a}}(33 \mathrm{mg}, 73.8 \mu \mathrm{mol})$ according to GP6 using HATU $(31 \mathrm{mg}, 81.2 \mu \mathrm{mol}$ ) and collidine (30 $\mu \mathrm{L}, 226 \mu \mathrm{mol})$ in DMF $(1 \mathrm{~mL})$. The crude product was purified by FC (95:5 $\mathrm{CH}_{2} \mathrm{Cl}_{2} / i-\mathrm{PrOH}$ ) to give phenacyl protected heptapeptide $2 \mathrm{c}$ as a white solid $(85 \mathrm{mg})$. The phenacyl group of $2 \mathrm{c}(50 \mathrm{mg}, 33.5 \mu \mathrm{mol})$ was removed according to GP2 and the crude product was purified by semipreparative RP-HPLC (gradient: $75-100 \% \mathrm{~B}$ in $20 \mathrm{~min}, t_{\mathrm{R}}=18.4$ $\mathrm{min}$ ) to give $22 \mathrm{c}$ as a white amorphous solid ( $34 \mathrm{mg}, 54 \%$ from $21 \mathrm{c}$ ). The ${ }^{1} \mathrm{H}$ NMR spectrum $(600 \mathrm{MHz})$ recorded at $300 \mathrm{~K}$ showed two sets of signals (ratio approximately $2: 1$ ) and peak broadening due to the occurrence of two rotamers of the $\mathrm{N}$-methylated amide bond. ${ }^{1} \mathrm{H}$ NMR $\left(600 \mathrm{MHz}, \mathrm{CD}_{3} \mathrm{OD}, 300 \mathrm{~K}\right) \delta 7.55(\mathrm{~d}, J=6.2 \mathrm{~Hz}, 2 \mathrm{H}, \mathrm{Ar})$, 7.32-7.27 (m, 3H, Ar), 7.25 (t, $J=7.5 \mathrm{~Hz}, 2 \mathrm{H}, \mathrm{Ar}), 7.20-7.16(\mathrm{~m}$, $3 \mathrm{H}, \mathrm{Ar}), 7.12(\mathrm{~d}, J=7.7 \mathrm{~Hz}, 2 \mathrm{H}, \mathrm{Ar}), 6.88(\mathrm{~d}, J=8.5 \mathrm{~Hz}, 2 \mathrm{H}, \mathrm{Ar}), 6.22$ (d, $J=15.8 \mathrm{~Hz}, 1 \mathrm{H}, \mathrm{H}-5$ Adda), 5.59-5.51 (m, 1H, H-4 Adda), 5.39 (d, $J=9.8 \mathrm{~Hz}, 1 \mathrm{H}, \mathrm{H}-7 \mathrm{Adda}), 4.67\left(\mathrm{~d}, J=2.2 \mathrm{~Hz}, 2 \mathrm{H},-\mathrm{OCH}_{2}-\right.$ ), 4.59-4.53 (m, 1H, H- $\alpha$ Tyr (Prg)), 4.40-4.28 (m, 5H, H- $\alpha$ Leu, H- $\alpha$ Glu, H- $\alpha$ Ala, H- $\alpha$ MeAsp, H- $\alpha$ NMeSecPh), 4.23 (b, 1H, H-3 Adda), $3.69-3.63(\mathrm{~m}, 1 \mathrm{H}, \mathrm{H}-\beta$ NMeSecPh major rotamer), $3.57-3.51(\mathrm{~m}$, $1 \mathrm{H}, \mathrm{H}-\beta$ NMeSecPh minor rotamer), 3.40-3.35 (m, $1 \mathrm{H}, \mathrm{H}-\beta$ $\mathrm{NMeSecPh}$ major rotamer $) 3.22\left(\mathrm{~s}, 3 \mathrm{H},-\mathrm{OCH}_{3}\right), 3.23-3.18(\mathrm{~m}$, $1 \mathrm{H}, \mathrm{H}-9$ Adda), 3.16-3.11 (m, $1 \mathrm{H}, \mathrm{H}-\beta \operatorname{Tyr}(\operatorname{Prg})), 3.04$ (b, $3 \mathrm{H}$, $-\mathrm{NCH}_{3}, \mathrm{H}-\beta$ MeAsp), 2.91 (s, $\left.1 \mathrm{H},-\mathrm{C} \equiv \mathrm{CH}\right), 2.87$ (dd, $J=13.9,9.4$ $\mathrm{Hz}, 1 \mathrm{H}, \mathrm{H}-\beta \operatorname{Tyr}(\operatorname{Prg})), 2.80$ (dd, $J=13.8,3.7 \mathrm{~Hz}, 1 \mathrm{H}, \mathrm{H}-10 \mathrm{Adda})$, 2.68-2.63 (m, 2H, H-2 Adda, H-10 Adda), 2.63-2.56 (m, 1H, H-8 Adda), 2.44-2.37 (m, 1H, H- $\gamma$ Glu), 2.34-2.25 (m, $2 \mathrm{H}, \mathrm{H}-\gamma$ Glu, H- $\beta$ Glu major rotamer), $2.04-1.98(\mathrm{~m}, 1 \mathrm{H}, \mathrm{H}-\beta$ Glu minor rotamer) $1.95-1.88$ (m, $1 \mathrm{H}, \mathrm{H}-\beta$ Leu $), 1.78-1.68(\mathrm{~m}, 2 \mathrm{H}, \mathrm{H}-\gamma$ Leu $\mathrm{H}-\beta$ Glu $)$, 1.62 (s, 3H, 3xH-6' Adda), 1.61-1.51 (m, 1H, H- $\beta$ Leu), 1.46 (s, 9H, $t$ - $\mathrm{Bu}), 1.42(\mathrm{~s}, 18 \mathrm{H}, 2 \mathrm{xt}-\mathrm{Bu}), 1.25\left(\mathrm{~d}, J=7.4 \mathrm{~Hz}, 3 \mathrm{H}, \mathrm{CH}_{3} \mathrm{Ala}\right), 1.19-$ 1.12 (b, 3H, 3xH-2' Adda), 1.02 (d, $J=6.7 \mathrm{~Hz}, 3 \mathrm{H}, 3 \times \mathrm{xH}^{\prime} 8^{\prime}$ Adda), $0.96(\mathrm{~d}, J=6.6 \mathrm{~Hz}, 3 \mathrm{H}, 3 \mathrm{xH}-\delta \mathrm{Leu}), 0.93\left(\mathrm{~d}, J=7.2 \mathrm{~Hz}, 3 \mathrm{H}, \mathrm{CH}_{3}\right.$ MeAsp), 0.88 (d, $J=6.5 \mathrm{~Hz}, 3 \mathrm{H}, 3 \mathrm{xH}-\delta \mathrm{Leu}) ;{ }^{13} \mathrm{C}$ NMR $(151 \mathrm{MHz}$, $\left.\mathrm{CD}_{3} \mathrm{OD}, 300 \mathrm{~K}\right): \delta=177.1(\mathrm{C}=\mathrm{O}), 176.3(\mathrm{C}=\mathrm{O}), 175.8(\mathrm{C}=\mathrm{O})$, $172.4(\mathrm{C}=\mathrm{O}), 175.2(\mathrm{C}=\mathrm{O}), 172.6(\mathrm{C}=\mathrm{O}), 171.8(\mathrm{C}=\mathrm{O}), 170.4$ $(\mathrm{C}=\mathrm{O}), 158.1\left(-\mathrm{C}-\mathrm{O}-\mathrm{CH}_{2}-\right), 140.6(\mathrm{C}, \mathrm{Ar}), 137.2$ (C-7 Adda), 137.0 (C-5 Adda), 134.0 (C-6 Adda), 133.9 (2C, Ar), 131.3 (2C, Ar), 131.1 (C, Ar), 130.5 (2C, Ar), 130.4 (2C, Ar), 129.2 (2C, Ar), 128.3 (C, Ar), 127.1 (C-4 Adda), 127.1 (2C, Ar), 116.0 (2C, Ar), 88.4 (C-9 Adda), $83.2\left(-\underline{\mathrm{C}}\left(\mathrm{CH}_{3}\right)_{3}\right), 82.9\left(-\mathrm{C}\left(\underline{\mathrm{CH}}_{3}\right)_{3}\right), 80.5\left(-\underline{\mathrm{C}}\left(\mathrm{CH}_{3}\right)_{3}\right), 79.9$ $(-\mathrm{C} \equiv \mathrm{CH}), 76.8(-\mathrm{C} \equiv \mathrm{CH}), 64.0(\mathrm{C}-\alpha), 58.8\left(-\mathrm{OCH}_{3}\right), 56.7(\mathrm{C}-\alpha)$, $56.6\left(-\mathrm{OCH}_{2}-\right), 55.9(\mathrm{C}-\alpha), 54.9(\mathrm{C}-\alpha), 53.8(\mathrm{C}-\alpha), 53.5(\mathrm{C}-\alpha)$, 50.7 (C- $\alpha$ Ala), 45.3 (C-2 Adda), 41.9 (- $\left.\mathrm{NCH}_{3}\right), 41.2$ (C- $\beta$ Leu), 39.1 (C-10 Adda), 37.9 (C- $\beta$ Tyr(Prg)), 37.8 (C-8 Adda), 37.7 (C- $\beta$ MeAsp), 30.8 (C- $\gamma \mathrm{Glu}), 28.8\left(3 \mathrm{C},-\mathrm{C}\left(\mathrm{CH}_{3}\right)_{3}\right), 28.4\left(3 \mathrm{C},-\mathrm{C}\left(\mathrm{CH}_{3}\right)_{3}\right)$, 28.4 (C- $\beta$ Glu ), $28.2\left(3 \mathrm{C},-\mathrm{C}\left(\mathrm{CH}_{3}\right)_{3}\right), 27.0$ (C- $\left.\beta \mathrm{NMeSecPh}\right), 25.8$ (C- $\gamma$ Leu), 23.9 (C- $\delta$ Leu), 21.3 (C- $\delta$ Leu), $17.5\left(\mathrm{CH}_{3} \mathrm{Ala}\right), 16.6$ (C$8^{\prime}$ Adda), 16.3 ( $\mathrm{CH}_{3} \mathrm{MeAsp}$ ), 15.7 (C-2' Adda), 13.2 (C-6' Adda); HRMS (ESI-Orbitrap) $m / z$ : $[\mathrm{M}+\mathrm{H}]^{+}$Calcd for $\mathrm{C}_{74} \mathrm{H}_{106} \mathrm{~N}_{7} \mathrm{O}_{16} \mathrm{Se}$ 1428.68558; Found 1428. 68698.

[Phe- $\left.d_{5}^{4}, N M e S e c P h^{7}\right]-M i c r o c y s t i n-L F$ (23b). The heptapeptide 22b $(21.7 \mathrm{mg}, 15.7 \mu \mathrm{mol})$ was macrocyclized using pentafluorophenol $(5.7 \mathrm{mg}, 30.7 \mu \mathrm{mol})$ and DCC ( $4 \mathrm{mg}, 19.2 \mu \mathrm{mol}$ ) according to GP7. The crude product was purified by semipreparative RP-HPLC (gradient: $50-75 \% \mathrm{~B}$ in $25 \mathrm{~min}, t_{\mathrm{R}}=20.5 \mathrm{~min}$ ) and macrocyclic peptide $23 \mathrm{~b}$ was obtained as a white amorphous solid $(5 \mathrm{mg}, 28 \%) .{ }^{1} \mathrm{H}$ NMR $\left(600 \mathrm{MHz}, \mathrm{CD}_{3} \mathrm{OD}, 300 \mathrm{~K}\right) \delta 8.04-8.02(\mathrm{~m}, 1 \mathrm{H}, \mathrm{NH}$ MeAsp), 8.00 (d, $J=6.4 \mathrm{~Hz}, 1 \mathrm{H}, \mathrm{NH} \mathrm{Leu}), 7.51$ (d, $J=7.7 \mathrm{~Hz}, 2 \mathrm{H}, \mathrm{Ar}), 7.35-$ $7.29(\mathrm{~m}, 3 \mathrm{H}, \mathrm{Ar}), 7.27-7.24(\mathrm{~m}, 2 \mathrm{H}, \mathrm{Ar}), 7.22-7.14(\mathrm{~m}, 4 \mathrm{H}, 3 \mathrm{xH}-\mathrm{Ar}$, $\mathrm{NH} \mathrm{Ala}$ ), 6.32 (d, $J=15.5 \mathrm{~Hz}, 1 \mathrm{H}, \mathrm{H}-5$ Adda), 5.49 (d, $J=9.7 \mathrm{~Hz}, 1 \mathrm{H}$, H-7 Adda), 5.43 (dd, $J=15.4,9.0 \mathrm{~Hz}, \mathrm{H}-4$ Adda), $4.65-4.59(\mathrm{~m}, 1 \mathrm{H}$ H-3 Adda), 4.48 (dd, $J=12.0,3.6 \mathrm{~Hz}, 1 \mathrm{H}, \mathrm{H}-\alpha$ Phe- $d_{5}$ ), 4.46-4.39 (m, 2H, H- $\alpha$ MeAsp, H- $\alpha$ Ala), 4.19-4.12 (m, 2H, H- $\alpha$ Glu, H- $\alpha$ Leu), 4.04 (dd, $J=9.7,4.9 \mathrm{~Hz}, 1 \mathrm{H}, \mathrm{H}-\alpha \mathrm{NMeSecPh}$ ), 3.73-3.66 (m, $2 \mathrm{H}, 2 \mathrm{xH}-\beta \mathrm{NMeSecPh}), 3.47-3.41\left(\mathrm{~m}, 1 \mathrm{H}, \mathrm{H}-\beta\right.$ Phe- $\left.d_{5}\right), 3.31-3.27$ (m, 1H, H-9 Adda) $3.26\left(\mathrm{~s}, 3 \mathrm{H},-\mathrm{OCH}_{3}\right), 3.19\left(\mathrm{~s},-\mathrm{NCH}_{3}\right), 2.93$ (dd, $J$ $=7.0,3.0 \mathrm{~Hz}, 1 \mathrm{H}, \mathrm{H}-\beta \mathrm{MeAsp}), 2.84(\mathrm{dd}, J=14.0,4.6 \mathrm{~Hz}, 1 \mathrm{H}, 1 \mathrm{H}, \mathrm{H}-$ 10 Adda), $2.81-2.76(\mathrm{~m}, 1 \mathrm{H}, \mathrm{H}-2$ Adda), 2.70 (dd, $J=13.9,7.2 \mathrm{~Hz}$, $1 \mathrm{H}, \mathrm{H}-10 \mathrm{Adda}$ ), 2.66-2.59 (m, 1H, H-8 Adda), 2.55 (dd, $J=14.2$, $11.9 \mathrm{~Hz}, 1 \mathrm{H}, \mathrm{H}-\beta$ Phe- $\left.d_{5}\right), 2.20-2.13(\mathrm{~m}, 1 \mathrm{H}, \mathrm{H}-\gamma \mathrm{Glu}), 1.96-1.89$ (m, 1H, H- $\beta$ Leu), 1.84-1.75 (m, 2H, H- $\beta$ Glu, H- $\gamma$ Leu), 1.64 (s, 3H, $3 \mathrm{xH}-6^{\prime}$ Adda), $1.58-1.47$ ( $\mathrm{m}, 3 \mathrm{H}, \mathrm{H}-\beta$ Glu, H- $\gamma$ Glu, H- $\beta$ Leu $), 1.08$ $\left(\mathrm{d}, J=6.8 \mathrm{~Hz}, 3 \mathrm{H}, 3 \mathrm{xH}-2^{\prime}\right.$ Adda), $1.04\left(\mathrm{~d}, J=6.7 \mathrm{~Hz}, 3 \mathrm{H}, 3 \mathrm{xH}-8^{\prime}\right.$ Adda), 0.97 (d, $J=6.6 \mathrm{~Hz}, 3 \mathrm{H}, 3 \mathrm{xH}-\delta$ Leu ), $0.93(\mathrm{~d}, J=7.4 \mathrm{~Hz}, 3 \mathrm{H}$, 
$\mathrm{CH}_{3} \mathrm{Ala}$ ), 0.88 (d, $\left.J=6.6 \mathrm{~Hz}, 3 \mathrm{H}, 3 \mathrm{xH}-\delta \mathrm{Leu}\right), 0.72(\mathrm{~d}, J=7.1 \mathrm{~Hz}$, $3 \mathrm{H}, \mathrm{CH}_{3}$ MeAsp); HRMS (ESI-TOF) $\mathrm{m} / \mathrm{z}:[\mathrm{M}+\mathrm{H}]^{+}$Calcd for $\mathrm{C}_{58} \mathrm{H}_{73} \mathrm{D}_{5} \mathrm{~N}_{7} \mathrm{O}_{12} \mathrm{Se}$ 1149.5182; Found 1149.5175.

[NMeSecPh ] -Microcystin-LY(Prg) (23c). The heptapeptide 22c (29 $\mathrm{mg}, 20.3 \mu \mathrm{mol})$ was macrocyclized using pentafluorophenol $(7.3 \mathrm{mg}$, $39.6 \mu \mathrm{mol})$ and DCC (5.1 mg, $24.8 \mu \mathrm{mol})$ according to GP7. The crude product was purified by semipreparative RP-HPLC (gradient: $50-80 \% \mathrm{~B}$ in $30 \mathrm{~min}, t_{\mathrm{R}}=20.6 \mathrm{~min}$ ) and the macrocyclic peptide $23 \mathrm{c}$ was obtained as a white amorphous solid ( $8 \mathrm{mg}, 33 \%) .{ }^{1} \mathrm{H}$ NMR (600 $\left.\mathrm{MHz}, \mathrm{CD}_{3} \mathrm{OD}, 300 \mathrm{~K}\right) \delta 8.83(\mathrm{~d}, J=9.6 \mathrm{~Hz}, 1 \mathrm{H}, \mathrm{NH} \mathrm{Tyr}(\operatorname{Prg})), 8.19$ (d, $J=8.9 \mathrm{~Hz}, 1 \mathrm{H}, \mathrm{NH}$ MeAsp), $8.00(\mathrm{~d}, J=6.5 \mathrm{~Hz}, 1 \mathrm{H}, \mathrm{NH} \mathrm{Glu})$, $7.52(\mathrm{dd}, J=8.0,1.4 \mathrm{~Hz}, 2 \mathrm{H}, \mathrm{Ar}), 7.36-7.28(\mathrm{~m}, 3 \mathrm{H}, \mathrm{Ar}), 7.26(\mathrm{t}, J=$ $7.5 \mathrm{~Hz}, 2 \mathrm{H}, \mathrm{Ar}$ ), 7.22-7.16 (m, 4H, 3xH-Ar, NH Adda), 7.12 (d, $J=$ $8.4 \mathrm{~Hz}, 1 \mathrm{H}, \mathrm{NH} \mathrm{Ala}), 7.09$ (d, $J=8.6 \mathrm{~Hz}, 2 \mathrm{H}, \mathrm{Ar}), 6.84(\mathrm{~d}, J=8.8 \mathrm{~Hz}$, $2 \mathrm{H}, \mathrm{Ar}), 6.34(\mathrm{~d}, J=15.5 \mathrm{~Hz}, 1 \mathrm{H}, \mathrm{H}-5 \mathrm{Adda}), 5.50(\mathrm{~d}, J=9.9 \mathrm{~Hz}, 1 \mathrm{H}$, H-7 Adda), 5.39 (dd, $J=15.5,8.7 \mathrm{~Hz}, 1 \mathrm{H}, \mathrm{H}-4$ Adda), 4.70-4.65 (m, $1 \mathrm{H}, \mathrm{H}-3 \mathrm{Adda}), 4.64$ (d, $J=2.4 \mathrm{~Hz}, 2 \mathrm{H},-\mathrm{OCH}_{2}-$ ), 4.51 (dd, $J=8.9$, 3.0 Hz, $1 \mathrm{H}, \mathrm{H}-\alpha$ MeAsp), 4.49-4.41 (m, 2H, H- $\alpha$ Ala, H- $\alpha$ Tyr(Prg)), $4.25(\mathrm{dd}, J=9.2,5.6 \mathrm{~Hz}, 1 \mathrm{H}, \mathrm{H}-\alpha \mathrm{Glu}), 4.15$ (ddd, $J=11.2,6.5,3.9$ $\mathrm{Hz}, 1 \mathrm{H}, \mathrm{H}-\alpha \mathrm{Leu}), 4.06$ (dd, $J=9.8,4.8 \mathrm{~Hz}, 1 \mathrm{H}, \mathrm{H}-\alpha \mathrm{NMeSecPh}$ ), $3.75-3.65(\mathrm{~m}, 2 \mathrm{H}, 2 \mathrm{xH}-\beta \mathrm{NMeSecPh}), 3.41(\mathrm{dd}, J=14.1,3.3 \mathrm{~Hz}, 1 \mathrm{H}$, $\mathrm{H}-\beta \operatorname{Tyr}(\operatorname{Prg}))$, 3.30-3.26 (m, 1H, H-9 Adda), 3.26 (s, 3H,-OCH ), $_{3}$ $3.21\left(\mathrm{~s}, 3 \mathrm{H},-\mathrm{NCH}_{3}\right), 2.91(\mathrm{t}, J=2.4 \mathrm{~Hz}, 1 \mathrm{H},-\mathrm{C} \equiv \mathrm{CH}), 2.87(\mathrm{qd}, J=$ 7.2, $3.0 \mathrm{~Hz}, 1 \mathrm{H}, \mathrm{H}-\beta$ MeAsp), 2.84 (dd, $J=14.0,4.8 \mathrm{~Hz}, 1 \mathrm{H}, \mathrm{H}-10$ Adda), 2.70 (dd, $J=14.0,7.3 \mathrm{~Hz}, 1 \mathrm{H}, \mathrm{H}-10$ Adda), 2.66-2.59 (m, $2 \mathrm{H}$, H-2 Adda, H-8 Adda), 2.49 (dd, $J=14.1,12.0 \mathrm{~Hz}, 1 \mathrm{H}, \mathrm{H}-\beta$ Tyr $(\operatorname{Prg})$ ), 2.18-2.12 (m, $1 \mathrm{H}, \mathrm{H}-\gamma \mathrm{Glu}), 1.90-1.84(\mathrm{~m}, 1 \mathrm{H}, \mathrm{H}-\beta \mathrm{Glu}), 1.84-1.74$ (m, $2 \mathrm{H}, \mathrm{H}-\beta$ Leu, $\mathrm{H}-\gamma$ Leu), 1.64 (s, 3H, 3xH-6' Adda), 1.59-1.54 (m, $1 \mathrm{H}, \mathrm{H}-\gamma \mathrm{Glu}$ ), $1.52-1.43$ (m, $2 \mathrm{H}, \mathrm{H}-\beta$ Glu, H- $\beta$ Leu), 1.09 (d, $J=6.9$ $\mathrm{Hz}, 3 \mathrm{H}, 3 \mathrm{xH}-2^{\prime}$ Adda), 1.04 (d, $J=6.7 \mathrm{~Hz}, 3 \mathrm{H}, 3 \mathrm{xH}-8^{\prime}$ Adda), 0.97 (d, $J=4.7 \mathrm{~Hz}, 3 \mathrm{H}, 3 \mathrm{xH}-\delta \mathrm{Leu}), 0.96\left(\mathrm{~d}, J=5.5 \mathrm{~Hz}, 3 \mathrm{H}, \mathrm{CH}_{3} \mathrm{Ala}\right), 0.88$ (d, $J=6.5 \mathrm{~Hz}, 3 \mathrm{H}, 3 \mathrm{xH}-\delta$ Leu ), 0.77 (d, $J=7.2 \mathrm{~Hz}, 3 \mathrm{H}, \mathrm{CH}_{3}$ MeAsp); ${ }^{13} \mathrm{C}$ NMR (151 MHz, $\left.\mathrm{CD}_{3} \mathrm{OD}, 300 \mathrm{~K}\right): \delta=178.3(\mathrm{C}=\mathrm{O}), 176.41$ $(\mathrm{C}=\mathrm{O}), 176.38(\mathrm{C}=\mathrm{O}), 175.80(\mathrm{C}=\mathrm{O}), 175.77(\mathrm{C}=\mathrm{O}), 175.3$ $(\mathrm{C}=\mathrm{O}), 174.9(\mathrm{C}=\mathrm{O}), 171.64(\mathrm{C}=\mathrm{O}), 171.54(\mathrm{C}=\mathrm{O}), 158.0(-\mathrm{C}-$ $\mathrm{O}-\mathrm{CH}_{2}-$ ), 140.5 (C Ar), 139.4 (C-5 Adda), 137.7 (C-7 Adda), 133.6 (C-6 Adda), 133.4 (2xC Ar), 131.7 (C Ar), 131.1 (2xC Ar Tyr(Prg)), 130.9 (C Ar), 130.5 (2xC Ar), 129.2 (2xC Ar), 128.5 (C Ar), 127.1 (2xC Ar), 125.8 (C-4 Adda), 116.0 (2xC Ar Tyr(Prg)), 88.4 (C-9 Adda), 79.8 ( $-\underline{\mathrm{C}} \equiv \mathrm{CH}), 76.8$ (-C $\equiv \underline{\mathrm{CH}}), 67.5$ (C- $\alpha \mathrm{NMeSecPh}), 58.6$ $\left(-\mathrm{OCH}_{3}\right), 56.5\left(-\mathrm{OCH}_{2}-\right), 56.0$ (C-3 Adda), 55.31, 55.28, 55.19 (m, 3C, C- $\alpha$ Leu, C- $\alpha$ MeAsp, C- $\alpha$ Tyr(Prg)), 53.2 (C- $\alpha$ Glu), 49.7 (C- $\alpha$ Ala), 46.0 (C-2 Adda), 40.9 (-NCH $\left.{ }_{3}\right), 40.7$ (C- $\beta$ Leu), 40.4 (C- $\beta$ MeAsp), 39.0 (C-10 Adda), 37.7 (C-8 Adda), 37.3 (C- $\beta$ Tyr(Prg)), 32.8 (C- $\gamma$ Glu), 29.4 (C- $\beta$ Glu), 26.4 (C- $\beta$ NMeSecPh), 25.8 (C- $\gamma$ Leu $), 23.6\left(\mathrm{CH}_{3} \mathrm{Leu}\right), 21.2\left(\mathrm{CH}_{3} \mathrm{Leu}\right), 17.3\left(\mathrm{CH}_{3} \mathrm{Ala}\right), 16.5\left(\mathrm{C}-8^{\prime}\right.$ Adda), 16.4 (C-2' Adda), 15.2 ( $\mathrm{CH}_{3}$ MeAsp), 12.9 (C-6' Adda); HRMS (ESI-Orbitrap) $m / z:[\mathrm{M}+\mathrm{H}]^{+}$Calcd for $\mathrm{C}_{61} \mathrm{H}_{80} \mathrm{~N}_{7} \mathrm{O}_{13} \mathrm{Se}$ 1198.49738; Found 1198. 49957.

\section{ASSOCIATED CONTENT}

\section{S Supporting Information}

The Supporting Information is available free of charge on the ACS Publications website at DOI: 10.1021/acs.joc.7b00175.

${ }^{1} \mathrm{H}$ and ${ }^{13} \mathrm{C}$ spectra of synthesized compounds; LC-MS chromatograms of compounds $\mathbf{1 a}, \mathbf{1 b}, \mathbf{1 c}$; and bioassay data (PDF)

\section{AUTHOR INFORMATION}

\section{Corresponding Author}

*E-mail: mail@valentin-wittmann.de

\section{ORCID $\odot$}

Valentin Wittmann: 0000-0003-4043-6813

\section{Notes}

The authors declare no competing financial interest.

\section{ACKNOWLEDGMENTS}

We thank Maximilian Häfner for his help during the synthesis of $\mathbf{2 b}$ and $\mathbf{2 1 b}$ and Prof. A. Richard Chamberlin (UC Irvine, USA) for providing several synthetic intermediates for the synthesis of Boc-Adda-OH 3. S.A. and D.R.D. were supported by a grant from the Arthur and Aenne Feindt Foundation, the Marsden Fund of the Royal Society of New Zealand (12-UOW087), and the Marie Curie International Research Staff Exchange Scheme Fellowship (PIRSES-GA-2011-295223).

\section{REFERENCES}

(1) Chorus, I.; Bartram, J. Toxic Cyanobacteria in Water: A guide to their public health consequences, monitoring and management; F \& FN Spon: London, 1999.

(2) (a) Michalak, A. M.; Anderson, E. J.; Beletsky, D.; Boland, S.; Bosch, N. S.; Bridgeman, T. B.; Chaffin, J. D.; Cho, K.; Confesor, R; Daloğlu, I.; DePinto, J. V.; Evans, M. A.; Fahnenstiel, G. L.; He, L.; Ho, J. C.; Jenkins, L.; Johengen, T. H.; Kuo, K. C.; LaPorte, E.; Liu, X.; McWilliams, M. R.; Moore, M. R.; Posselt, D. J.; Richards, R. P.; Scavia, D.; Steiner, A. L.; Verhamme, E.; Wright, D. M.; Zagorski, M. A. Proc. Natl. Acad. Sci. U. S. A. 2013, 110, 6448-6452. (b) Pelley, J. ACS Cent. Sci. 2016, 2, 270-273.

(3) (a) Qu, M.; Lefebvre, D. D.; Wang, Y.; Qu, Y.; Zhu, D.; Ren, W. Science 2014, 346, 175-176. (b) Paerl, H. W.; Gardner, W. S.; McCarthy, M. J.; Peierls, B. L.; Wilhelm, S. W. Science 2014, 346, 175175.

(4) Shoemaker, J. A.; Tettenhorst, D. R.; Delacruz, A. Determination of microcystins and nodularin in drinking water by solid phase extraction and liquid chromatography/tandem mass spectrometry (LC/MS/MS). National Exposure Research Laboratory; Shoemaker, J. A., Tettenhorst, D. R., Delacruz, A., Ed.; Office of Research and Development: Cincinnati, Ohio, 2015.

(5) Francis, G. Nature 1878, 18, 11-12.

(6) (a) Konst, H.; McKercher, P. D.; Gorham, P. R.; Robertson, A.; Howell, J. Can. J. Comp. Med. Vet. Sci. 1965, 29, 221-228. (b) Rinehart, K. L.; Harada, K.; Namikoshi, M.; Chen, C.; Harvis, C. A.; Munro, M. H. G.; Blunt, J. W.; Mulligan, P. E.; Beasley, V. R.; Dahlem, A. M.; Carmichael, W. W. J. Am. Chem. Soc. 1988, 110, 8557-8558. (c) Pearson, L. A.; Dittmann, E.; Mazmouz, R.; Ongley, S. E.; D’Agostino, P. M.; Neilan, B. A. Harmful Algae 2016, 54, 98-111.

(7) (a) Craig, M.; Luu, H. A.; McCready, T. L.; Holmes, C. F. B.; Williams, D.; Andersen, R. J. Biochem. Cell Biol. 1996, 74, 569-578. (b) Zemskov, I.; Kropp, H. M.; Wittmann, V. Chem. - Eur. J. 2016, 22, 10990-10997.

(8) (a) Campos, A.; Vasconcelos, V. Int. J. Mol. Sci. 2010, 11, 268287. (b) Puddick, J.; Prinsep, M. R.; Wood, S. A.; Kaufononga, S. A. F.; Cary, S. C.; Hamilton, D. P. Mar. Drugs 2014, 12, 5372-5395.

(9) (a) Clave, G.; Ronco, C.; Boutal, H.; Kreich, N.; Volland, H.; Franck, X.; Romieu, A.; Renard, P. Y. Org. Biomol. Chem. 2010, 8, 676-690. (b) Tappan, E.; Chamberlin, A. R. Chem. Biol. 2008, 15, 167-174. (c) Webster, K. L.; Maude, A. B.; O’Donnell, M. E.; Mehrotra, A. P.; Gani, D. J. Chem. Soc., Perkin Trans. 1 2001, 16731695. (d) Mehrotra, A. P.; Webster, K. L.; Gani, D. J. Chem. Soc., Perkin Trans. 1 1997, 2495-2512. (e) Taylor, C.; Quinn, R. J.; Alewood, P. Bioorg. Med. Chem. Lett. 1996, 6, 2107-2112. (f) Taylor, C.; Quinn, R. J.; Suganuma, M.; Fujiki, H. Bioorg. Med. Chem. Lett. 1996, 6, 2113-2116. (g) Fontanillo, M.; Zemskov, I.; Häfner, M.; Uhrig, U.; Salvi, F.; Simon, B.; Wittmann, V.; Köhn, M. Angew. Chem. 2016, 128, 14191-14195.

(10) Humphrey, J. M.; Aggen, J. B.; Chamberlin, A. R. J. Am. Chem. Soc. 1996, 118, 11759-11770.

(11) Aggen, J. B.; Humphrey, J. M.; Gauss, C.-M.; Huang, H.-B.; Nairn, A. C.; Chamberlin, A. R. Bioorg. Med. Chem. 1999, 7, 543-564.

(12) (a) Böttcher, T.; Pitscheider, M.; Sieber, S. A. Angew. Chem., Int. Ed. 2010, 49, 2680-2698. (b) Shreder, K. R.; Liu, Y.; Nomanhboy, T.; Fuller, S. R.; Wong, M. S.; Gai, W. Z.; Wu, J.; Leventhal, P. S.; Lill, J. R.; Corral, S. Bioconjugate Chem. 2004, 15, 790-798. 
(13) (a) Dawson, J. F.; Holmes, C. F. B. Front. Biosci., Landmark Ed. 1999, 4, D646-D658. (b) Goldberg, J.; Huang, H.-b.; Kwon, Y.-g.; Greengard, P.; Nairn, A. C.; Kuriyan, J. Nature 1995, 376, 745-753. (14) Lauer, J. L.; Fields, C. G.; Fields, G. B. Lett. Pept. Sci. 1995, 1, 197-205.

(15) Tillett, D.; Dittmann, E.; Erhard, M.; von Döhren, H.; Börner, T.; Neilan, B. A. Chem. Biol. 2000, 7, 753-764.

(16) (a) Pearson, C.; Rinehart, K. L.; Sugano, M.; Costerison, J. R. Org. Lett. 2000, 2, 2901-2903. (b) Cundy, D. J.; Donohue, A. C.; McCarthy, T. D. J. Chem. Soc., Perkin Trans. 1 1999, 559-568. (c) Beatty, M. F.; Jennings-White, C.; Avery, M. A. J. Chem. Soc., Perkin Trans. 1 1992, 1637-1641. (d) Deiters, A.; Schultz, P. G. Bioorg. Med. Chem. Lett. 2005, 15, 1521-1524. (e) Bauer, S. M.; Armstrong, R. W. J. Am. Chem. Soc. 1999, 121, 6355-6366. (f) Samy, R.; Kim, H. Y.; Brady, M.; Toogood, P. L. J. Org. Chem. 1999, 64, 2711-2728. (g) Valentekovich, R. J.; Schreiber, S. L. J. Am. Chem. Soc. 1995, 117, 9069-9070. (h) Panek, J. S.; Hu, T. J. Org. Chem. 1997, 62, 49144915.

(17) Kokinaki, S.; Leondiadis, L.; Ferderigos, N. Org. Lett. 2005, 7, $1723-1724$.

(18) Riggs Costerison, J. PhD Thesis, University of Illinois: Urbana,2002.

(19) Okeley, N. M.; Zhu, Y.; van der Donk, W. A. Org. Lett. 2000, 2, 3603-3606.

(20) Armstrong, A.; Geldart, S. P.; Jenner, C. R.; Scutt, J. N. J. Org. Chem. 2007, 72, 8091-8094.

(21) Humphrey, J. M.; Bridges, R. J.; Hart, J. A.; Chamberlin, A. R. J. Org. Chem. 1994, 59, 2467-2472.

(22) Bochenska, M.; Biernat, J. Rocz. Chem. 1972, 46, 1429-1433.

(23) Carpino, L. A.; El-Faham, A. J. Org. Chem. 1994, 59, 695-698.

(24) (a) Fischer, A.; Hoeger, S. J.; Stemmer, K.; Feurstein, D. J.; Knobeloch, D.; Nussler, A.; Dietrich, D. R. Toxicol. Appl. Pharmacol. 2010, 245, 9-20. (b) Heresztyn, T.; Nicholson, B. C. Water Res. 2001, 35, 3049-3056.

(25) Dunn, P. J.; Haener, R.; Rapoport, H. J. Org. Chem. 1990, 55, 5017-5025.

(26) Sakaguchi, K.; Yamamoto, M.; Kawamoto, T.; Yamada, T.; Shinada, T.; Shimamoto, K.; Ohfune, Y. Tetrahedron Lett. 2004, 45, 5869-5872.

(27) dos Anjos, J. V.; Sinou, D.; de Melo, S. J.; Srivastava, R. M. Synthesis 2007, 2007, 2647-2652.

(28) Deiters, A.; Cropp, T. A.; Mukherji, M.; Chin, J. W.; Anderson, J. C.; Schultz, P. G. J. Am. Chem. Soc. 2003, 125, 11782-11783. 